Book Chapter

Crack growth from naturally occurring material discontinuities

McMillan, A.

This book chapter was published in Jones, R., Matthews, N., Baker, A.A. and Champagne, J. Jnr, Aircraft Sustainment and Repair, Chapter 5. Oxford: Elsevier, 2017. ISBN 9780081005408.

Copyright Elsevier. The definitive version of this article is available at: http://www.sciencedirect.com/science/book/9780081005408

Recommended citation:

McMillan, A. (2017), 'Crack growth from naturally occurring material discontinuities', in Jones, R., Matthews, N., Baker, A.A. and Champagne, J. Jnr, Aircraft Sustainment and Repair, Chapter 5. Oxford: Elsevier, 2017. ISBN 9780081005408 
R. Jones, N. Matthews, A. A. Baker and V. Champagne, Jnr, Aircraft Sustainment and Repair, Elsevier, Heinemann Butterwork Press, 2017, ISBN 9780081005408.

\title{
CHAPTER 5 CRACK GROWTH FROM NATURALLY OCCURRING MATERIAL DISCONTINUITIES
}

\author{
Rhys Jones $^{1,2}$, Daren Peng ${ }^{1}$ and A. McMillan ${ }^{2}$ \\ ${ }^{1}$ Centre of Expertise for Structural Mechanics, Department of Mechanical and Aerospace \\ Engineering, Monash University, Clayton, Victoria, 3800, Australia
}

${ }^{2}$ School of Applied Sciences, Computing and Engineering, Wrexham Glyndwr University, Mold Road, Wrexham, LL11 2AW, UK.

\section{Table of Contents}

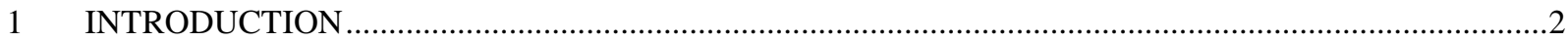

2 DAMAGE TOLERANT AB INITIO DESIGN AND AIRCRAFT SUSTAINMENT ..................................4

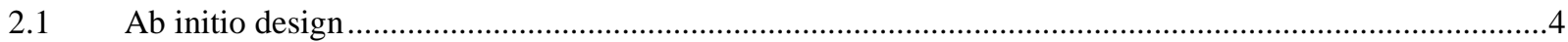

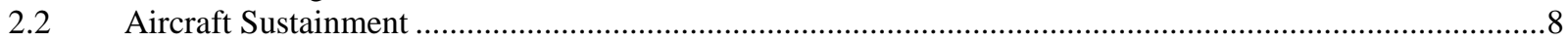

3 COMPUTING CRACK GROWTH ASSOCIATED WITH AIRCRAFT SUSTAINMENT RELATED

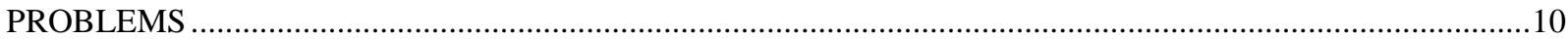

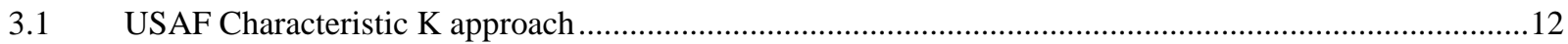

3.2 Crack growth under a representative RAAF AP3C (Orion) spectrum .................................................14

3.3 Crack growth at a dome nut hole containing intergranular cracking (IGC) .........................................16

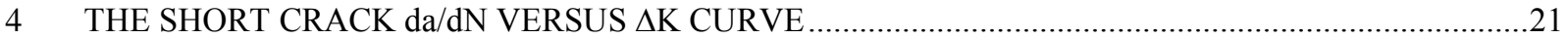

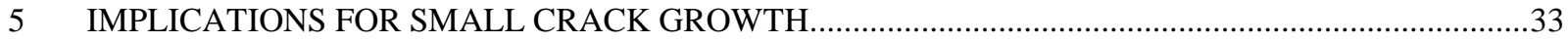

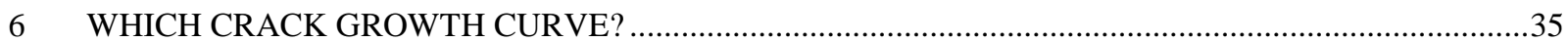

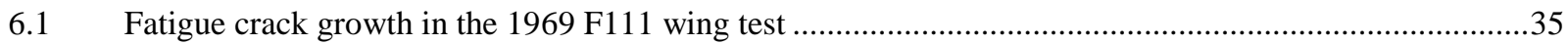

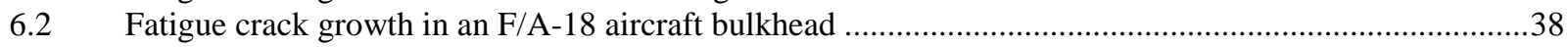

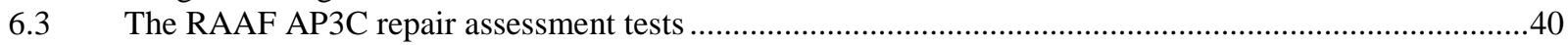

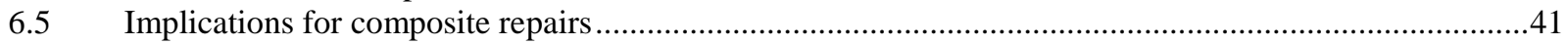

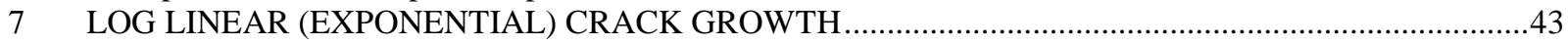

7.1 A non-dimensional master curve representation of crack growth in full scale structures ........................45

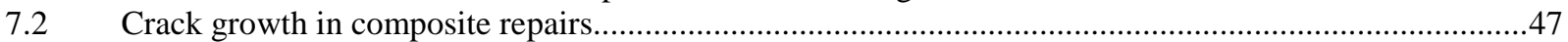

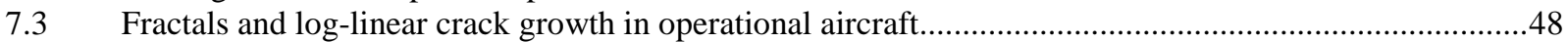

8 THE USAF APPROACH TO ASSESSING RISK OF FAILURE AND THE CUBIC RULE....................49

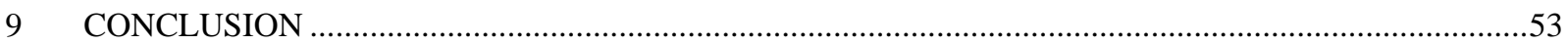

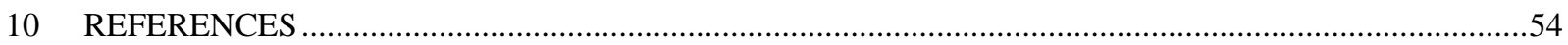

\section{ABSTRACT}

All repairs to airframes now need to be assessed as to their effect on the damage tolerance the aircraft. To this end this Chapter first discusses difference between the analysis tools needed for ab initio design and aircraft sustainment. It is shown that using small or physically short crack $\mathrm{da} / \mathrm{dN}$ versus $\Delta \mathrm{K}$ data results in reduced through life costs and increased aircraft availability. The tests procedures needed to validate composite, or supersonic particle deposition (SPD), repairs to operational aircraft are also discussed as is their relationship to the ASTM fatigue test standard E647-13a. This leads to an examination of the problem of crack growth from small naturally occurring material discontinuities under operational load spectra. A range of tools are available to account for crack growth in operational aircraft and several such tools are discussed, 
viz: cycle by cycle analysis; the USAF characteristic K approach, etc. Specific attention is paid to the growth of lead cracks in operational aircraft which are shown to exhibit near exponential crack growth and to essentially have a cubic dependency on stress. It is shown that cracks growing in composite repairs exhibit the same crack length and stress dependency. This finding is then linked to current approaches which use the cubic rule to assess repairs to RAAF aircraft.

\section{INTRODUCTION}

All repairs need to be assessed as to their effect on the damage tolerance of the aircraft/structure. Consequently before we can design/assess the effect of a composite repair we first need to know how to assess crack growth in operational aircraft. In general the design of aerospace vehicles requires that all structures be designed in accordance with damage tolerance design principles which for military aircraft are detailed in the Joint Services Structural Guidelines JSSG2006 and [1]. This design philosophy has evolved as a result of a number of high profile incidents some of which are reviewed in [2]. However, as explained in [3] the approaches and tools required for initial design and for sustainment purposes differ. In this context it is widely accepted that a significant proportion of the fatigue life of operational structures is consumed in crack growth from small naturally occurring material discontinuities. This is reflected in the statement in ASTM fatigue test standard E647-13a that:

"Fatigue cracks of relevance to many structural applications are often small or short for a significant fraction of the structural life."

As such in the context of aircraft sustainment and repair the need to be able to accurately represent the growth of cracks from small naturally occurring material discontinuities and small manufacturing defects is particularly important. When discussing the equations needed to accurately predict the growth of cracks from such small naturally occurring material discontinuities it is now widely accepted that there is generally little crack tip shielding (closure, etc.) $[3-5,6,7]$. This is reflected by numerous statements in ASTM E647-13a Appendix X3. In this context ASTM E647-13a states:

"the growth behavior of these small cracks is sometimes significantly different from what would be expected based on large-crack growth rate data and standard fatigue crack growth analysis techniques. Direct measurement of small-crack growth rates may be desirable in these situations."

In the absence of such small crack test data ASTM E647-13a has introduced the ASTM ACR (adjusted compliance ratio) method in an attempt to determine the closure free da/dN versus $\Delta \mathrm{K}$ relationship. Indeed, this approach was used to assess the life of critical locations in the Lockheed F-22 [8].

In this Chapter we first briefly discuss how the damage tolerance philosophies applied to ab initio design [1] and aircraft sustainment [3] differ and the change in aircraft certification that has 
arisen as a result of the introduction by FAA of the concept of a Limit of Validity (LOV) [9, $10]^{1}$. We then illustrate how the Hartman-Schijve variant of the NASGRO equation, see [3], can be used to compute the growth of small sub mm cracks growing under a measured operational RAAF AP3C (Orion) load spectrum. This example, when taken in conjunction with previous studies [3, 6, 7, 14-16] into cracks growing under combat aircraft load spectra, highlights how for cracks that grow from naturally occurring material discontinuities under operational load spectra there is little crack closure so that the crack growth history can often be easily and accurately computed using what is essentially a simple Paris crack growth equation.

It is a common misconception that since the US damage tolerance design approach mandates an initial flaw size of typically $1.27 \mathrm{~mm}$ that the associated crack growth analysis should ideally use the $\mathrm{da} / \mathrm{dN}$ versus $\Delta \mathrm{K}$ curves determined as per the main body of the ASTM E647-13a fatigue test standard. This concept is evaluated by considering crack growth in F-111 and F/A-18 aircraft and is shown to be incorrect and that the small, or physically short, crack da/dN versus $\Delta \mathrm{K}$ curve is needed even when the initial crack is greater than $1.27 \mathrm{~mm}$. Furthermore, in the examples studied, as well as in the recent Lockheed studies performed as part of the C-130J (Hercules) fatigue life extension program [17] and the F-22 program [8], it is shown that using long crack $\mathrm{da} / \mathrm{dN}$ versus $\Delta \mathrm{K}$ data can yield inspection intervals that are too short and hence can significantly reduce aircraft availability and increase both manpower requirements and maintenance costs [15].

The USAF Damage tolerant Design Handbook [1] outlines how the USAF Characteristic K approach can be used to assess both crack growth and the effect of repairs. This Chapter shows how this approach can also be used to assess the growth of cracks from small naturally occurring material discontinuities under a representative civil aircraft load spectrum (MiniTwist). This example when taken in conjunction with the results presented in [18-20] means that the USAF Characteristic $\mathrm{K}$ approach is applicable to the design/assessment of composite repairs to operational aircraft.

The fundamental question of how to account for the large scatter seen in crack growth in operational aircraft is also addressed. It is shown that, as first discussed in [3, 6], the scatter in the growth of both long and small cracks can be accounted for by allowing for a family of da/dN versus $\triangle \mathrm{K}$ curves and that these curves can be approximated by the Hartman-Schijve variant of the NASGRO crack growth equation allowing for minor changes in the threshold term $\Delta \mathrm{K}_{\text {thr }}$. In this context it is shown that the various experimental procedures commonly used to determine small crack da/dN versus $\Delta \mathrm{K}$ curves produce curves that are consistent with those determined using the Hartman-Schijve crack growth equation setting closure to zero and allowing for small variations in the threshold term $\Delta \mathrm{K}_{\mathrm{thr}}$.

A means of determining the effect on the crack growth rate of a variation in the stress level, for the same basic spectrum and material, is often needed for the interpretation of an aircraft fatigue test results, the design of repairs and/or for assessing the effect of a repair on the life of the

${ }^{1}$ For the background to this see [11 -13]. 
airframe [23]. This Chapter describes one such tool colloquially known as the stress-cubed (or cubic) rule [21, 23], which is based on the lead crack philosophy [22], and provides examples of its application to a number of materials, spectra and stress concentrations. It is shown that the growth of lead cracks, i.e. the fastest crack, in aircraft generally shows a near linear relationship between the $\log$ of the crack length/depth and the number of cycles (flight hours), i.e. that there is exponential crack growth $[19,20]$. It is also shown that for lead cracks the crack growth rate at one stress level can be predicted accurately with knowledge of the second stress level and the effective initiating crack size. The fundamental physics underpinning this exponential crack growth and the cubic rule [24] is also discussed.

It is mentioned that cracks repaired with composites patches also exhibit exponential crack growth $[25,26]$ and that the crack length histories for lead cracks in operational aircraft and composite repairs can be described by the same master curve representation [27]. Consequently having established the validity of the cubic rule and the fact that composite repairs do indeed exhibit exponential crack growth, a requirement that is needed if the cubic rule is to be used to estimate crack growth, and noting that the cubic rule is routinely used to assess (and certify) the effect of repairs on RAAF aircraft [23] it follows that this approach may be useful for estimating the effect of composite and SPD repairs on operational aircraft. This concept is discussed in more detail in the Chapter 8 which also discusses the design/certification methodology needed for composite repairs.

The ability of the Hartman-Schijve variant of the NASGRO equation to accurately compute the effect of intergranular cracking at fastener holes representative of domenut holes in P3C (Orion) aircraft, subjected to a measured flight load spectra, is also highlighted. Its ability to accurately compute the effect of supersonic particle deposited (SPD) repairs, also known as Cold Spray, to intergranular cracking is illustrated in Chapter 16, Section 9. Its ability to accurately compute the effect of a boron epoxy patch on the growth of cracks that, prior to patching, have grown from small sub $\mathrm{mm}$ surface defects to a size of approximately $1.27 \mathrm{~mm}$ is illustrated in Chapter 8 , Section 18.

Unless otherwise stated the stress intensity factor $(\mathrm{K})$ solutions used in the various examples discussed in this Chapter were determined using the methodology outlined in Chapter 4.

\section{2 \\ DAMAGE TOLERANT AB INITIO DESIGN AND AIRCRAFT SUSTAINMENT}

\subsection{Ab initio design}

Let us begin by discussing the difference between the analysis tools needed for ab initio design and aircraft sustainment. In general the design of aerospace vehicles requires that all structures be designed in accordance with damage tolerance design principles which for military aircraft are detailed in the Joint Services Structural Guidelines JSSG2006 and in the USAF Damage Tolerant Design Handbook [1]. This design philosophy has evolved as a result of a number of 
high profile (military aircraft) incidents some of which ${ }^{2}$, together with a number of civilian aircraft failures, are reviewed in [2]. As explained in [2]

"While there have been lessons learned from nearly all of the accidents and incidents, those that were seminal with respect to the design and certification of aircraft structures were the 1954 Comet failures, the 1958 B-47 accidents, the 1969 F-111 accident, the 1976 AVRO 748 accident, the 1978 Dan Air 707 Lusaka accident and the 1988 Aloha Boeing 737 accident. The Comet failures resulted in the use of fail-safe design in commercial aircraft; the B-47 accidents resulted in the development of the Air Force Aircraft Structural Integrity Program (ASIP); the F-111 accident accelerated the introduction of damage tolerance design requirements in military aircraft; the AVRO 748 and Dan Air Boeing 707 accidents resulted in complementing commercial fail-safe design with damage tolerance requirements; and the Aloha Boeing 737 accident brought attention to the importance that $\mathrm{WFD}^{3}$ has in limiting the safe operation of airplane structures."

The basic principle underlying both the USAF and the FAA requirements ${ }^{4}$ is: at no time during the life of the aircraft should the residual strength reduce to beneath limit load. Full scale fatigue tests play an essential part in meeting this requirement and, as a result of the introduction by the FAA of the requirement for full scale fatigue tests to be performed in order to establish a limit of validity $(\mathrm{LOV})^{5}$, are now mandatory for civil transport $[9,10]$ above a takeoff weight of 75,000 pounds. As outlined in $[9,10]$ this requirement applies to:

a) Turbine-powered transport category airplanes, existing at the effective date of the rule (January 14, 2011), that are operated under part 121 or 129 and have a type certificate issued after January 1, 1958, and a maximum takeoff gross weight greater than 75,000 pounds as approved by the original type certificate or an amended or supplemental type certificate.

b) Transport category airplanes that have had the maximum takeoff gross weight reduced from greater than 75,000 pounds to 75,000 pounds or less if the application for that change was made after January 14, 2011.

c) All transport category airplanes with a current LOV, when that LOV is being extended. This would include LOVs approved under Federal Aviation Regulations (FAR) sections

\footnotetext{
${ }^{2}$ Reference [2] also provides an historical perspective as to how the military, the Federal Aviation Administration (FAA) and industry have dealt with these threats.

${ }^{3}$ Widespread fatigue damage (WFD) is defined [11] as the simultaneous presence of cracks at multiple structural locations that are of sufficient size and density such that the structure will no longer meet the residual strength requirements of FAR section \$25.571(b).

${ }^{4}$ Damage tolerance requirements were not adopted by the FAA until 1978, see [12].

${ }^{5}$ Limit of validity - The period of time (in flight cycles, flight hours, or both) up to which widespread fatigue damage will not occur in the airplane structure.
} 
$\S 25.571,26.21$, or 26.23 and the fatigue life of civil transport aircraft above a weight of 75,000 pounds."

The practical implications of the LOV rule for new (civil) aircraft designs is outlined on page 17 of [10] where it is stated: operators must not fly their aircraft beyond half of the number of fatigue cycles seen in the associated full scale fatigue test. As such the operational life (LOV) of civil transport aircraft above a takeoff weight of 75,000 pounds is now essentially set by the results of full scale fatigue tests. Furthermore, since extension of the LOV can only be done on the basis of full scale testing or flight experience $[9,10]$ the importance of modelling crack growth in this class of civil transport aircraft has been significantly diminished. This is explicitly stated in [7] where Robert Eastin, the FAA Chief Scientific/Technical Advisor for Fatigue and Damage Tolerance, states:

"Amendment 25-96 was a game changer when it comes to managing fatigue in WFD susceptible areas. No longer could the applicant establish inspections or other procedures based on the results of a crack growth and residual strength evaluation."

One possible reason for this is that after more than twenty years of research into WFD in civil aircraft the problem, which was first encountered in Aloha Airlines accident [13], was still endemic [7]. This finding also (unfortunately) supports the conclusion reached by Paris et al. that "a specific accumulation damage model for the computation of damage growth under a wide variety of service loads is still lacking"

This situation, i.e. that aircraft can't be flown once the aircraft has exceeded half of the number of cycles seen in the associated full scale fatigue test, does not hold for military aircraft. As a result design fatigue crack growth calculations play a more important role in establishing the continuing airworthiness of military aircraft. However, it should be noted that, in the context of the initial design, the size of the initiating flaw is mandated in the USAF Damage Tolerance Design Handbook [1], typically $1.27 \mathrm{~mm}$. The methodology outlined in Section 2, i.e. the use of crack closure based equations together with ASTM E647 long crack da/dN versus $\Delta \mathrm{K}$ crack growth curves, and implemented in the computer codes AFGROW, NASGRO and FASTRAN generally works well for such large initial flaws ${ }^{6}$. However, care must be taken when choosing the appropriate $\mathrm{da} / \mathrm{dN}$ versus $\Delta \mathrm{K}_{\text {eff }}$ relationship for use in the analysis. For example, when using FASTRAN to compute the crack length versus cycles history associated with crack growth at different fatigue critical locations in P3C (Orion) aircraft different crack growth curves ${ }^{7}$ had to be used for locations that saw a tension dominated spectrum and for locations for which the spectra experienced a combination of tension and compression loads. This particular shortcoming was overcome in [7] by using a da/dN versus $\Delta \mathrm{K}_{\text {eff }}$ relationship that was derived

${ }^{6}$ Unfortunately the same can't be said for sustainment related crack growth issues where the crack grows from small naturally occurring material discontinuities. This topic will be discussed later in the Chapter.

${ }^{7}$ By this it is meant that at different fatigue critical locations a different relationship between the constraint factor $\alpha$ and the crack growth rate da/dN had to be used. 
from the NASGRO (the Hartman-Schijve variant) crack growth equation fit to published da/dN versus $\Delta \mathrm{K}$ data.

As implied above the accuracy of any crack growth prediction is a strong function of the input $\mathrm{da} / \mathrm{dN}$ versus $\Delta \mathrm{K}$, or the $\Delta \mathrm{K}_{\mathrm{eff}}$, relationship. For ab initio design this data is generally obtained from ASTM E647 tests. Unfortunately the ASTM constant R loading reducing test can yield erroneous results with artificially large thresholds [3, 8, 17, 30, 31, 32] and can thereby result in non-conservative estimates of the fatigue life, see ASTM E647-13 Appendix X3 for more details. The work of Forth [30] is a good example of this. Here Forth [30] explains that using the value of $\Delta \mathrm{K}_{\text {th }}$ determined from $\mathrm{K}_{\max }$ tests, rather than the value obtained via the ASTM load reducing tests, led to a reduction in the life of the US Space Shuttle from an effectively infinite life to approximately four missions [30].

As a result of this shortcoming (in the data generated using the ASTM load reducing standard to determine the $\mathrm{da} / \mathrm{dN}$ versus $\Delta \mathrm{K}$ curve) a number of methods, viz: compression pre-cracking (CPC) $[33,34]$, the ACR technique [8, 35-37], the partial crack closure approach [37, 38, 39] and high $K_{\max }$ tests $[30,40]$ have been proposed to obtain a better estimate of the intrinsic, i.e. crack tip shielding free, da/dN versus $\Delta \mathrm{K}$, or $\Delta \mathrm{K}_{\text {eff }}$, relationship. Of these the ACR technique is perhaps the most widely accepted technique and this approach has now been incorporated into ASTM E647. An added advantage of this procedure is that it appears to yield a da/dN versus $\Delta \mathrm{K}_{\text {eff }}$ curve that is relatively consistent with that seen by physically short cracks $^{8}[3,41]$. Interestingly [3] revealed that when using the ACR method to study $\mathrm{R}=0.33$ crack growth seen in 7050-T7451 tested in a high humidity environment $(\mathrm{RH}>95 \%)$ the resultant ACR (closure corrected) da/dN versus $\Delta \mathrm{K}_{\text {eff }}$ data [42] coincided with the small crack lab air test data presented in [43] where the initial flaw size was approximately $0.007 \mathrm{~mm}$. Similarly in Section 4 it will be shown that the closure free data obtained by Yamada and Newman 74] using a modified CPC procedure in which local strain gages placed along the crack path were used to measure the crack opening load also yielded data that were consistent with measured 7050-T7451 small crack data. These example are an illustration of the conclusion reached in $[3,4,44,45]$ that the growth of short cracks is essentially crack tip shielding free and that short crack data can be obtained from long crack data by accounting for crack shielding effects.

However, care must be taken since [3, 39] the ACR and the CPC approaches generally produce $\mathrm{da} / \mathrm{dN}$ versus $\Delta \mathrm{K}$ curves that tend to resemble that obtained for physically short cracks. Such curves do not have the same shape as the small crack da/dN versus $\Delta \mathrm{K}$ curves which, as explained in the review paper [7] that examined the data obtained in a large number of small/short crack tests, often has a very low threshold and a da/dN versus $\Delta \mathrm{K}$ curve that can often be approximated by a simple Paris law. It is postulated that this is because these approaches may not account for all of the crack tip shielding mechanisms that arise for long cracks but have a minimal effect on the growth of cracks from small naturally occurring material discontinuities [14, 44, 45]. In this context Lugo, Daniewicz and Newman [46] present an

\footnotetext{
${ }^{8}$ As distinct from that seen by cracks that grow from small naturally occurring material discontinuities.
} 
interesting computational study into the ACR method that discusses its sensitivity to the measurement location.

\subsection{Aircraft Sustainment}

In Section 2.1 it was mentioned that whereas the methodology developed to compute the growth of long cracks generally works reasonably well this is not the case for cracks that grow from small naturally occurring material defects such as those found in aerospace vehicles [22, 28, 29]. As a result it should be noted that the DSTO-RAAF approach to the management of fatigue cracking in combat, maritime reconnaissance and trainer aircraft makes use of the "lead crack" concept [22]. In this approach, the life of the fleet is determined by the growth of lead fatigue cracks which in [11] were defined to have the following features:

a) Crack growth initiates from small naturally occurring material discontinuities, such as inclusions and pits, which have dimensions that are equivalent to a fatigue crack-like size typically of about $10 \mu \mathrm{m}$ in depth [18-29] ${ }^{9}$.

b) Crack growth essentially starts from the day that the aircraft enters service. (This implies that the fatigue threshold $\Delta \mathrm{K}_{\mathrm{th}}$ is very small and is in agreement with statements presented in ASTM E647-13a and [3, 20, 22, 47, 48].)

c) The shape of the crack growth versus flight hours curve can be approximated by a near exponential crack growth curve. This finding is substantiated by the crack growth data presented in [18-22, 48-51] as well as in the compendium of F/A-18 crack growth data [52] which presents data associated with more than three hundred and fifty different cracks in a range of aluminium and titanium alloys.

In this context it should be noted that, as first postulated by Frost and Dugdale [53] for crack growth in constant amplitude tests on centre cracked panels, the shape of the crack growth versus cycles curve can often be approximated by an exponential crack growth curve $[3,18,19,22,26$, 27, 48, 51, 52], viz:

$$
a=a_{i} e^{\omega N}
$$

where $a_{i}$ is the initial crack size, $\mathrm{N}$ is the number of cycles, or flight hours, and $\omega$ is a constant. As such the fact that the shape of the crack growth versus flight hours curve seen in operational aircraft and representative full scale fatigue tests can be approximated by an exponential crack growth curve represents an extension of the Frost-Dugdale observation to operational aircraft. This finding, i.e. a near an exponential crack growth curve, is consistent with the USAF studies

\footnotetext{
${ }^{9}$ This (initiating defect) size is consistent with the work of Merati [54], where it was found that the size of initial defects in civil transport aircraft lie in the range 0.009 to $0.029 \mathrm{~mm}$ and with the paper by Schijve [55] where it was reported that the size of initial defects in civil transport aircraft lie in the range 0.007 to $0.030 \mathrm{~mm}$.
} 
[48-51] where as a result of fractographic examination of failure surfaces it was found that crack growth in operational aircraft and full scale fatigue tests could approximated as

$$
d a / d N \propto a^{b}
$$

where $\mathrm{b}$ was approximately 1 so that crack growth is (near) exponential. This exponential crack growth law was subsequently built into the USAF approach to assessing the "Risk of Failure" [48].

It has long been known [3] that for cracks that grow from naturally occurring material discontinuities in operational structures the majority of the life is consumed by the time to grow to a size that is readily detectable by NDI. This conclusion, i.e. that the majority of the life is consumed by the time to grow to size that is a readily detectable by NDI, is also found in [48, 56] as well as in a number of other reviews and also follows from the compendium of F/A-18 crack growth data presented in [52].

As such given that one of the primary conclusions reached in the USAF-McDonnell Douglas (now Boeing) study into sustainment issues associated with cracking in F-15 aircraft [57] was the need to use the short crack da/dN versus $\Delta \mathrm{K}$ curve rather than the corresponding ASTM long crack curve it is clear that understanding the growth of fatigue cracks from small naturally occurring material discontinuities is of fundamental importance to sustainment related issues. Indeed, the central role that small cracks play in understanding the durability of aircraft and other engineering structures is highlighted in [55]. Furthermore, as stated by Lados, Apeliana, Paris and Donald [41]: "The use of long crack data can lead to significantly non-conservative estimates of the fatigue response and serious design errors." This statement is echoed in Appendix X3 of ASTM E647-13a. The extent of these non-conservative estimates is aptly illustrated in [94] where it was shown that using FASTRAN together with a da/dN versus $\Delta \mathrm{K}$ curve obtained from tests on long cracks to predict the crack growth from a small 0.003 initial defect in a F/A-18 centre barrel crack gave an estimate of the fatigue life that was more $300 \%$ greater than that seen in the test. Indeed, even when used to compute the growth of cracks in 7050-T7451 where the crack length was greater than approximately $1 \mathrm{~mm}$ it was found that when these cracks have grown from small naturally occurring material discontinuities, the use of FASTRAN (even when used in concert with the high $\mathrm{R}$ ratio da/dN versus $\Delta \mathrm{K}$ curve associated with small cracks) gave non-conservative results [15]. Unfortnately this is not always the case and Section 6 presents two examples where by the use of FASTRAN gives overly conservative lives.

The reason for this is that, as explained in $[3,4,5]$, there is little crack tip shielding associated with cracks that grow from small naturally occurring material discontinuities. As such we expect to find little $\mathrm{R}$ ratio dependency. This is confirmed in [7] which presents the small crack da/dN versus $\Delta \mathrm{K}$ curves for tests involving a large number of materials and $\mathrm{R}$ ratio's and in [14] which presents data associated with the growth of very small cracks from a notch. 
and ASTM long crack da/dN versus $\Delta K$ curves in sustainment related problems is generally inappropriate and any crack growth equation should allow for closure to decay as the crack length reduces and should use the appropriate short crack da/dN versus $\Delta K$ curve.

These conclusions will be discussed in more detail in Sections 3-7.

\section{COMPUTING CRACK GROWTH ASSOCIATED WITH AIRCRAFT SUSTAINMENT RELATED PROBLEMS}

Section 2 raises the question of how to compute the growth of cracks from small naturally occurring material discontinuities under representative operational flight load spectra. In this context the 2014 state of the art review paper [3] explained that the growth of cracks from small naturally occurring material discontinuities can often be computed using the Hartman-Schijve variant of the NASGRO crack growth equation, i.e. equation (3), with the constants obtained from long crack data by setting crack closure to be zero ${ }^{10}$ and using a small value of $\Delta K_{\text {thr }}$. The NASGRO equation can be written in the form:

$$
\mathrm{da} / \mathrm{dN}=\mathrm{D} \Delta \mathrm{K}_{\text {eff }}^{(\mathrm{m}-\mathrm{p})}\left(\Delta \mathrm{K}_{\text {eff }}-\Delta \mathrm{K}_{\text {eff,thr }}\right)^{\mathrm{p}} /\left(1-\mathrm{K}_{\max } / \mathrm{A}\right)^{\mathrm{q}}
$$

where

$$
\Delta \mathrm{K}_{\mathrm{eff}}=\Delta \mathrm{K}-\Delta \mathrm{K}_{\mathrm{op}}
$$

and

$$
\Delta \mathrm{K}_{\mathrm{op}}=\left(1-\mathrm{e}^{-\lambda \mathrm{a}}\right) \Delta \mathrm{K}_{\mathrm{opl}}
$$

The Hartman-Schijve variant is obtained from equation (3) by setting $\mathrm{m}=\mathrm{p}$ and $\mathrm{q}=\mathrm{p} / 2$, see [3] for more details. In many cases the value of $p$ is approximately 2 , see $[3,7,58,59]$. In this formulation $D$ is a constant, $K_{\max }$ and $K_{\min }$ are the maximum and minimum values of $K$ seen in a cycle, $\Delta \mathrm{K}_{\mathrm{opl}}$ is the long crack value of $\Delta \mathrm{K}_{\mathrm{op}}\left(=\mathrm{K}_{\mathrm{op}}-\mathrm{K}_{\mathrm{min}}\right), \mathrm{K}_{\mathrm{op}}$ is the value of the stress intensity factor at which the crack first opens, $\lambda$ is a material dependent constant and the terms $\Delta \mathrm{K}_{\text {thr }}$ and $\mathrm{A}$ are best interpreted as parameters chosen so as to fit the measured da/dN versus $\Delta \mathrm{K}$ data, see [3] for more details. As such [3] noted that it follows that for cracks growing from small naturally occurring material discontinuities for a significant proportion of the fatigue life equation (3) can be approximated by what is essentially a simple Paris type law and that this observation is consistent with a large number of experimental studies, see [3] and Appendix D in [7].

Crack growth in operational aircraft is often associated with a significant scatter in the crack growth versus flight hours histories. In this context it has been shown $[3,6,7,14,15]$ that

\footnotetext{
${ }^{10}$ It should also be noted that, as shown in Figure 12 in [60] which analysed the growth of small cracks in 7050-T7451 even if small crack da/dN versus $\Delta \mathrm{K}$ data is used not setting closure to a small value can lead highly non-conservative crack length/depth histories seen in tests on cracks that grow from small naturally occurring material discontinuities.
} 
variations in the crack growth histories ${ }^{11}$ can be modelled by allowing for small changes in the value of $\Delta \mathrm{K}_{\mathrm{thr}}$. In this context [3] illustrated how this approach can also be used to capture the scatter seen in long crack tests in the paper by Virkler, Hillberry and Goel [61] which is recognised [62] as being one of the definitive studies that illustrates the variability in crack growth rates. This Chapter presented the results of sixty eight $R=0.2$ tests on 2024-T3 panels where the initial crack length was $9 \mathrm{~mm}$. To illustrate how equation (3), with $\mathrm{m}=\mathrm{p}=2$ and $\mathrm{q}=$ $\mathrm{p} / 2$, see [3] for more details can be used to estimate the variability in fatigue life. The representation given in $[3,58]$ for this material was used, viz:

$$
\mathrm{da} / \mathrm{dN}=1.210^{-9}\left(\Delta \mathrm{K}-\Delta \mathrm{K}_{\mathrm{thr}}\right)^{2} /\left(1-\mathrm{K}_{\max } / \mathrm{A}\right)
$$

with A set at $70 \mathrm{MPa} \sqrt{ }$. Reference [3] revealed that the variability in the crack growth histories in these tests is captured reasonably well by merely allowing for small changes in the value of $\Delta \mathrm{K}_{\mathrm{thr}}$ used in equation (6), i.e. using vales of $2.9,3.2,3.4,3.6,3.8,4$ and 4.2. As such the test data reported in [61] leads to a family of da/dN versus $\Delta \mathrm{K}$ curves, see Figure 1.

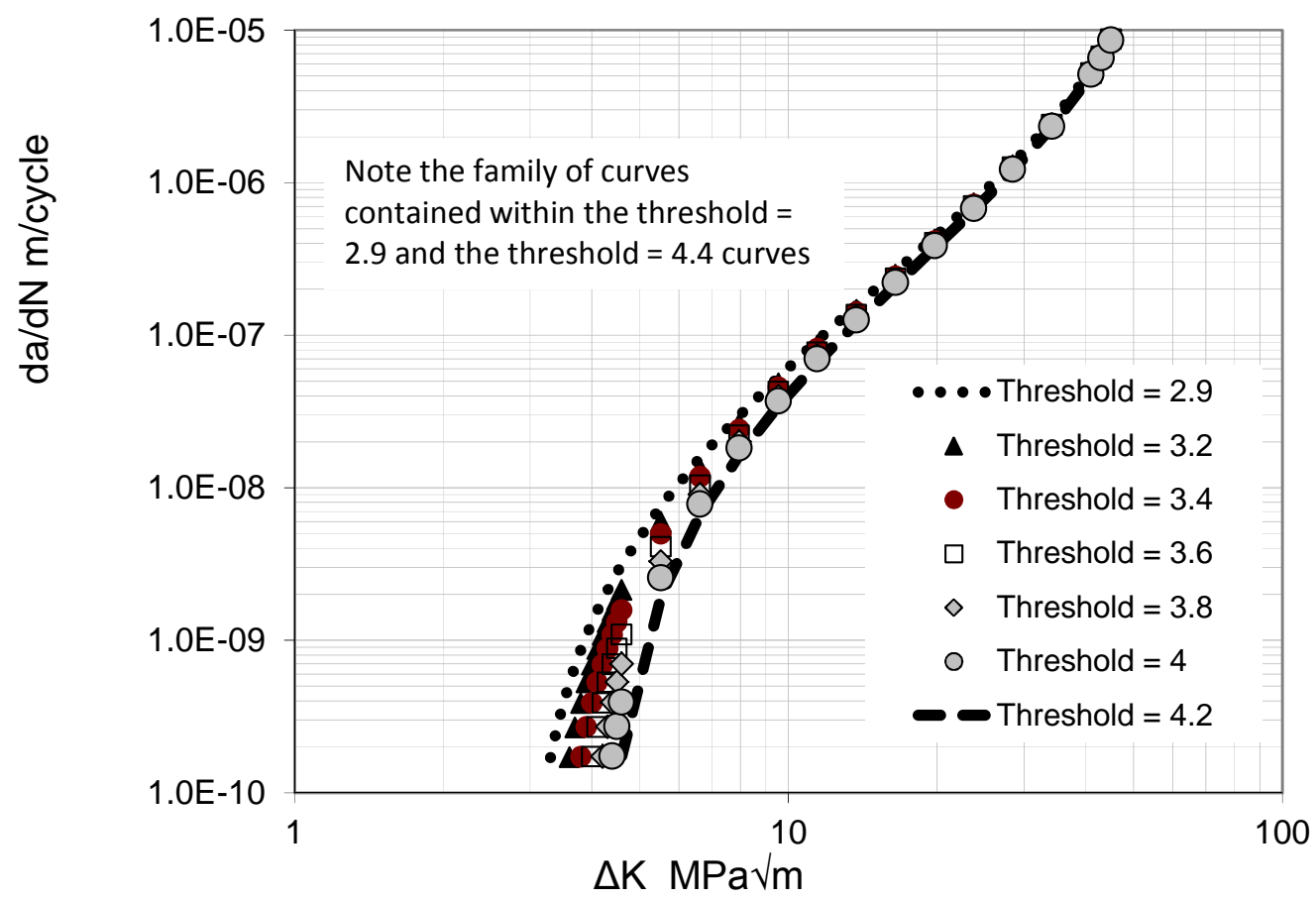

Figure 1 Family of curves associated with the test data presented in [16]

\footnotetext{
${ }^{11}$ The ability of a variant of this approach, where in equation (3) the term $\mathrm{K}$ is replaced by $\sqrt{\mathrm{G}}$, to capture the scatter seen in Mode I, II and mixed Mode I/II disbond growth in adhesively bonded structures as well as Mode I, II and mixed Mode I/II delamination growth composites, and nano-composites is shown in [63-66].
} 
The review paper [3] also illustrated how this approach can be used to compute the crack growth history seen in operational aircraft via the problem of crack growth in the 1969 General Dynamics, now Lockheed Martin, F-111 wing fatigue test which used a representative F-111 usage spectrum. (An early F-111 in-flight failure was largely responsible for the USAF adopting a damage tolerance approach [2].) Examples of how this approach can be used to compute crack growth from etch pits at both low and high $\mathrm{K}_{\mathrm{T}}$ features under representative combat aircraft flight load spectra are given in [14].

\subsection{USAF Characteristic K approach}

It was mentioned in [3] that for cracks that grow from small naturally occurring material discontinuities under operational loading, which as mentioned above generally see little crack closure, that the USAF characteristic K approach outlined in [1], where the characteristic (also called the reference) stress intensity factor is usually taken as either the root mean square value of $\Delta \mathrm{K}$ in the load block $\left(\Delta \mathrm{K}_{\mathrm{rms}}\right)$ or the maximum value of $\mathrm{K}\left(\mathrm{K}_{\max }\right)$ in the load block, is also often a useful approach. This was illustrated [3] by considering a range of (small) crack growth tests in 7050-T7451 under both an operational F/A-18 (Hornet) flight load spectrum and FALLSTAFF, which is an industry standard combat aircraft spectrum. In each case it was shown that $\mathrm{da} / \mathrm{dN}$ could be expressed as:

$$
\mathrm{da} / \mathrm{dN}=7 \mathrm{x} 10^{-10}\left(\Delta \mathrm{K}_{\mathrm{rms}}-\Delta \mathrm{K}_{\mathrm{rms}, \mathrm{thr}}\right)^{2} /\left(1-\mathrm{K}_{\max } / \mathrm{A}\right)
$$

where $\Delta \sigma_{\text {rms }}$ is the root mean square value of the stress in the spectrum, $\beta$ is the geometry correction (beta) factor, $\Delta \mathrm{K}_{\mathrm{rms}}\left(=\beta \Delta \sigma_{\mathrm{rms}} \sqrt{ }(\pi \mathrm{a})\right)$ is the root mean square value of $\Delta \mathrm{K}$, and the term $\Delta \mathrm{K}_{\mathrm{rms}, \text { thr }}$ is the equivalent threshold value of $\Delta \mathrm{K}_{\mathrm{rms}}$. It was also shown [3] that equation (7) described the constant amplitude representation for the growth of both long and short cracks in this material, see [3] for more details.

In this context it should be noted that, as mentioned above, the crack closure based analysis presented in [60] for the growth of small cracks in 7050-T7451 dogbone specimen under a MiniTWIST spectrum with a peak stress of $250 \mathrm{MPa}$ gave a non-conservative crack length/depth history, see Figure 2. This shortcoming vanishes if equation (5) is used, see Figure 2 which presents a comparison of the measured [67] and computed crack depth histories using as per [14] $\mathrm{A}=47 \mathrm{MPa} \sqrt{\mathrm{m}}$. Here we see that, as discussed above, allowing for small variations in the term $\Delta \mathrm{K}_{\mathrm{rms} \text {,thr }}$ enables the scatter in the various tests to be captured reasonably accurately. The values of $\Delta \mathrm{K}_{\mathrm{rms}, \text { thr }}$ used in this analysis are given in Table 1. 
Table 1. List of $\Delta \mathrm{K}_{\mathrm{rms}, \text { thr }}$ used in the Characteristic $\mathrm{K}$ analysis

\begin{tabular}{|c|c|}
\hline Coupon & $\begin{array}{c}\Delta \mathrm{K}_{\text {rms.thr }} \\
(\mathrm{MPa} \sqrt{\mathrm{m}})\end{array}$ \\
\hline LM727 & 0.58 \\
\hline LM737 & 0.67 \\
\hline LM804 & 0.36 \\
\hline LM848 & 0.45 \\
\hline LM900 & 0.41 \\
\hline
\end{tabular}

The ability of the cycle by cycle formulation, with closure set to zero, to capture crack growth in these test specimens is presented in [68].

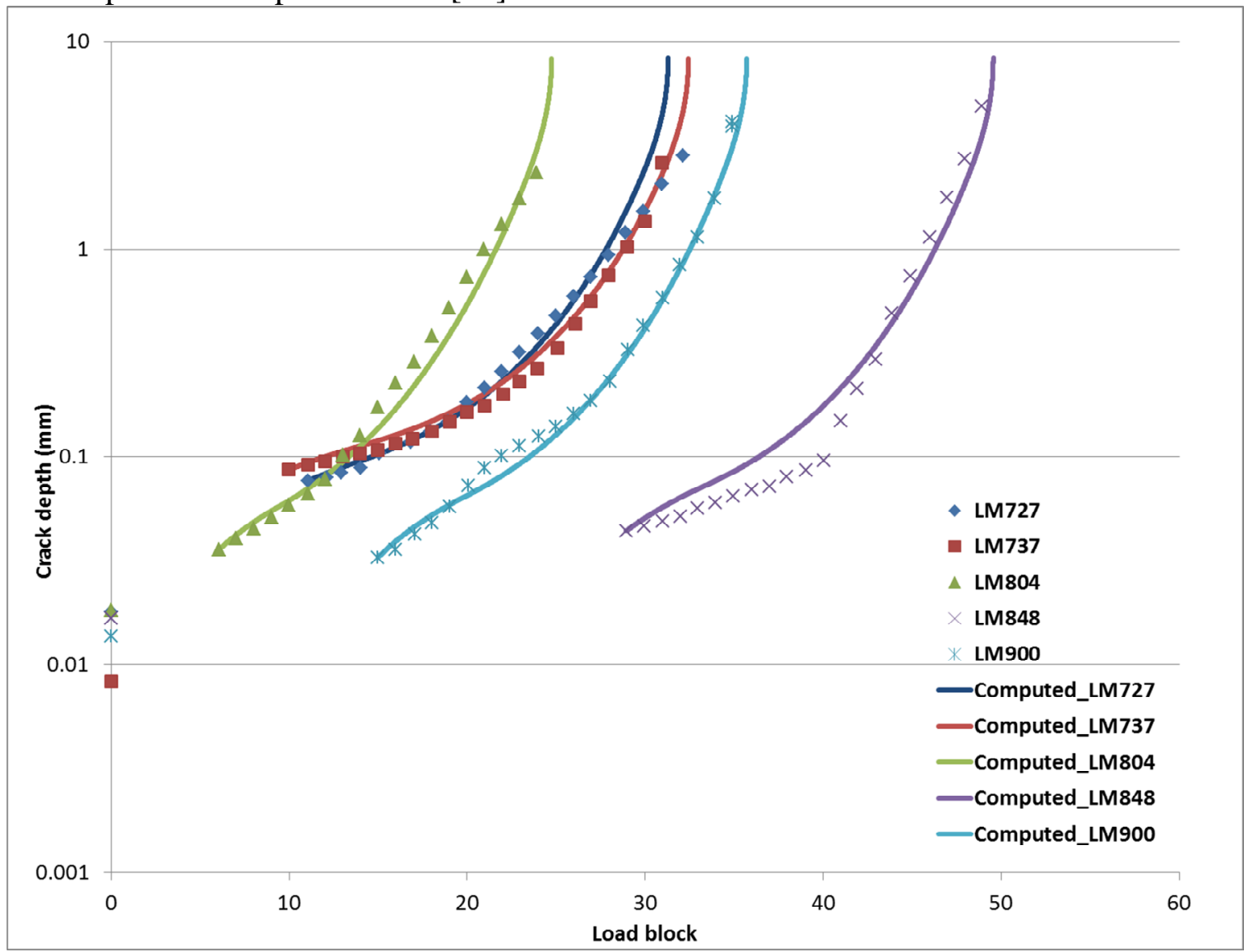

Figure 2.Measured and computed crack depth histories for specimens tested at 250MPa under a mini-TWIST load spectrum, from [68].

The paper by Molent and Gallagher [18], which examined sixty three 7050-T7451 specimen tests where the specimens were subjected to a range of representative fighter aircraft spectra with each spectra having tests performed at four different load levels, found that the growth of cracks from small naturally occurring material discontinuities conforms to a simple Paris like law where $\mathrm{da} / \mathrm{dN}$ is essentially proportional to $\mathrm{K}_{\max }{ }^{2}$ and that there was no apparent threshold. This finding mirrors the observation discussed above and in [3] that for cracks that grow from small 
naturally occurring material discontinuities da/dN is essentially related to $\Delta K$ by a simple Paris law.

\subsection{Crack growth under a representative RAAF AP3C (Orion) spectrum}

Prior studies have shown the ability of the Hartman-Schijve variant of the NASGRO equation to accurately compute the growth of cracks from small naturally occurring material discontinuities under combat aircraft load spectra $[3,7,14,15]$. This raises the question: Does this approach hold for other spectra?

To investigate this question consider the data presented in [69] for the growth of small cracks, both for an "as machined" specimen and a specimen with etch pits, in a high $\mathrm{K}_{\mathrm{t}}$ ('double-ear') specimen with a gross $\mathrm{K}_{\mathrm{t}}$ of 5 made from a $3.175 \mathrm{~mm}$ thick $7075-\mathrm{T} 6$ aluminium plate subjected to a Royal Australian Airforce (RAAF) FCA-351 load spectrum with a peak remote stress of 139 $\mathrm{MPa}$. The machined surface finish was to simulate the surface finish seen in reamed holes present in F/A-18 structure [69]. The etched surface finish was to imitate one of the surface treatments applied to certain F/A-18 components, see [69] for details. The test specimens described in [69] had a working section of $114.3 \mathrm{~mm}$ (long) by $38.1 \mathrm{~mm}$ (wide) and a close up view of the local geometry is shown in Figure 3. The FCA-351 spectrum is a repeated block load spectrum that is a representation of the load time history seen at the lower front spar inboard area near the inboard engine of RAAF AP3C (Orion) aircraft, see [70] for more details. It was developed from the fleet operational usage data collected from 1991 through 1997. One block consists of 1,264,912 cycles. This corresponds to 15,000 flight hrs and one load block represents the nominal design life of the aircraft. 


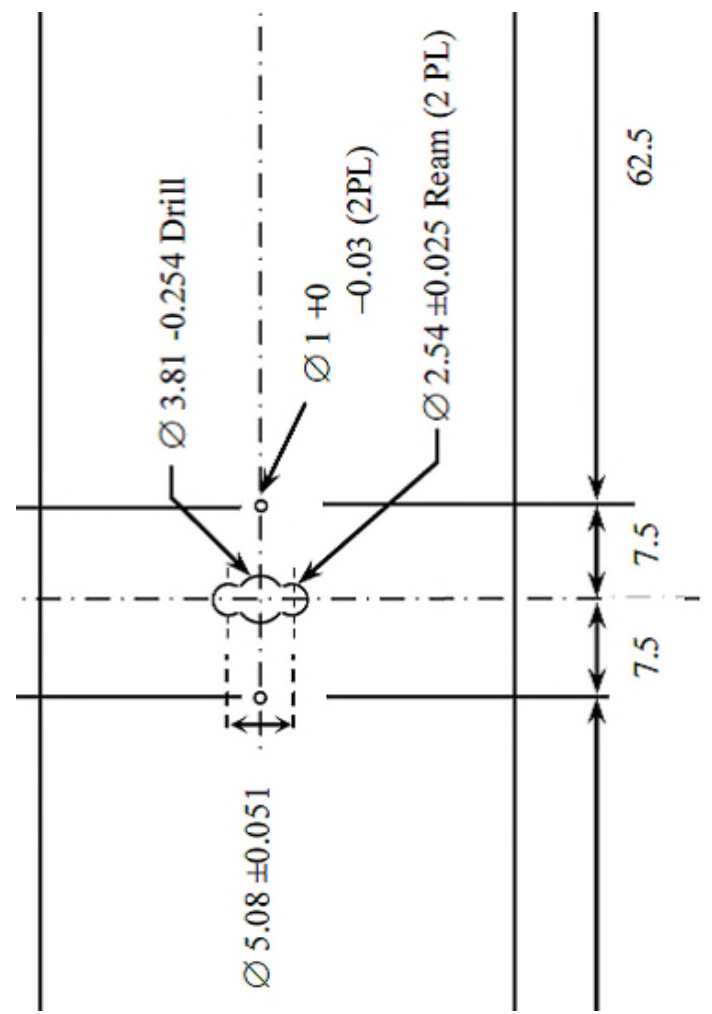

Fig. 3. Schematic of the local specimen geometry, from [69].

As in [59, 7], which studied the (constant amplitude) growth of long cracks in tests, and [16] which studied the growth of small cracks from a fastener hole surrounded by intergranular corrosion as well as the growth of small surface cracks in this material crack growth was computed using the Harman-Schijve variant of the NASGRO equation, i.e. equation (1) with $\mathrm{m}=$ $\mathrm{p}, \mathrm{q}=\mathrm{p} / 2$ and $\mathrm{p}=2$. However, since in this instance we are analysing cracks that grow from small naturally occurring material discontinuities closure effects were set to zero, as recommended in [3]. The values of D and A used in the analysis were as given in [7, 59] for this material so that the crack growth equation became:

$$
\mathrm{da} / \mathrm{dN}=1.8610^{-9}\left[\left(\Delta \mathrm{K}-\Delta \mathrm{K}_{\mathrm{thr}}\right)^{2}\right] /\left(1-\mathrm{K}_{\max } / 111\right)
$$

The resultant measured and computed crack length histories are shown in Figure 4 where we see good agreement both for the "as machined" and the "etched" specimens. This analysis used $\Delta \mathrm{K}_{\mathrm{thr}}$ $=0.2 \mathrm{MPa} V_{\mathrm{m}}$ for the "etched" specimen and $\Delta \mathrm{K}_{\mathrm{thr}}=0.93 \mathrm{MPa}{ }_{\mathrm{m}}$ for the "as machined" specimen.

When taken together with the results presented in [3, 7, 14-16] this example illustrates how, as suggested in [3], the Hartman-Schijve variant of the NASGRO equation with closure set to zero and the threshold term $\Delta \mathrm{K}_{\text {thr }}$ set to a small value can be used to compute the growth of small 
crack under a representative maritime aircraft flight spectrum as well as under representative combat aircraft spectra $[3,7,14-16]$.

The use of the Hartman-Schijve variant of the NASGRO equation to accurately compute the effect of intergranular cracking at fastener holes representative of domenut holes in P3C (Orion) aircraft subjected to a measured flight load spectra in shown in Chapter 16. Chapter 16 also illustrates how this methodology can be used to accurately compute the effect of SPD repairs to intergranular cracking.

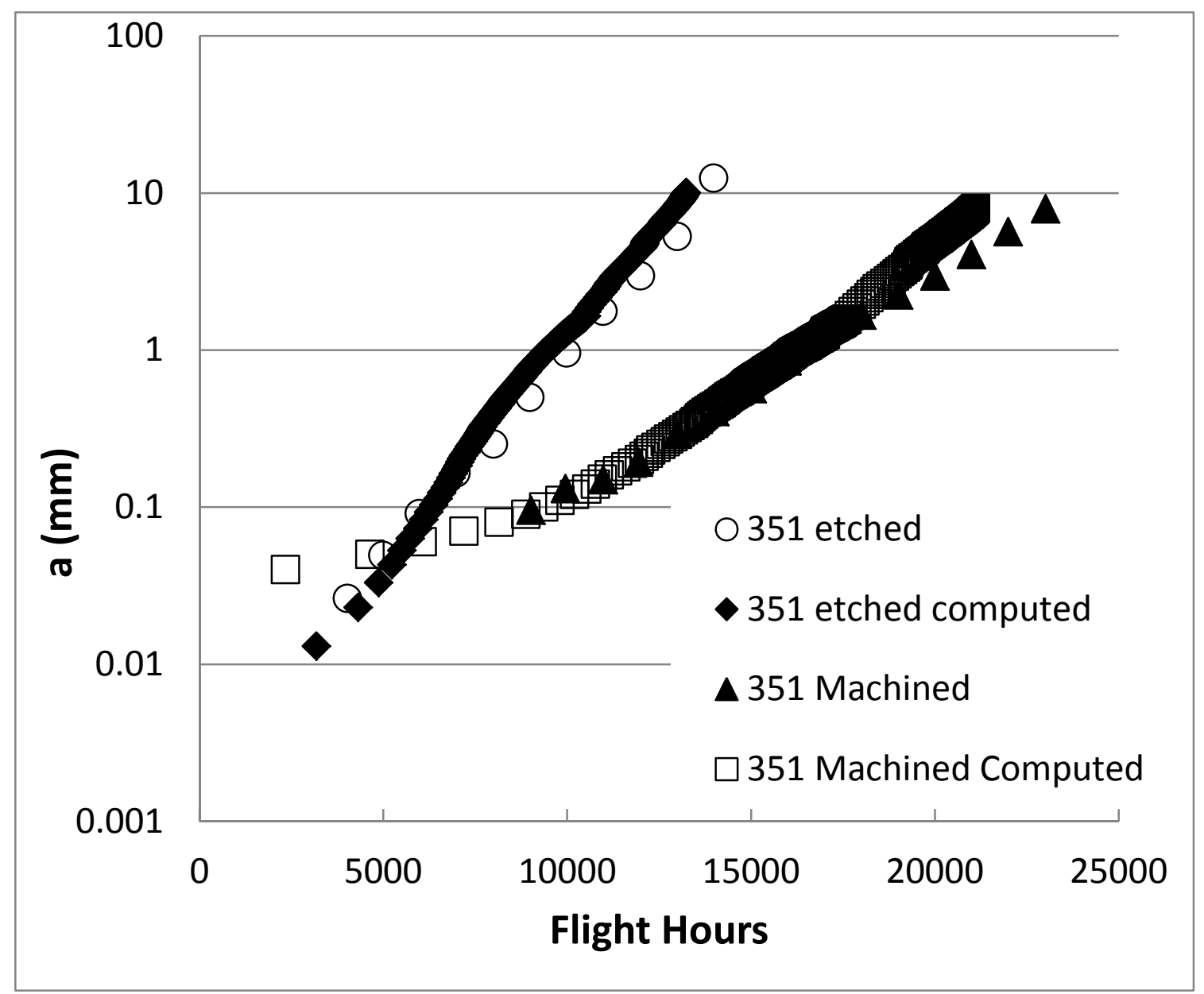

Figure 4. Measured and computed crack growth histories.

\subsection{Crack growth at a dome nut hole containing intergranular cracking (IGC)}

To illustrate the effect of intergranular cracking (IGC) on structural integrity this section focuses on crack growth in dome nut hole specimens (DNHS) that were representative of those seen in RAAF P3C (Orion) aircraft- see Figure 5, that contained had intergranular corrosion (IGC) that 
were tested at DSTO [3]. The geometry of the test specimens is shown inn Figure 6.

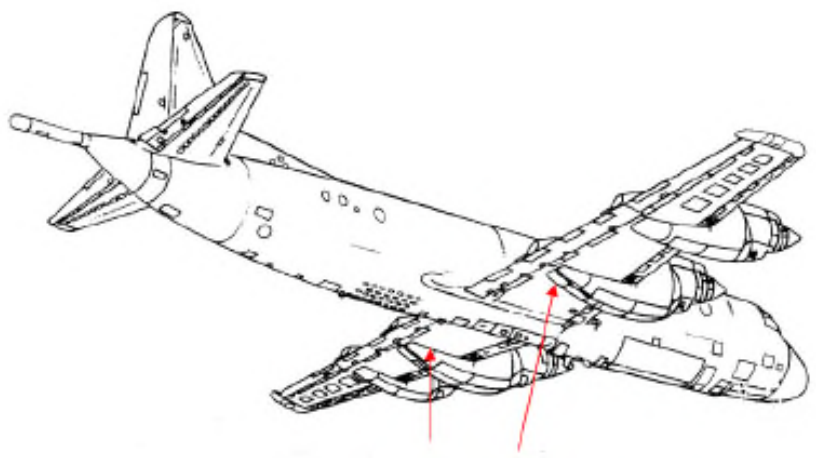

Figure 5 - Wing locations affected by intergranular cracking, from [71].

Detail A

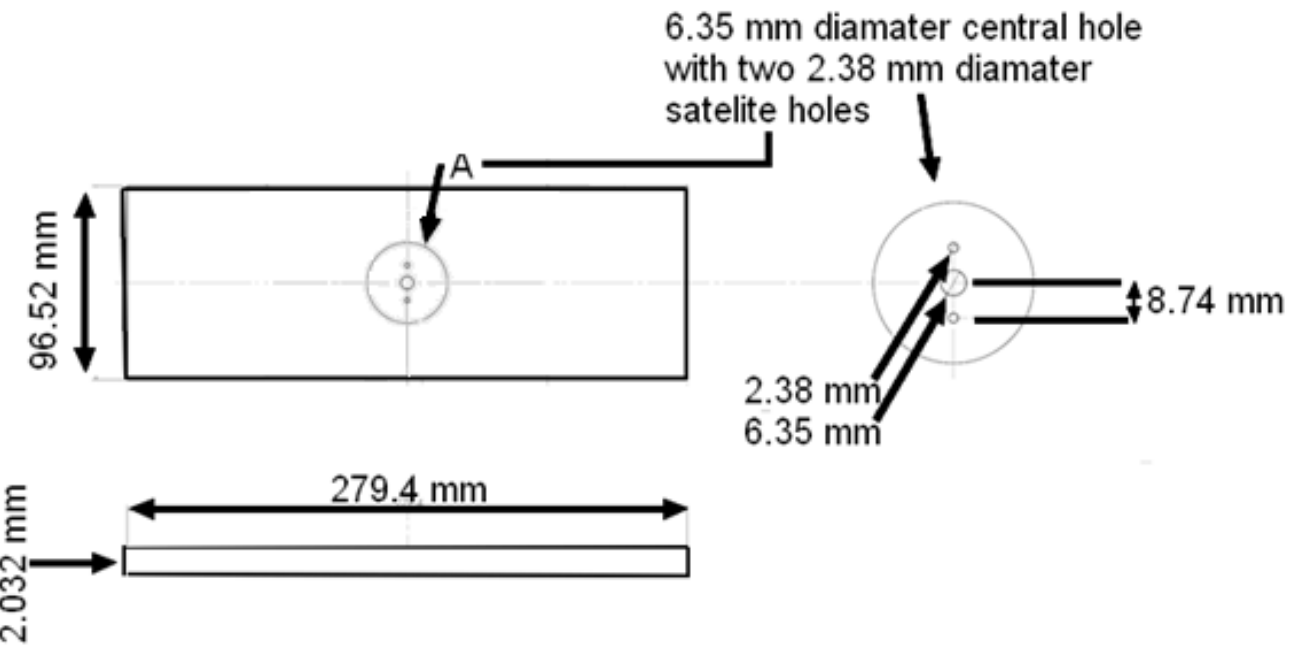

Figure 6 Schematic of the DNH coupon tested in [71].

In this section attention is focused on specimens which had the fastest growing crack growth rates, viz: P3-IG-33 and P3-IG-16, where the IGC was approximately $1.5 \mathrm{~mm}$ and 0.8 deep respectively, which were subjected to a measured RAAF FCA-352 (clipped) spectra, which had a peak stress in the spectrum of approximately $133 \mathrm{MPa}$, and specimens P3-IG-04 and P3-IG-01, where the IGC was approximately $0.42 \mathrm{~mm}$ and 0.33 deep respectively, which were tested under a RAAF FCA-16 spectrum, see [71] for more details. These specimens were approximately 1.5 $\mathrm{mm}$ thick. Both the spectra and the crack growth data were given in [71]. In these specimens the IGC occurred at different depths beneath the surface, see Figures 7 and 8 which present both the depth and location of the IGC for specimens P3-IG-16 and P3-IG-33. 


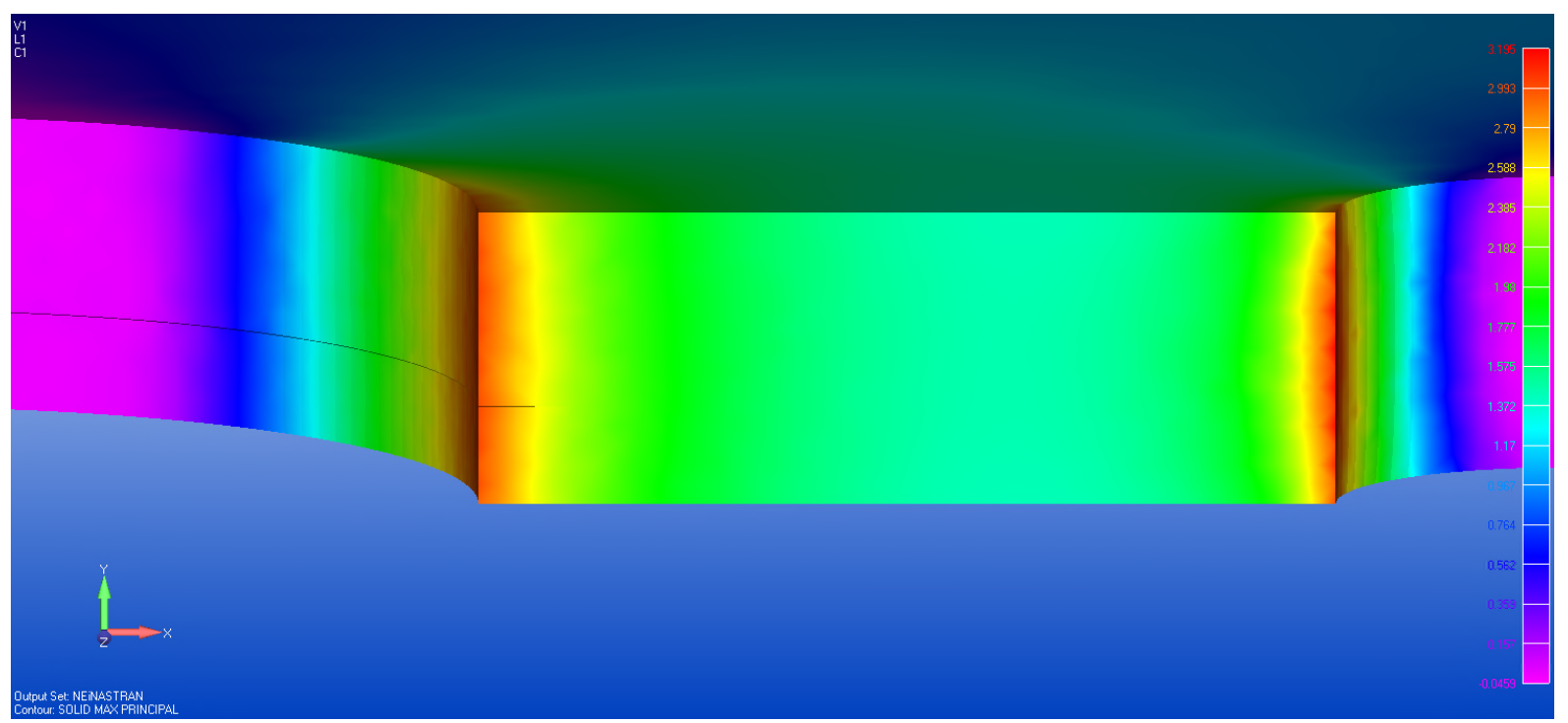

Figure 7. FEA model of dome nut hole coupon with an $0.8 \mathrm{~mm}$ deep IGC representing the IGC found in DSTO specimen P3-IG-16.

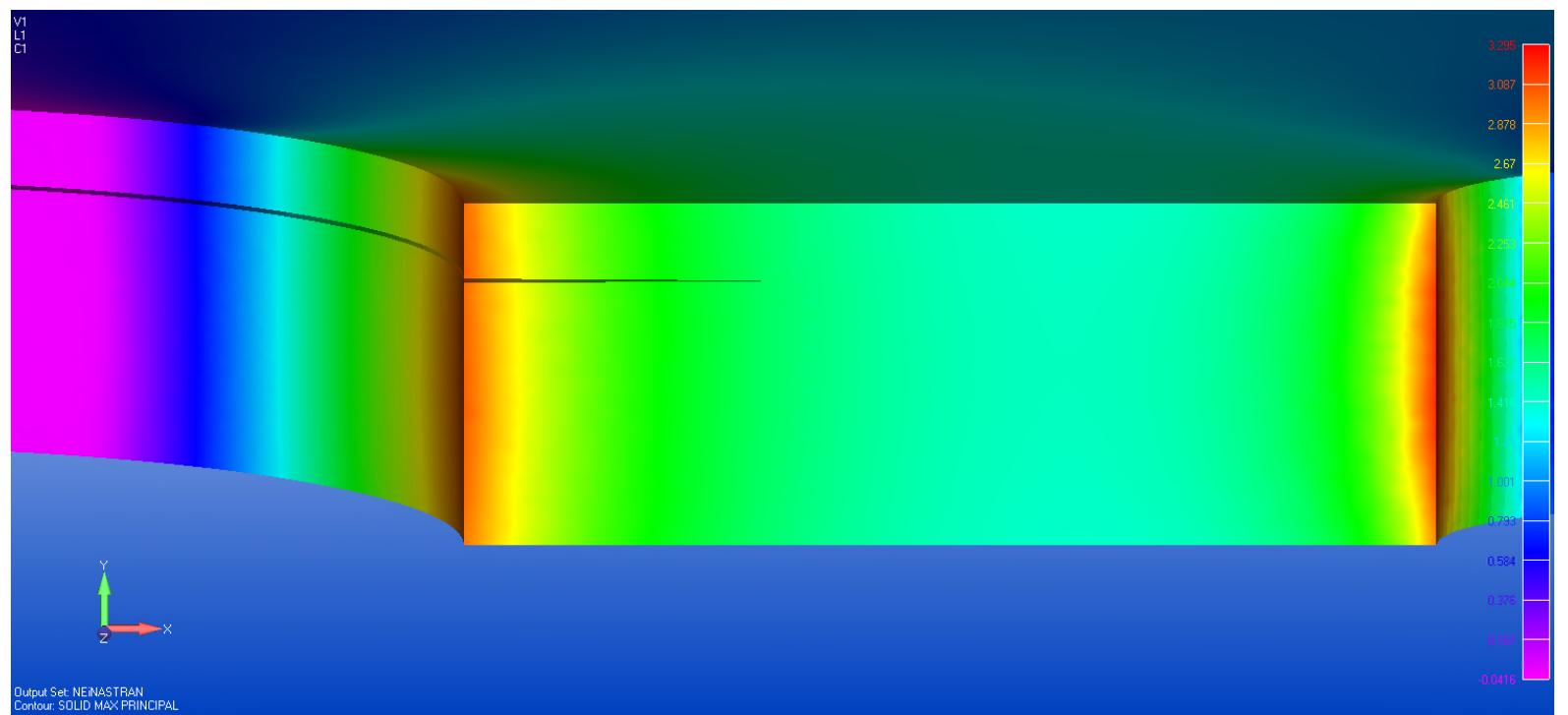

Figure 8. FEA model of dome nut hole coupon with an $1.5 \mathrm{~mm}$ deep IGC representing the IGC found in DSTO specimen P3-IG-33.

Three dimensional finite element models were created for each specimen. Models were created for specimens both with and the without IGC, see Figures 7 and 8. In each case crack growth was allowed to occur naturally and the associated stress intensity factors were computed using three dimensional weight function theory. The advantage of this formulation is that cracks do not have to be explicitly modelled, there is no restriction on the aspect ratio's which are allowed to change as the $\operatorname{crack}(\mathrm{s})$ grow and only the uncracked finite element model is required, see [4] for more details. The depth of the initial equivalent precrack (EPS) was taken as per [22-28] to be $0.01 \mathrm{~mm}$ and as previously the computed crack growth histories were obtained using equation 
(8).

As can be seen in Figure 9 the computed and measured crack growth histories for tests under an FCA352 spectrum are in good agreement. Of particular interest is the fact, in this instance, that the computed results with and without IGC were almost identical. Similarly the nature of the assumed initial cracks had little effect on the crack growth history.

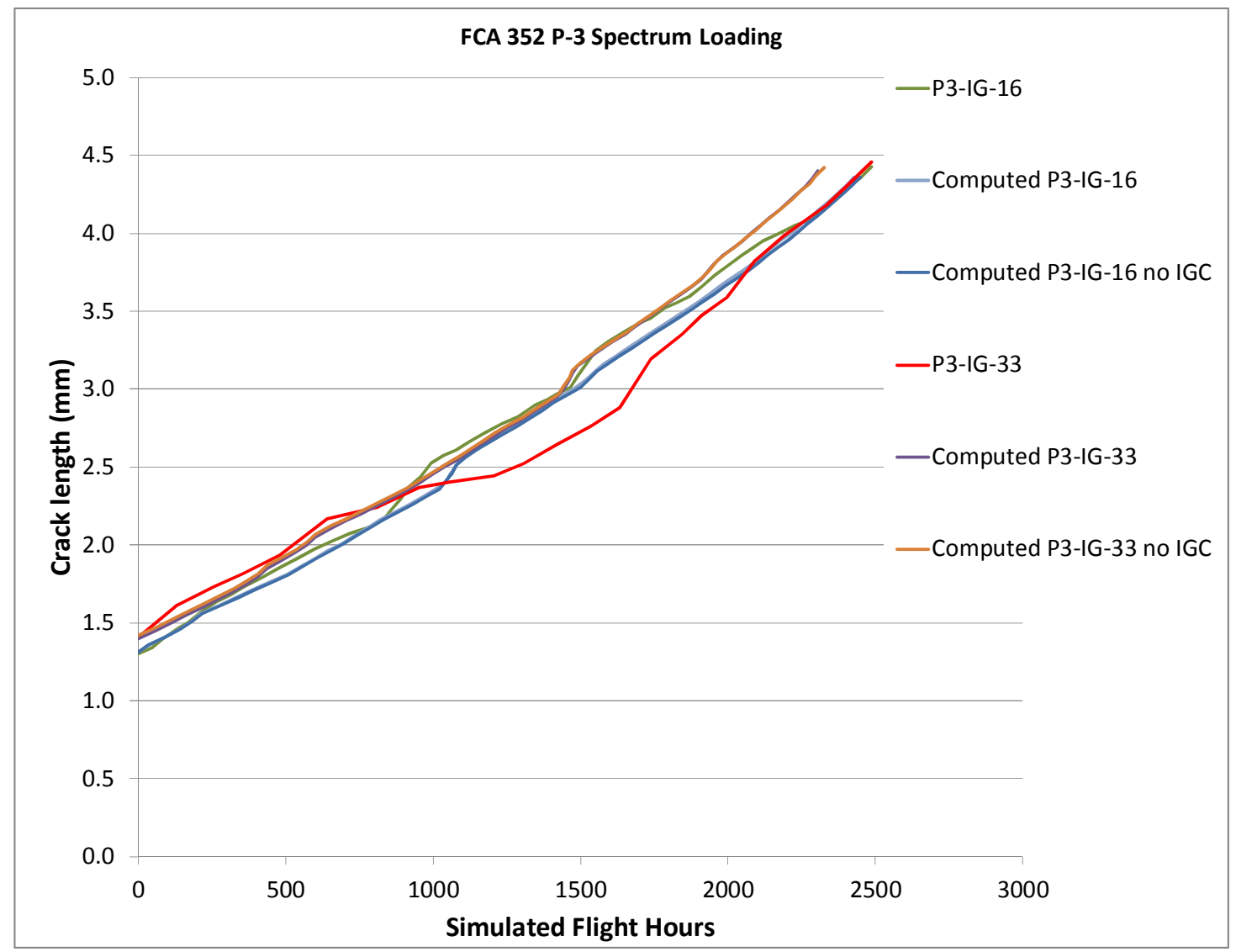

Figure 9. Comparison of the computed and measured crack growth histories for specimens P3IG-16 and P3-IG-33, from [71].

As previously explained that the variation in crack growth histories can be captured by allowing for small changes in the threshold term $\Delta \mathrm{K}_{\mathrm{thr}}$. The variation in the measured and computed crack growth histories for test specimens P3-IG-03, P3-IG-16, P3-IG-24, P3-IG-032 and P3-IG-033 is shown in Figure 10 along with the computed crack growth histories. The associated values of the threshold $\Delta \mathrm{K}_{\mathrm{thr}}$ used in the analysis are given in Table 2 . Here it is clear that both the crack growth history associated with the fastest growing crack and the scatter in the measured crack growth histories are captured quite well. It can also be seen that the presence of IGC made little difference on the computed crack growth history and that the nature of the assumed initial cracks also made little difference on the computed crack growth history. 


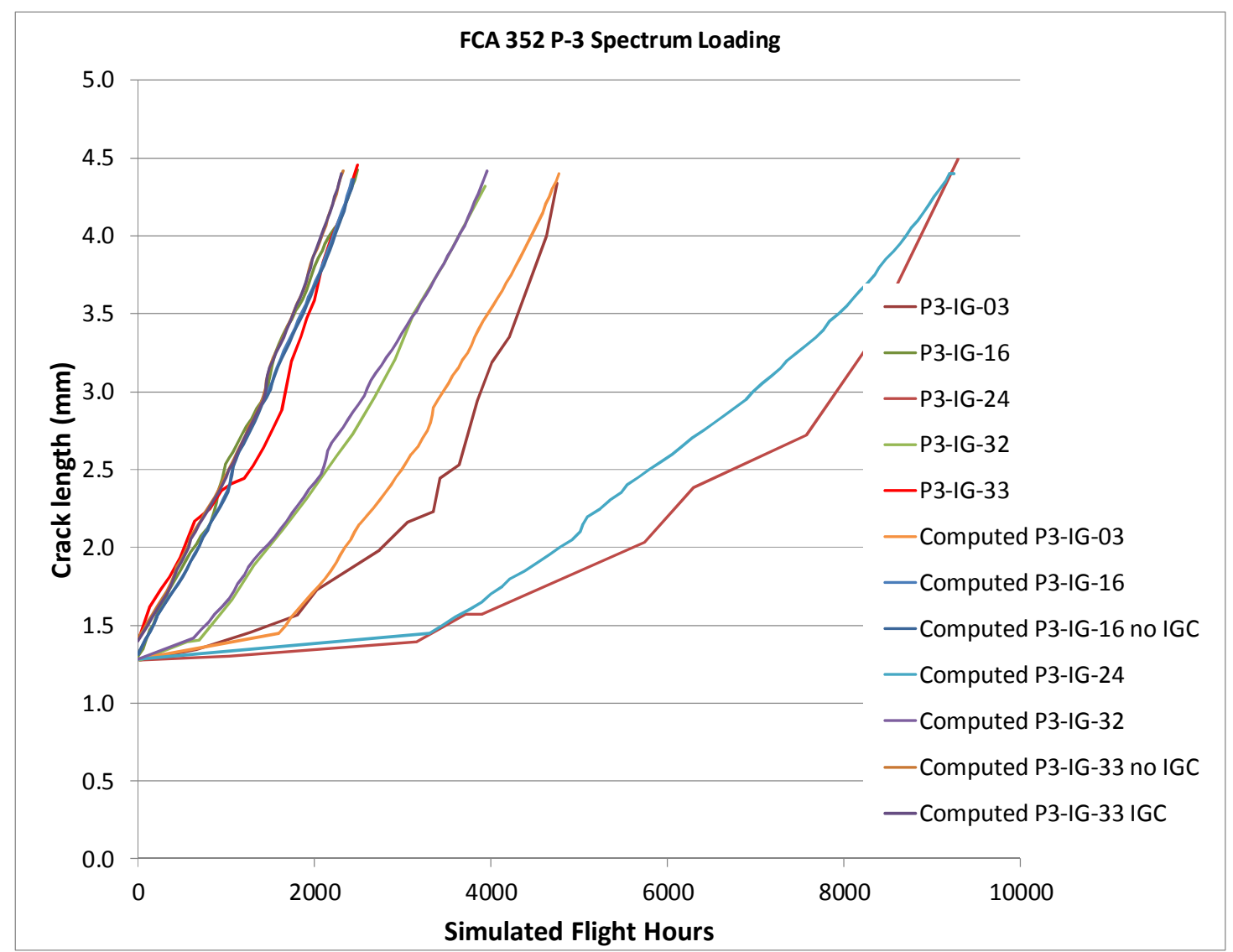

Figure 10. Comparison of the computed and measured crack growth histories in DSTO specimens tested under a FCA-352 spectrum, from [71].

Table 2 Values of the threshold used

\begin{tabular}{|l|l|}
\hline Test Specimen & $\Delta \mathrm{K}_{\text {thr }}(\mathrm{MPa} \sqrt{\mathrm{m}})$ \\
\hline P3-IG-03 & 1.2 \\
\hline P3-IG-16 & 0.2 \\
\hline P3-IG-24 & 1.6 \\
\hline P3-IG-32 & 0.6 \\
\hline P3-IG-33 & 0.2 \\
\hline
\end{tabular}

The analysis was repeated for DSTO DNH IGC specimens P3-IG-01, P3-IG-04, P3-IG-22 and P3-IG-029 which were tested under a RAAF FCA-361 spectrum [71] with a peak stress in the spectrum of approximately $124 \mathrm{MPa}$. These two specimens were analysed since they represent the fastest and slowest crack growth for cracks in the first inner ligament. As previously to evaluate the effect of different initial crack configurations analysis on crack growth in specimens P3-IG-04 and P3-IG-01 two types of initial crack configurations were analysed, viz: an initial corner crack and an initial semi-elliptical crack that spans the IGC, as was the case when there was no IGC. The resultant experimental and computed crack growth histories are shown in Figure 11. The values of the threshold $\Delta \mathrm{K}_{\mathrm{thr}}$ used in this analysis are given in Table 3. As 
previously we see that the crack growth history associated with the fastest growing crack and also the scatter in the measured crack growth histories are captured quite well. It can also be seen that the presence of IGC (again) made little difference on the computed crack growth history and that the nature of the assumed initial crack also made little difference on the computed crack growth history.

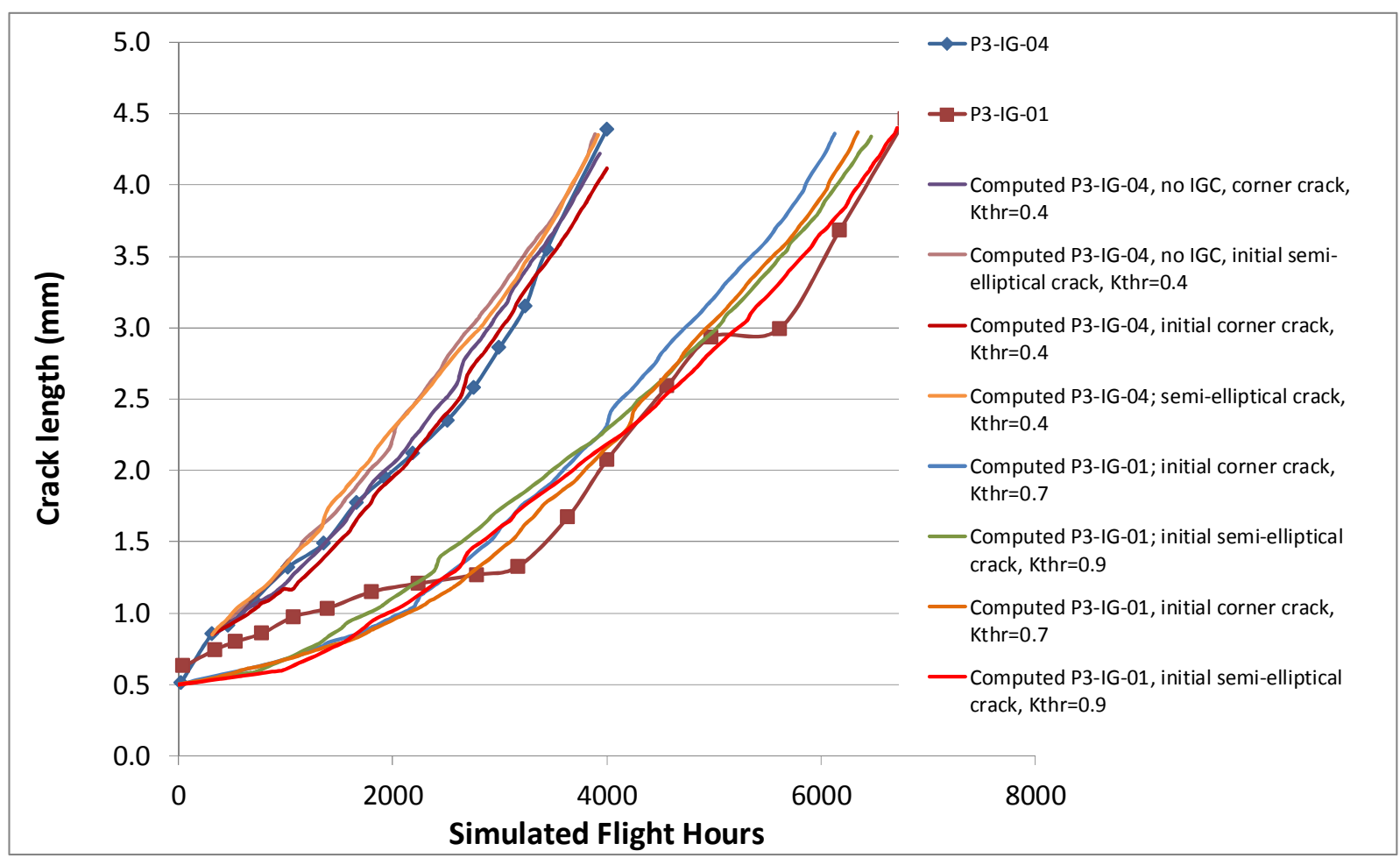

Figure 11. Comparison of modelling predictions for specimen P3-IG-01 and P3-IG-04.

Table 3 Values of the threshold used

\begin{tabular}{|l|l|}
\hline Test Specimen & $\Delta \mathrm{K}_{\text {thr }}(\mathrm{MPa} \sqrt{\mathrm{m}})$ \\
\hline P3-IG-01 & 0.9 \\
\hline P3-IG-04 & 0.4 \\
\hline P3-IG-22 & 1.6 \\
\hline P3-IG-29 & 0.8 \\
\hline
\end{tabular}

\section{THE SHORT CRACK da/dN VERSUS $\triangle K$ CURVE}

If, as in [72,73], enough tests are performed then, as we have seen above for the growth of long cracks in 2024-T3, the associated crack length histories can lead to a family of da/dN versus $\Delta \mathrm{K}$ curves. This raises the question: Does this also hold for the growth of small cracks?

To answer this question consider the extensive study presented in [72] into the growth of small 
cracks in 7050-T7451 aluiminium alloy under a range of F/A-18 related flight load spectra. In one series of specimen tests, designated $\mathrm{KW}$, the surfaces were etched so as to produce a large number of small (near micron) initial cracks, see Figure 12. These specimens were tested under repeated block loading, with approximately 13,480 turning points, which represented a measured F/A-18 flight load spectrum. Barter [73] presented the results for specimen KW4 which resulted in nineteen cracks and the resultant crack growth per load block (da/dBlock) versus crack depth relationships, from [73], are shown in Figure 13. Barter [73] also included a line which represented a linear relationship between da/Block and the crack depth. This line is also shown in Figure 13.

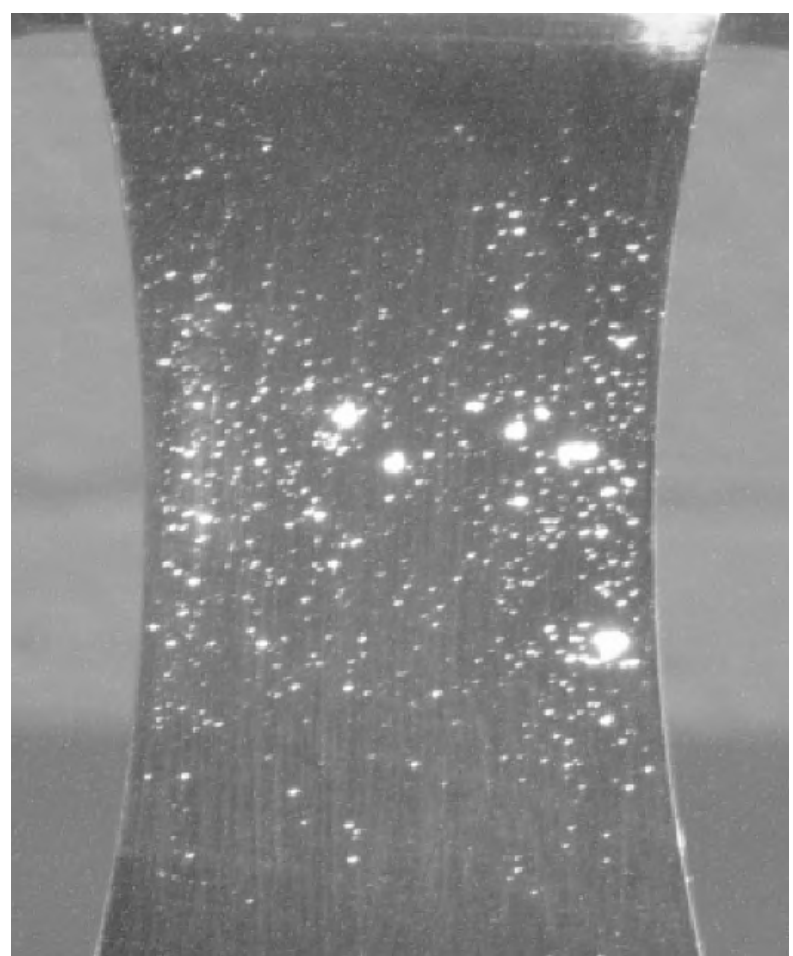

Figure 12 A KW SHG coupon after testing, dye penetrant has been used to show the extent of fatigue cracking, from [73]. 


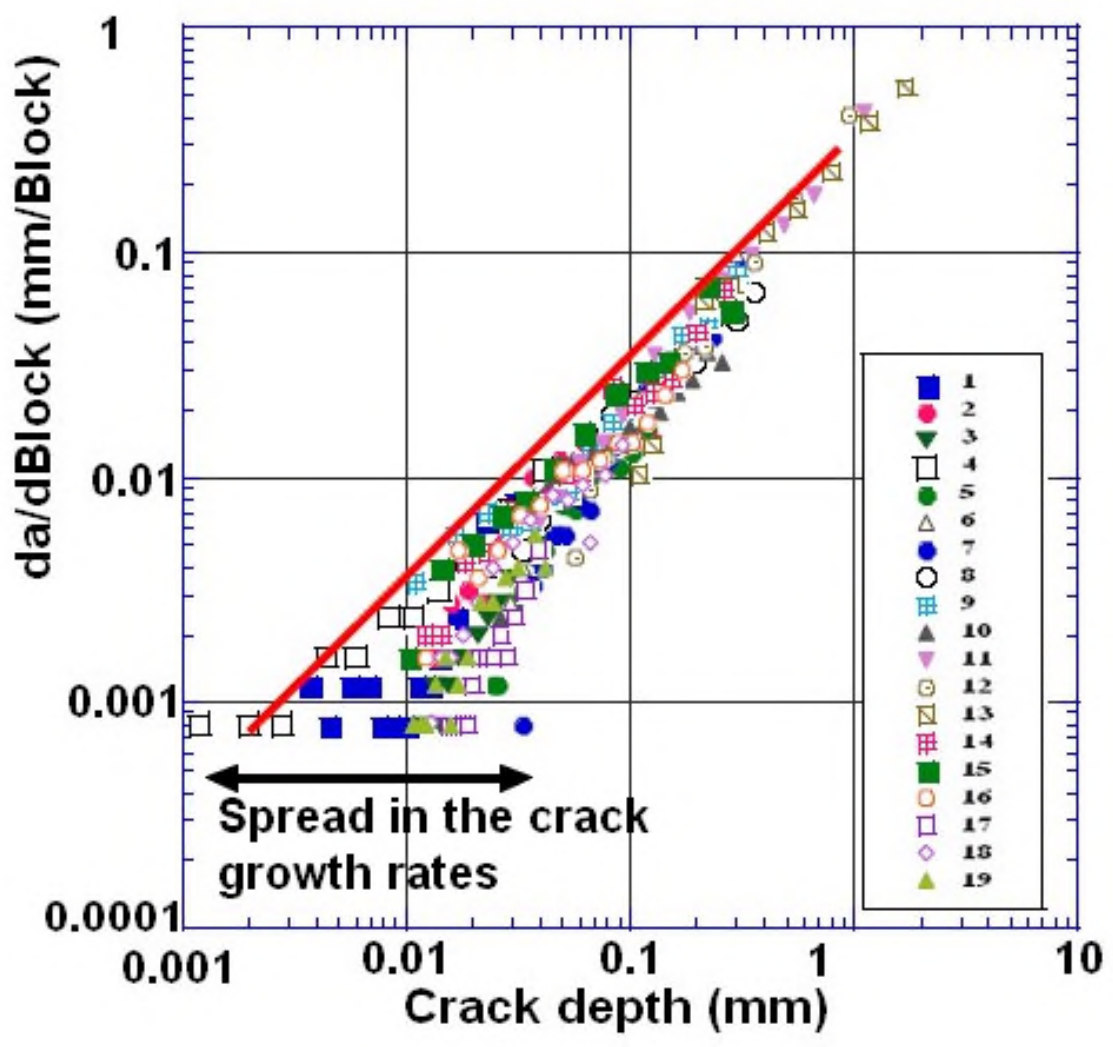

Figure 13 Crack growth in the KW SHG, from [73].

In another series of tests discussed in [73] specimen KY-SHG was first highly polished (to remove as many of the natural surface discontinuities as possible) and 800 small slots were then cut with a Coherent Industrial AVIA ${ }^{\mathrm{TM}}$ pulsed frequency tripled Nd-YAG LASER. The resulting slots were measured to be approximately $50 \mu \mathrm{m}$ long, $20 \mu \mathrm{m}$ deep and about $2 \mu \mathrm{m}$ wide [73]. They were separated by a distance of $1 \mathrm{~mm}$ in the $\mathrm{x}$ direction (i.e. across the width of the coupon), while each row of notches was separated by $0.5 \mathrm{~mm}$ in the y direction (the long axis of coupon). The rows of slots were staggered so that each alternate row was $0.5 \mathrm{~mm}$ offset to the rows above and below it, see Figure 14 and [73] for more details. Each side of the coupon was cut with 400 slots centred in the middle of the coupon. The failure surface associated with specimen KY-SHG revealed forty cracks, which were labelled $\mathrm{C} 1$ to $\mathrm{C} 40$, and Figure 15 presents the crack depth versus load blocks relationship for twenty of these cracks. In this instance Barter [73] did not give the associated da/dB versus a (crack depth) relationship. 


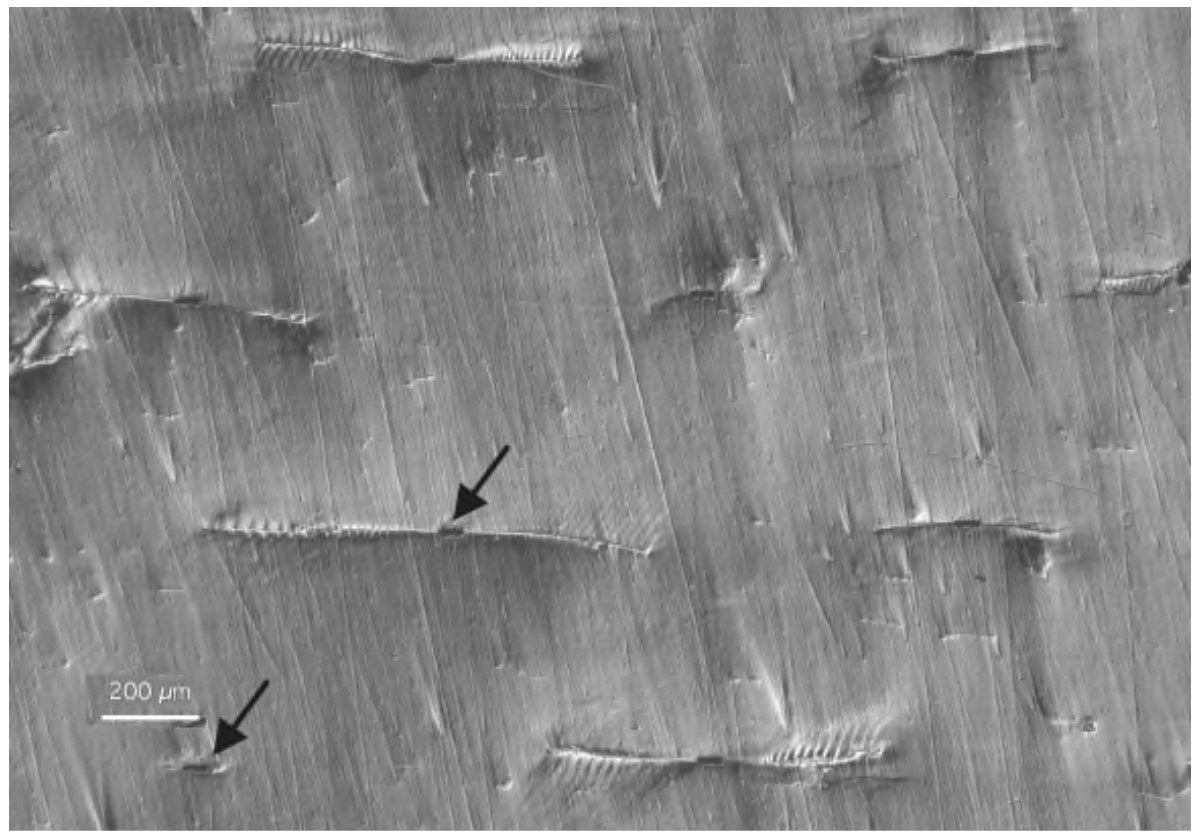

Figure 14 Variation in the crack lengths in a laser slot specimens, from [73]

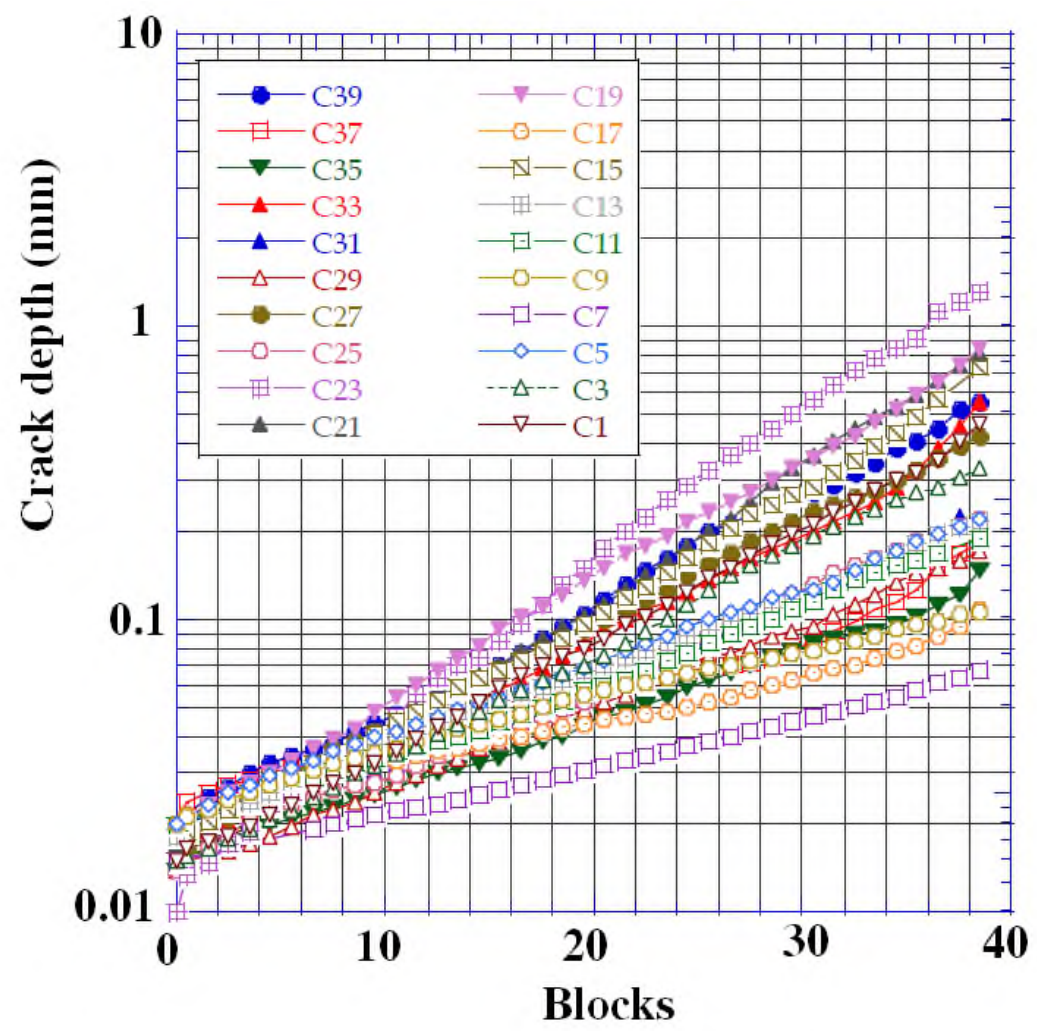

Figure 15 Crack depth versus number of load blocks for twenty cracks in the KS-SHG test, from [73] 
Figures 13 and 15 reveal that, as first explained by Ritchie and Wu [45], for a given crack depth the crack growth rate per block $(\mathrm{da} / \mathrm{dB})$ versus crack depth relationship is not unique. This in turn extends the finding presented above for long cracks in that it implies that the da/dN versus $\Delta \mathrm{K}$ relationship is not unique and that for small cracks there also exists a family $\mathrm{da} / \mathrm{dN}$ versus $\Delta \mathrm{K}$ curves.

This finding, i.e. that there exists a family da/dN versus $\Delta \mathrm{K}$ curves, is consistent with the results given in [14] where it was shown that, for small semi-elliptical surface cracks in 7050-T7451 and for small cracks that emanated from a fastener hole in 7050-T7451 specimen tested under an operational F/A-18 load spectra, crack growth could be expressed as:

$$
\mathrm{da} / \mathrm{dN}=7 \mathrm{x} 10^{-10}\left(\Delta \mathrm{K}-\Delta \mathrm{K}_{\mathrm{thr}}\right)^{2} /\left(1-\mathrm{K}_{\max } / \mathrm{A}\right)
$$

with $\mathrm{A}=47 \mathrm{MPa} \sqrt{\mathrm{m}}_{\mathrm{m}}$. Here it was also shown that the scatter in these various crack growth histories could be captured by using small values for the threshold term $\Delta \mathrm{K}_{\mathrm{thr}}$ and by allowing for small variations in the value of the term $\Delta \mathrm{K}_{\mathrm{thr}}$. The values of $\Delta \mathrm{K}_{\mathrm{thr}}$ determined in these studies were $\Delta \mathrm{K}_{\text {thr }}=0.1,0.4,0.65,0.77$ and $1.1 \mathrm{MPa} \vee \mathrm{m}$. Substituting these values into equation (9) yields a family of $R=0.1$ small crack da/dN versus $\Delta K$ curves, see Figure 16 . Here it should be noted that for $\mathrm{da} / \mathrm{dN}<10^{-7} \mathrm{~m} /$ cycle the resultant curves are essentially $\mathrm{R}$ ratio independent. To illustrate this Figure 17 presents the measured small crack da/dN versus $\Delta \mathrm{K}$ curves for a range of $R$ values as well as the predicted curves for $R=0.1$ and 0.7 using $A=47 \mathrm{MPa} \sqrt{ } \mathrm{m}$ and $\Delta \mathrm{K}_{\text {thr }}=0.1 \mathrm{MPa} \sqrt{\mathrm{m}}$. Figure 17 also contains the NASA high $\mathrm{K}_{\max }(=35 \mathrm{MPa} \sqrt{\mathrm{m}})$ and $\mathrm{R}=0.1$ curves given in [43]. 


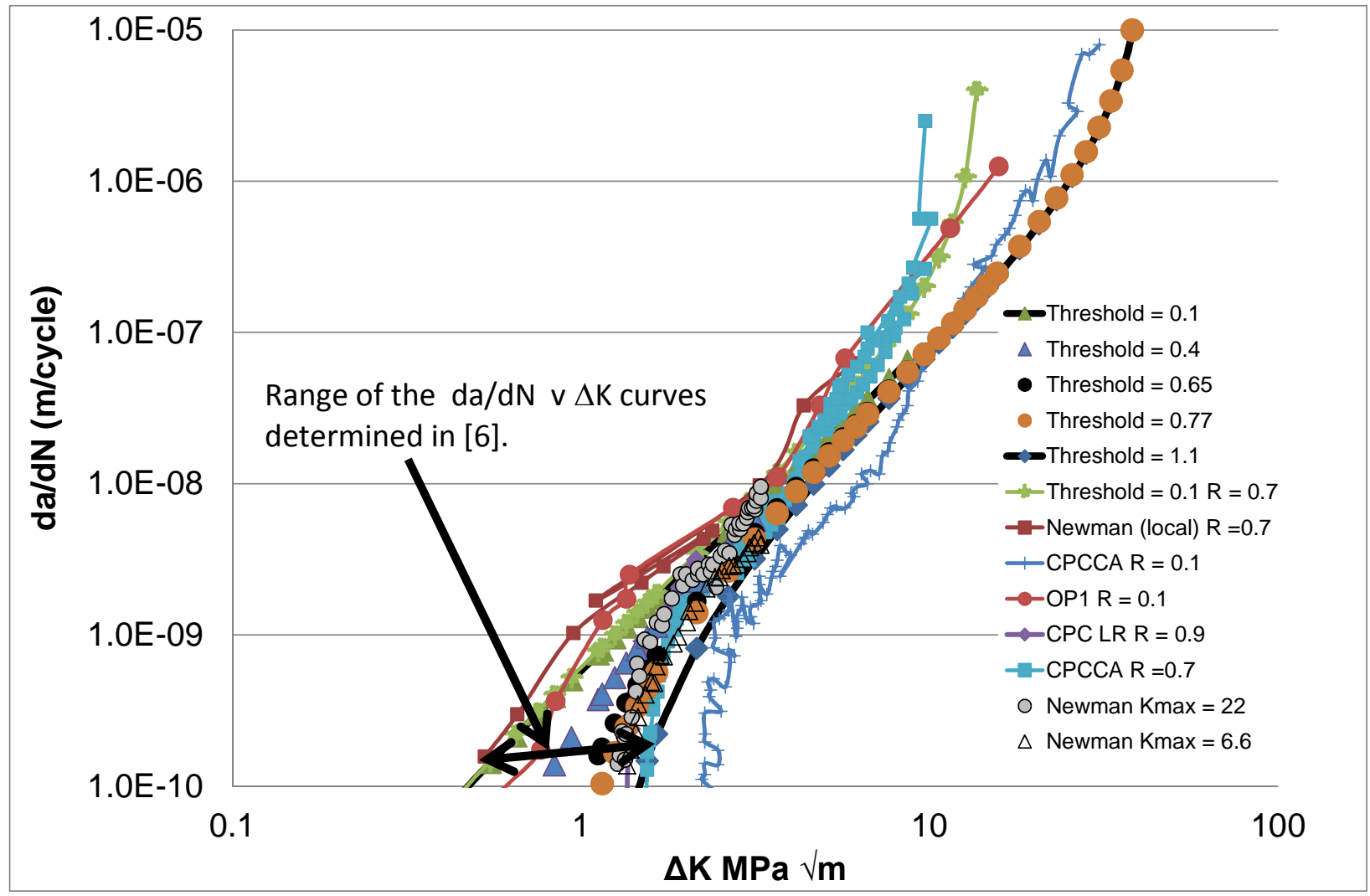

Figure 16 Comparison of the family of $\mathrm{R}=0.1 \mathrm{da} / \mathrm{dN}$ versus $\Delta \mathrm{K}$ closure free curves determined in [14] with those given in [74]. 


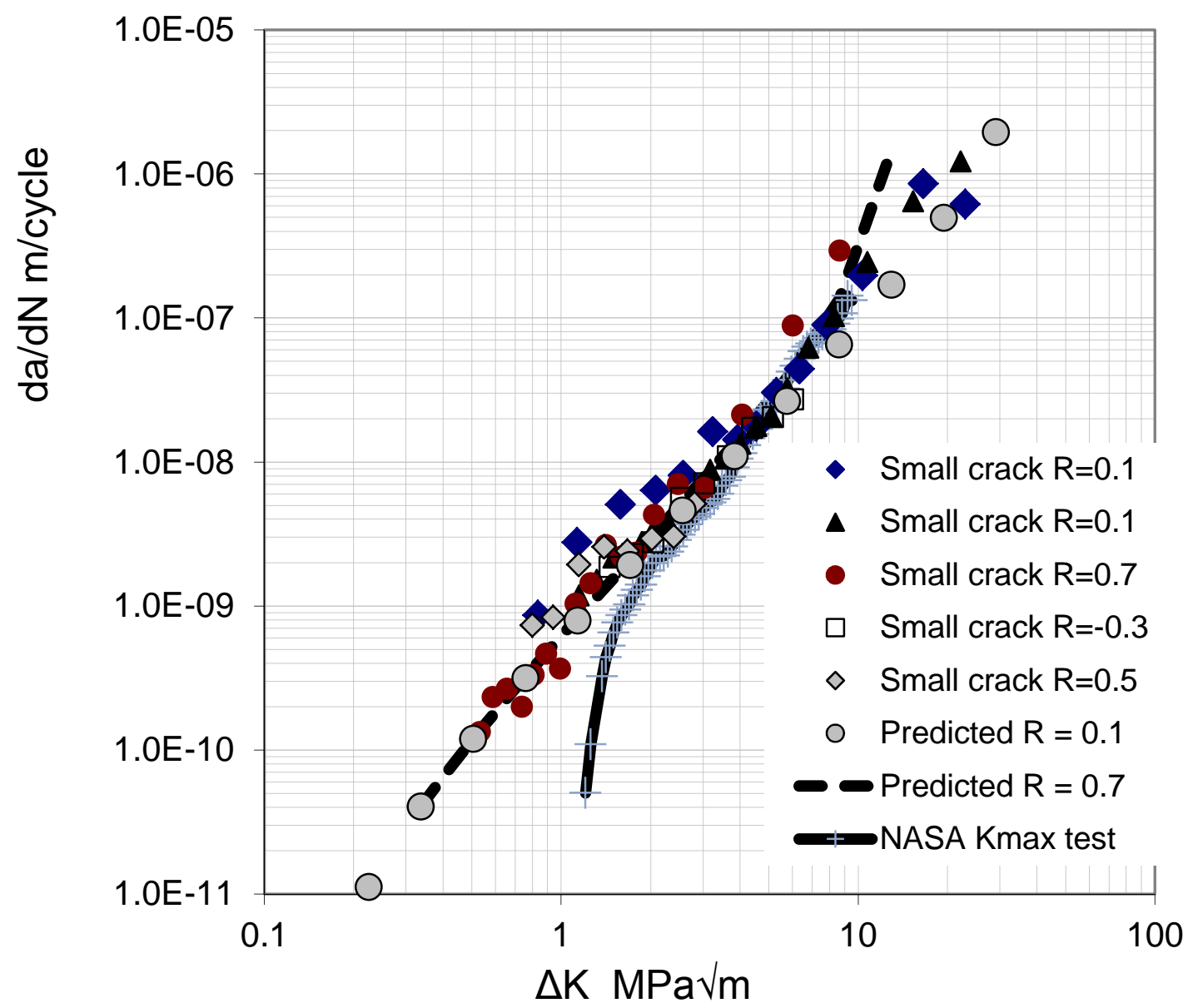

Figure 17 Comparison of the measured and computed small crack growth curves and the NASA $\mathrm{K}_{\max }$ test given in [58]

As previously noted ASTM E647-13a Appendix X3 and [3, 4, 7, 8, 15, 75,] notes that small cracks are distinguished from large cracks by a reduced closure. As a result several approaches have been developed to produce such da/dN versus $\Delta \mathrm{K}$ curves. A number of methods, viz: compression pre-cracking (CPC) [74, 76,77,], the offset opening load technique (with a typical offset value of $2 \%$ ) [78], the ACR technique [79, 80, 81], the partial crack closure approach [8183] and high $K_{\max }$ tests [84] have been proposed to obtain a better estimate of the intrinsic, i.e. crack tip shielding free, da/dN versus $\Delta \mathrm{K}$, or $\Delta \mathrm{K}_{\text {eff }}$, relationship. The offset opening load technique was adopted as an ASTM E647 standard, Appendix X2, in 1995. The ACR method was adopted as an ASTM E647 standard, Appendix X3, in 2014 and application of the ASTM ACR method to assess crack growth in the Lockheed F-22 is given in [8].

However, as discussed in Section 2.1 and in [3], care must be taken since the ACR and CPC approaches produce $\mathrm{da} / \mathrm{dN}$ versus $\Delta \mathrm{K}$ curves that are more representative of physically short cracks and as such do not have the same shape as the small crack da/dN versus $\Delta \mathrm{K}$ curves which 
as shown in $[3,7]$ are essentially $\mathrm{R}$ ratio independent ${ }^{12}$, i.e. are essentially closure free, generally have a very low threshold and a da/dN versus $\Delta \mathrm{K}$ curve that can often be approximated by a simple Paris like equation. A discussion on the sensitivity of the da/dN versus $\Delta \mathrm{K}_{\text {eff }}$ curve, determined using ACR method, to the measurement location is given [86].

With this in mind let us examine the study by Yamada and Newman [74] which evaluated the use of the ASTM offset opening load technique (corresponding results in Figure 9 are labelled $\mathrm{OP} 1$ ), $\mathrm{K}_{\max }$ tests (tests at $\mathrm{K}_{\max }=22$ and $6.6 \mathrm{MPa}{ }_{\mathrm{m}}$ ), compression pre-cracking followed by constant amplitude tests at various R ratio's (which [74] labelled CPCCA) and compression precracking followed by ASTM load reducing tests (which [74] labelled CPCLR) to determine the "closure free" da/dN versus $\Delta \mathrm{K}$ curve for 7050-T7451. Yamada and Newman [74] also presented the "closure free" $\mathrm{R}=0.7 \mathrm{da} / \mathrm{dN}$ versus $\Delta \mathrm{K}$ curve obtained when strain gauges, placed on the back face (BFS) and local strain gages placed along the crack path, were used to measure the crack opening load. In [74] the latter results were labelled " $R=0.7$ local" and this labelling convention is also used in Figure 9. The results of these various tests for $\mathrm{R}=0.1$ are also shown in Figure 9.

The ACR method has also been used [85] to examine crack growth seen in 7050-T7451 tested at $\mathrm{R}=0.33$ in a high humidity environment (RH > 95\%). In [3] it was shown that the resultant ACR (closure corrected) da/dN versus $\Delta \mathrm{K}$ data essentially coincided with the small crack lab air test data presented in [58] where the initial flaw size was approximately $0.007 \mathrm{~mm}$. This data is shown in Figure 18 along with the NASA $\mathrm{K}_{\max }$ test data given in [43].

Figures 16 and 18 show that, allowing for experimental error, each of these independent approaches to determining the closure free $\mathrm{da} / \mathrm{dN}$ versus $\Delta \mathrm{K}$ curves are consistent with the family of curves (independently) determined in [14]. Some of these curves are close to the fastest curve determined in [14], others are closer to the slower curves determined in [14].

In this context it should be noted that in [7] it was shown that the growth of both long and short cracks in 7075-T6 tested under constant amplitude loading could be expressed as per equation (3), with $\mathrm{m}=\mathrm{p}=2$ and $\mathrm{q}=\mathrm{p} / 2$, and that this approach resolved what appeared to be an anomaly associated with long crack test data reported in $[87,88]$ where different test geometries gave significantly different da/dN versus $\Delta \mathrm{K}$ curves. Indeed Section 2.1 has shown how equation (3), with $\mathrm{m}=\mathrm{p}=2$ and $\mathrm{q}=\mathrm{p} / 2$, also holds for the growth of small cracks in 7075-T6 tested under a RAAF AP3C maritime aircraft spectrum.

The paper by Jones, Peng, Singh, Huang, Tamboli and Matthews [15] reinforces the findings outlined above in that, allowing for the assumptions made in [89] when determining $\Delta \mathrm{K}$, the scatter in the of $\mathrm{da} / \mathrm{dN}$ versus $\Delta \mathrm{K}$ curves presented in [89] for the growth of small cracks from corrosion pits in 7075-T651 was shown to be essentially bounded by the da/dN curves computed using equation (3) with closure switched off $\mathrm{D}=1.8610^{-9}, \mathrm{~A}=111 \mathrm{MPa} \sqrt{\mathrm{m}, \mathrm{p}}=2$ and $\Delta \mathrm{K}_{\text {th }}$ values of 0.0 and $0.8 \mathrm{MPa} \sqrt{ } \mathrm{m}$, see Figure 19 which also presents the result obtained using $\Delta \mathrm{K}_{\text {th }}$

${ }^{12}$ Appendix D in [7] presents a range of examples that illustrate this near $\mathrm{R}$ ratio independence 
$=0.12 \mathrm{MPa} \sqrt{ } \mathrm{m}$, see [15] for details.

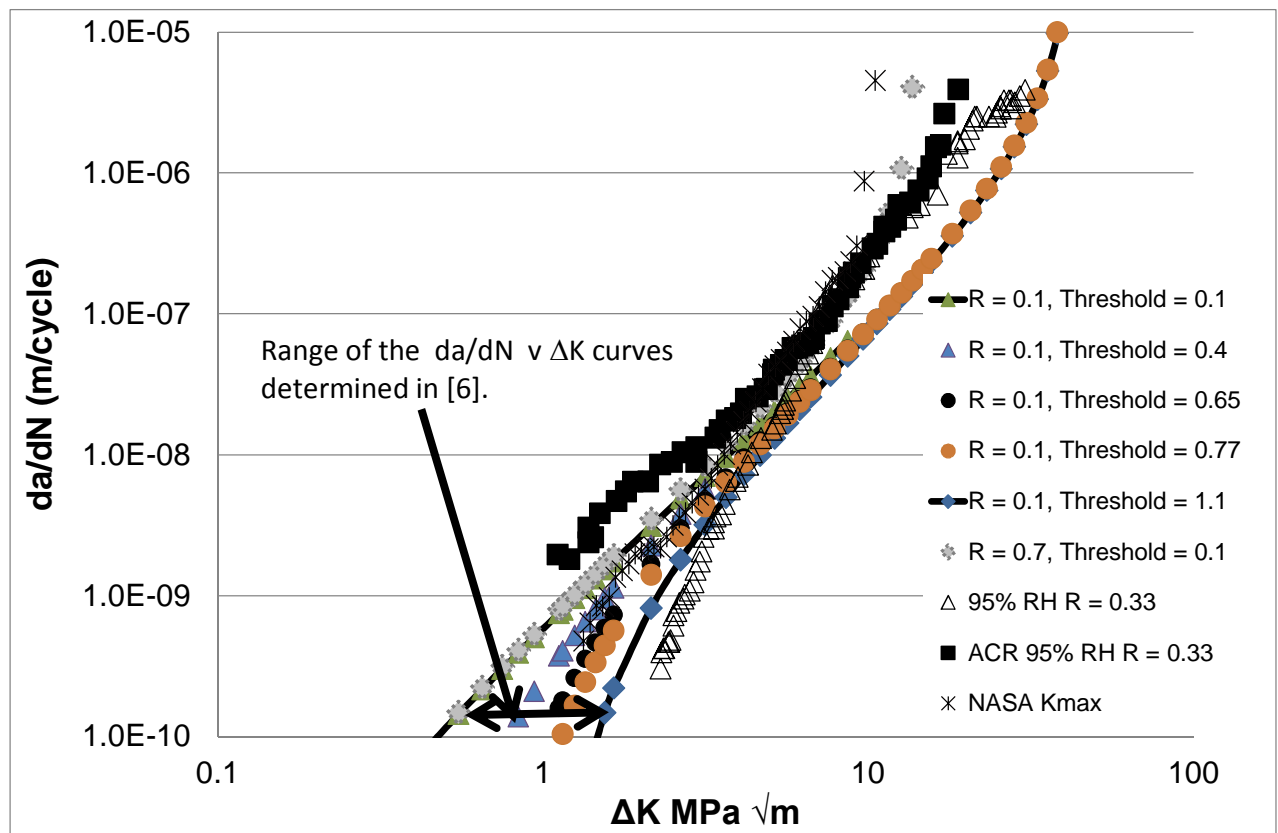

Figure 18 Comparison of a range of "closure free" $\mathrm{da} / \mathrm{dN}$ versus $\Delta \mathrm{K}$ curves

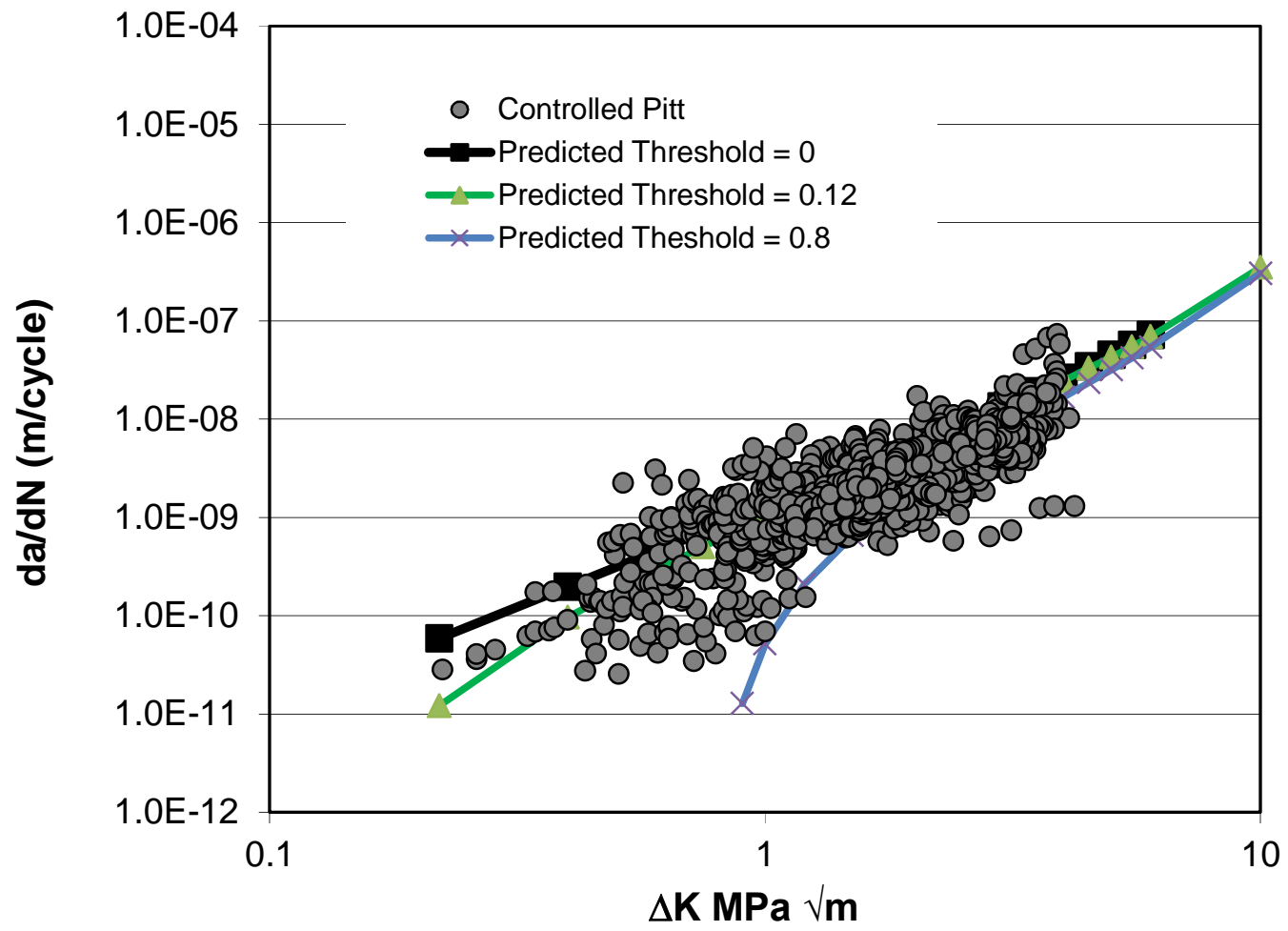

Figure 19 Measured [72] and computed [15] crack growth curves for 7075-T651, from [15]. 
The paper by Jones, Tamboli, Huang and Peng [90] has also shown that, allowing for experimental error, the cracks growth data presented in [91] for the growth of small cracks from an edge notch in 7075-T6 can also be accurately captured by modelling crack growth using a family of da/dN versus $\Delta \mathrm{K}$ curves with the same values of $\mathrm{D}, \mathrm{A}$ and $\mathrm{p}$, i.e. $\mathrm{D}=1.8610^{-9}, \mathrm{~A}=$ $111 \mathrm{MPa} \sqrt{ }, \mathrm{p}=2$. In this case the family of curves were determined using the values of $\mathrm{D}, \mathrm{A}$ and $p$ given above together and using $\Delta \mathrm{K}_{t h r}$ values of $0.6,0.795,0.825,1$ and $1.1325 \mathrm{MPa} \sqrt{\mathrm{m}}_{\text {, }}$ see Figure 20.

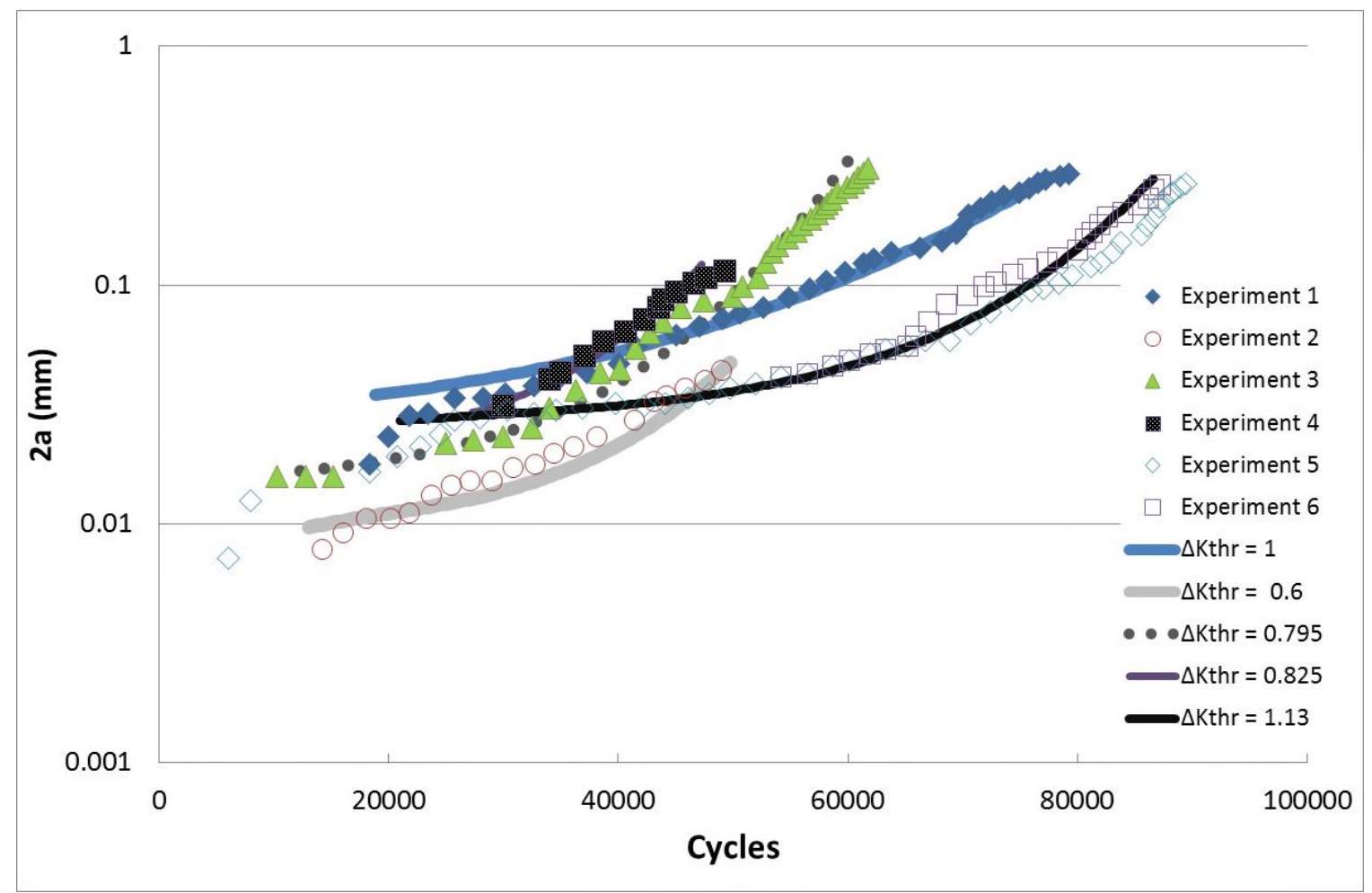

Figure 20 Measured [91] and computed [90] small crack growth histories, from [90].

The experimental approaches mentioned above, i.e. CPC, ACR, $\mathrm{K}_{\max }$ tests and the ASTM E647 crack opening approach, are predated on the assumption that the primary difference between small and long cracks is primarily due to the difference in the level of closure. However, it is clear that when assessing/evaluating in-service crack growth the crack growth curve to be used should correspond to that associated with the fastest possible, i.e. most severe, crack growth curve which in Figures 16-18 and in $[3,7,57]$ are shown to essentially exhibit a simple power law relationship between da/dN versus $\Delta \mathrm{K}$. Another feature of these $\mathrm{da} / \mathrm{dN}$ versus $\Delta \mathrm{K}$ curves is, as remarked in [3] and ASTM E647-13a, a significant reduction in the fatigue threshold, see Figure 17. Indeed Appendix X3 of ASTM E647-13a remarks: "It is not clear if a measurable threshold exists for the growth of small fatigue cracks". 
Forth, James, Johnston, and Newman [92], revealed that crack closure approaches are inappropriate for modeling crack growth in materials that have a weak $\mathrm{R}$ ratio dependency. In this context they stated: "there is little closure in high strength steels". To illustrate this consider the (long) crack growth data presented by Forth [93] for D6ac steel. Figure 21 presents the experimental (long crack) da/dN versus $\Delta \mathrm{K}$ curves for specimens Ct3-10b-lt, Ct3-12-lt, Ct3-25lt, Ct3-27-lt, Ct3-29-lt, Ct3-46-lt and Ct3-47-lt which were tested at $\mathrm{R}$ ratio's that varied from 0.1 to 0.9 . Figure 21 also presents the result for specimen Ct3-5-tl which was tested as per the ASTM $\mathrm{K}_{\max }$ recommended procedure, see Table 4 for more details. This test data reveals that the $\mathrm{R}=0.9,0.8,0.5,0.3$ and $0.1 \mathrm{da} / \mathrm{dN}$ versus $\Delta \mathrm{K}$ curves essentially coincide. From this it follows that for D6ac steel there is essentially no crack closure. This data set thereby supports the conclusions given in [92] that "there is little closure in high strength steels". Furthermore, we also see that the $\mathrm{K}_{\max }$ test gave a da/dN versus $\Delta \mathrm{K}$ curve that was essentially identical to those obtained in the $\mathrm{R}=0.9,0.8,0.7,0.3$ and 0.1 tests.

This study when taken in conjunction with the F-111, F-15, F/A-18, F-22 and C-130J tests [8-18, 57, 94] suggests that the CPC, ACR, $K_{\max }$ tests and the ASTM E647 crack opening approach may not yield a small crack like da/dN versus $\Delta K$ curve for this steel. As such valid short crack test data is essential to assessing the operational life of an aircraft [3, 8] and thus for any associated composite repair to an operational aircraft. 


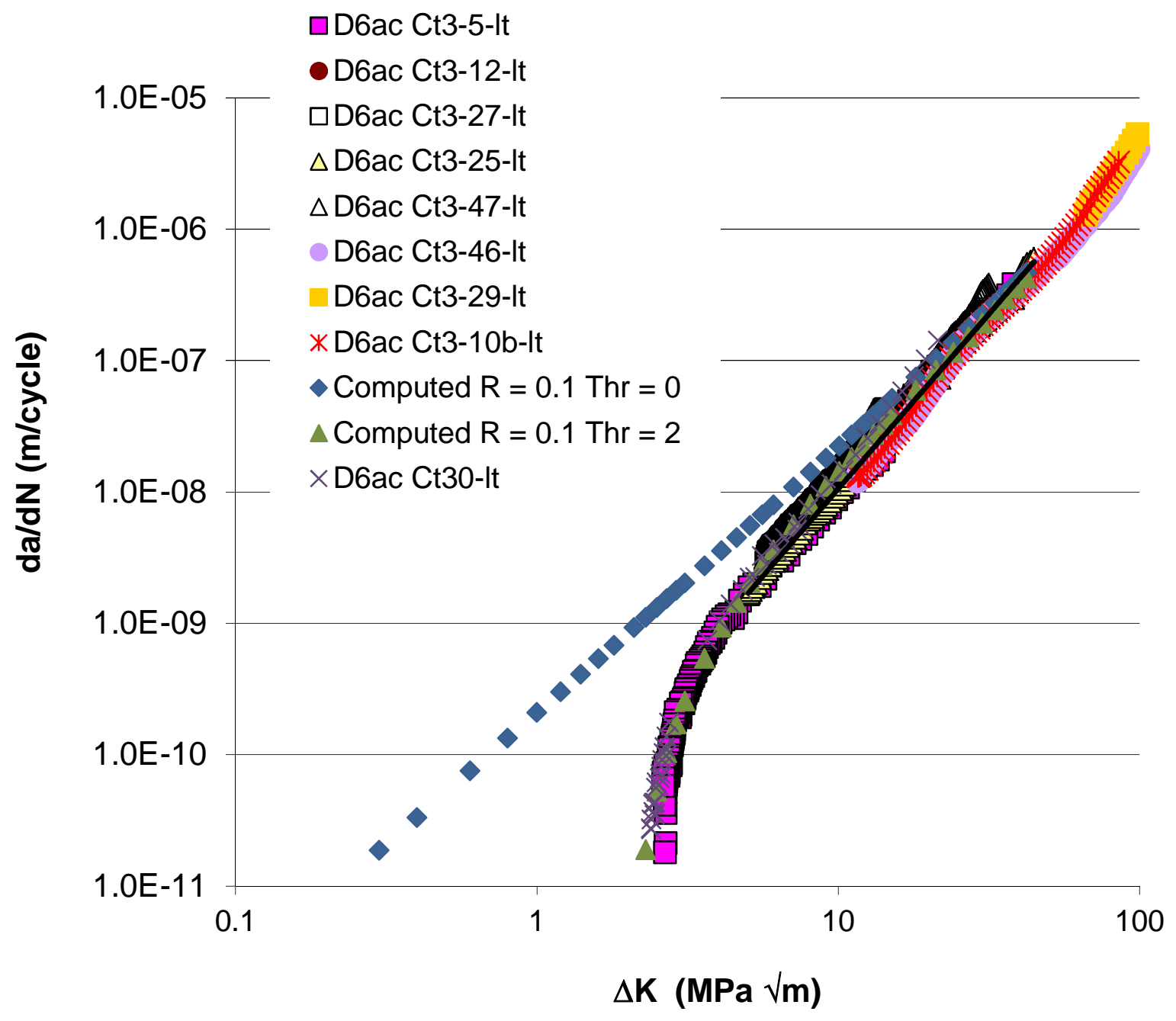

Figure 21 Measured and computed crack growth in D6ac steel

Table 4: Description of the various tests

\begin{tabular}{|l|l|}
\hline Specimen & Type of test \\
\hline $\mathrm{Ct3}$-5-tl & $\mathrm{K}_{\max }=20 \mathrm{LR} 18 \mathrm{~Hz}^{*}$ \\
\hline $\mathrm{Ct} 3-10 \mathrm{~b}-\mathrm{lt}$ & $\mathrm{R}=0.3 \mathrm{LI}, 20 \mathrm{~Hz}$ \\
\hline $\mathrm{Ct} 3-12-\mathrm{lt}$ & $\mathrm{R}=0.9 \mathrm{LI}, 20 \mathrm{~Hz}$ \\
\hline $\mathrm{Ct} 3-25-\mathrm{lt}$ & $\mathrm{R}=0.7 \mathrm{LI}, 20 \mathrm{~Hz}$ \\
\hline $\mathrm{Ct} 3-27-\mathrm{lt}$ & $\mathrm{R}=0.9 \mathrm{LI}, 22 \mathrm{~Hz}$ \\
\hline $\mathrm{Ct} 3-29-\mathrm{lt}$ & $\mathrm{R}=0.3 \mathrm{LI}, 10 \mathrm{~Hz}$ \\
\hline $\mathrm{Ct} 3-46-1 \mathrm{t}$ & $\mathrm{R}=0.1 \mathrm{LI}, 20 \mathrm{~Hz}$ \\
\hline $\mathrm{Ct} 3-47-\mathrm{lt}$ & $\mathrm{R}=0.8 \mathrm{LI}, 10 \mathrm{~Hz}$ \\
\hline
\end{tabular}

$\mathrm{LR}=$ ASTM Load reducing test, $\mathrm{LI}=$ ASTM Load increasing test, $\mathrm{K}_{\max }=$ constant $\mathrm{K}_{\max }$ test, $*$ Test frequency (when reported). 
A more detailed discussion on the ability of the Hartman-Schijve variant of the NASGRO equation to capture the variability in $\mathrm{da} / \mathrm{dN}$ versus $\Delta \mathrm{K}$ curves, for both long and small cracks, by allowing for small variations in the term is presented in [6].

\section{IMPLICATIONS FOR SMALL CRACK GROWTH}

The question thus arises: What are the implications of this finding for the growth of small cracks?

To answer this question it is important to recall that, as noted in [3], one of the primary conclusions reached in the USAF-McDonnell Douglas (now Boeing) study into sustainment issues associated with cracking in F-15 aircraft [57] was the need to use the short crack da/dN versus $\Delta \mathrm{K}$ curve rather than the corresponding ASTM long crack curve.

Furthermore, as previously mentioned in this Chapter and is apparent in the crack growth curves determined as part of the F-22 program [8], these short crack curves generally have a Paris like shape with no clear threshold. (This means that AFGROW and Nasgro can be used to compute the crack growth histories for both repaired and unrepaired airframes.) Examples of this can be seen in Figures 17 and 22 and also in Appendix D in [7]. (To the best of the author's knowledge the paper by Rao, Yu and Ritchie [95] was one of the first papers to reveal that the growth of short cracks in aerospace quality aluminium and aluminium-lithium alloys often took a form similar to that shown in Figures 17 and 22.)

Unfortunately, the experimentally determined da/dN versus $\Delta \mathrm{K}$ curves for D6ac steel, which are essentially $\mathrm{R}$ ratio independent and hence exhibit little (if any) closure, shown in Figure 21 do not exhibit this feature, i.e. a Paris like relationship with a low fatigue threshold (by this it is meant with a threshold that is significantly lower than that seen in the long crack tests $[3,7])$. As such this suggests that, as mentioned in the previous section, the absence of crack closure is not sufficient to guarantee a small crack like $\mathrm{da} / \mathrm{dN}$ versus $\triangle \mathrm{K}$ curve. Consequently the generality of the use of $K_{\max }, A C R$ and $C P C$ testing to generate an appropriate small crack curve is questionable. That said it should be recalled that for many aluminium and titanium alloys these tests do appear to yield reasonable estimates for the da/dN versus $\Delta \mathrm{K}$ curves associated with physically short cracks. 


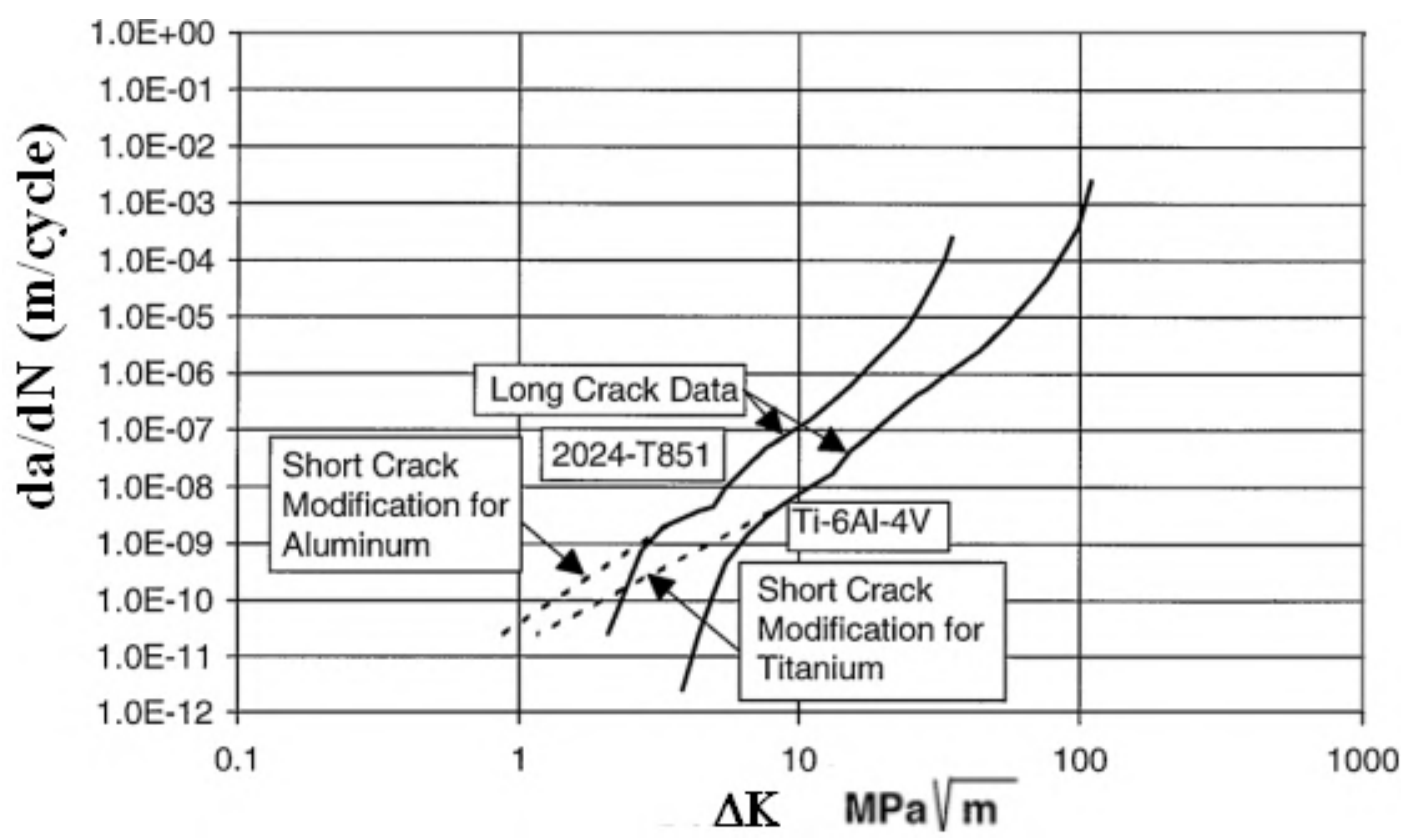

Figure 22 The short crack curves used in the F-15 study, from [42].

The need to use the short crack da/dN versus $\Delta \mathrm{K}$ curve rather than the corresponding ASTM long crack curve is supported by the analysis presented in [96] which revealed that using AFGROW together with D6ac long crack data gave un-conservative ${ }^{13}$ estimates for the crack growth history seen in the 1969 F-111 wing fatigue test. However, [3] revealed that using the Hartman-Schijve representation, i.e. equation (3) with $\mathrm{m}=\mathrm{p}, \mathrm{q}=\mathrm{p} / 2$ and the values of $\mathrm{D}, \mathrm{A}$ and $\mathrm{p}$ determined from long crack da/dN versus $\Delta \mathrm{K}$ data, ignoring closure and setting the fatigue threshold to a small value, as recommended in [3], gave a computed crack length history that was in excellent agreement with the measured F-111 wing crack growth data.

This analysis [3] used $\mathrm{D}=2.0510^{-10}, \mathrm{~A}=220 \mathrm{MPa} \sqrt{\mathrm{m}}_{\mathrm{m}} \Delta \mathrm{K}_{\mathrm{thr}}=0 \mathrm{MPa} \sqrt{\mathrm{m}}_{\mathrm{m}}$ and $\mathrm{m}=\mathrm{p}=2$. The associated computed small crack D6ac da/dN versus $\Delta \mathrm{K}$ curve is shown in Figure 21 where we see that this results in what is essentially a simple Paris law and that the resultant $\mathrm{da} / \mathrm{dN}$ versus $\Delta \mathrm{K}$ curve resembles that shown in Figures 17 and 22. At this point it should be noted that the long crack representation of these tests can be captured using $\Delta \mathrm{K}_{\mathrm{thr}}=2 \mathrm{MPa} \vee \mathrm{m}$. This computed (long crack) curve is also shown in Figure 21 where we see that the computed long crack curve is in excellent agreement with the experimental (long crack) data. As such, as proposed in [3], we see that using the Hartman-Schijve representation as determined from long crack da/dN versus $\Delta K$ data then setting closure effects to zero and using a small value of $\Delta K_{\text {thr }}$ yields a curve, see Figure 21, that is consistent with the small crack growth curves seen in Figures 17 and 22.

Reference [3], also revealed how this approach, whereby both closure effects and the threshold

${ }^{13}$ This will discussed further in the next section. 
term were set to zero, enabled small crack growth in the 1969 F-111 wing test to be accurately computed. This approach has also been shown to capture crack growth in an F/A-18 centre barrel test [15]. As previously mentioned this approach has also been shown [59] to account for anomalies seen in long crack tests on 7075-T6511 [87] and to essentially collapse the long crack test data given in [87] onto the small crack test data given in [88].

\section{WHICH CRACK GROWTH CURVE?}

As discussed above different analyses are needed to assess design and sustainment related crack growth problems. In this context, the paper by Jones and Tamboli [7] was one of the first to show that when assessing the effect of repairs to aircraft the use of ASTM like test specimens was inappropriate in that they had the potential to yield un-conservative estimates of the effect on the repair on the operational life of the aircraft. In this section we will show that when assessing the remaining life of aircraft from US Joint Services Structural Guidelines (JSSG2006) mandated initial flaw sizes the use of ASTM (long crack) is often inappropriate since it can yield inspection intervals that are too short and hence can significantly reduce aircraft availability and thereby increase both manpower requirements and maintenance costs. To this end we will illustrate this by considering crack growth in:

i) The 1969 General Dynamics, now Lockheed Martin, F-111 wing fatigue tested under a representative F-111 usage spectrum, see [96] for details. (This example was chosen since an early F-111 in-flight failure was largely responsible for the USAF adopting a damage tolerance approach $[1,2]$.)

ii) Cracking from a small etch pit in an F/A-18 Y488 bulkhead tested as part of the DSTO Flaw IdeNtification through the Application of Loads (FINAL) test program, see [94, 97].

iii) Crack growth tests performed on coupons as part of the RAAF AP3C repair assessment program [108].

\subsection{Fatigue crack growth in the 1969 F111 wing test}

In this test a crack initiated at a cut-out location designated as fuel flow hole ${ }^{14}$ number 58 on the lower (tension) surface of the D6ac steel wing pivot fitting, see Figures 23 - 25. The crack growth data and crack growth predictions obtained using AFGROW together with long crack $\mathrm{da} / \mathrm{dN}$ versus $\Delta \mathrm{K}$ data were presented in [96] and are reproduced in Figure 20 which shows the time for the crack to have grown from a $1.27 \mathrm{~mm}$ crack to failure.

Jones [3] also presented an analysis of this problem. In this instance the analysis used the following Hartman-Schijve variant of the NASGRO equation together with the small crack $\mathrm{da} / \mathrm{dN}$ versus $\Delta \mathrm{K}$ representation for D6ac steel, viz:

$$
\mathrm{da} / \mathrm{dN}=2.0510^{-10}\left[(\Delta \mathrm{K})^{2} /\left(1-\mathrm{K}_{\max } / 220\right)\right]
$$

\footnotetext{
14 This feature is also termed a mousehole or a weep hole.
} 
which was obtained from the long crack representation by setting both closure effects and the threshold term to zero ${ }^{15}$, see [3]. Equation (10) is essentially a simple Paris crack growth law that has been modified to reflect the increase in growth rate that occurs when $K_{\max }$ approaches the fracture toughness of the material. The stress intensity factors were computed using the stress field determined from the finite element analysis of the full three dimensional model of the wing shown in Figures 23-25 see [3] for more details. In this analysis the size of the initiating crack was $0.010 \mathrm{~mm}$, which is similar to the depth of etch pits reported above, and the crack growth history, post $1.27 \mathrm{~mm}$, is also shown in Figure 26.

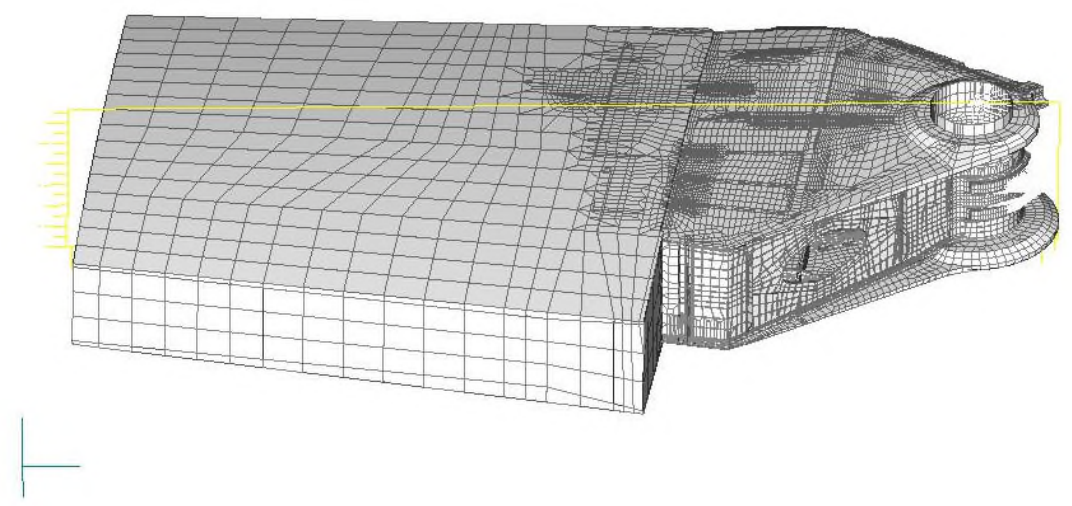

Figure 23. Full 3D F-111 model, from [94].

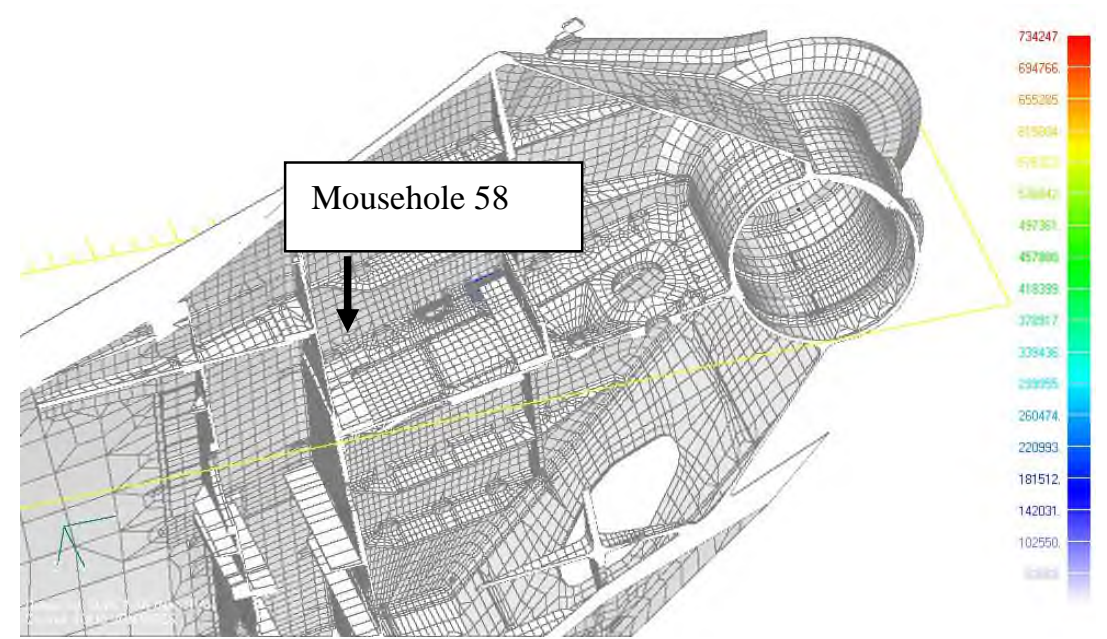

Figure 24. Interior of the DSTO 3D F111 model, from [94].

\footnotetext{
${ }^{15}$ Appendix X3 of ASTM test standard E647-13a states that: "It is not clear if a measurable threshold exists for the growth of small fatigue cracks".
} 


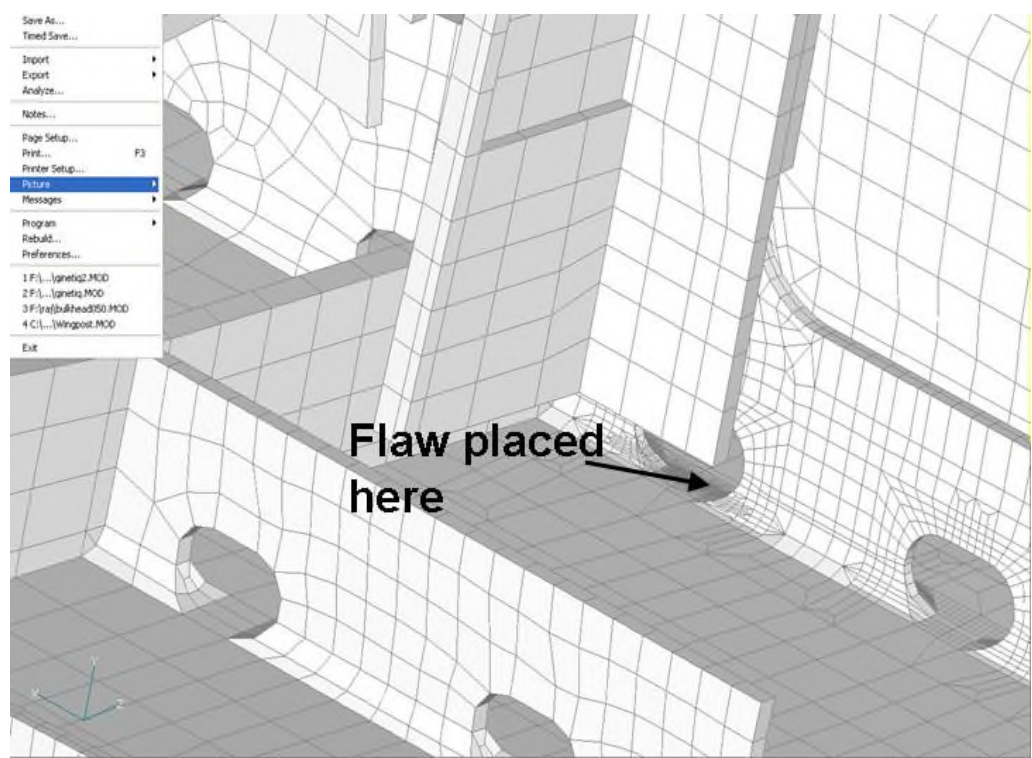

Figure 25. Interior of the DSTO 3D F111 model, from [94].

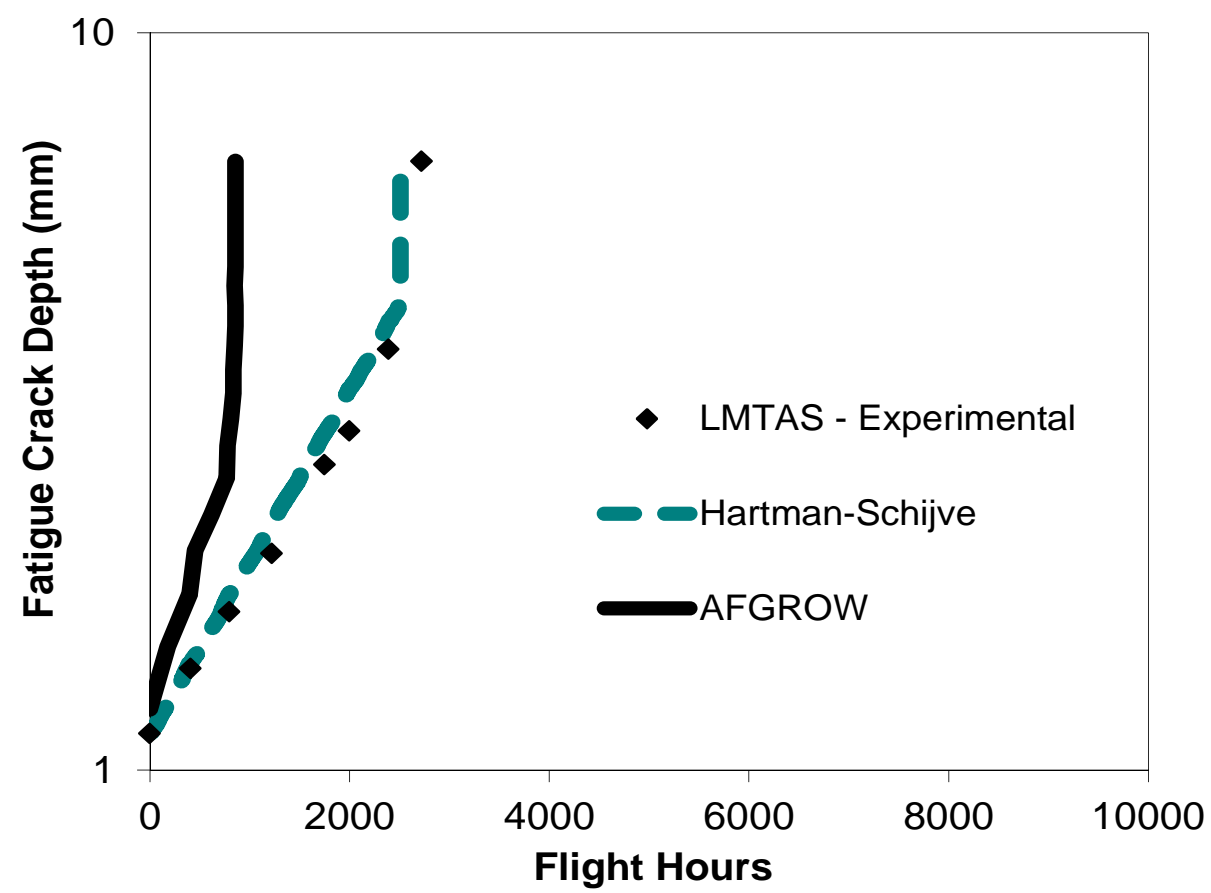

Figure 26 Measured and computed crack growth in the F-111 wing test, from [15]

Comparing the various predictions shown in Figure 26 we see that unlike the AFGROW analysis presented in [96], which used the long crack da/dN versus $\Delta \mathrm{K}$ relationship, which predicted failure after approximately 859 flight hours, which is significantly shorter than the 
(approximately) 2724 flight hours seen the test, the use of the short crack representation yields a crack growth curve that is excellent agreement with the measured crack growth history.

\subsection{Fatigue crack growth in an F/A-18 aircraft bulkhead}

The next problem considered involved cracking that initiated from an etch pit in an F/A-18 Y488 bulkhead tested as part of the DSTO Flaw IdeNtification through the Application of Loads (FINAL) test program, see [97]. This test program utilised ex-service Canadian Forces (CF) and U.S. Navy (USN) wing attachment centre barrel (CB) sections, which are fabricated from AA7050-T7451, loaded using an industry standard modified mini-FALSTAFF spectrum, see [97], which is representative of flight loads seen by fighter aircraft. Since cracking in the bulkhead was three-dimensional, a three-dimensional FE model was required, see Figures 27 and 28. As explained in [98] in the case of the F/A-18 Hornet it is known that a significant proportion of cracking initiates from pits from the chemical etching of the AA7050-T7451 which is conducted as a precursor to the IVD aluminium corrosion preventative scheme. In such cases the equivalent pre-crack size (EPS), correlates strongly to these pit's depth, has a typical (mean) depth of $10 \mu \mathrm{m}$, see [98]. As such this analysis assumed an initial crack size of $10 \mu \mathrm{m}$ and the approximate location of the etch pit from which the crack grew is shown in Figure 28, where node 4390 represents the centre of the initial semi-elliptical surface flaw. As in the previous example and in [94] a weight function technique together with the stress field as determined from the FE model of the bulkhead was used to compute the associated stress intensity factors. Reference [94] also presented the measured crack growth history and the crack growth history computed using FASTRAN, together with the long crack da/dN versus $\Delta \mathrm{K}$ relationship, see Figure 7.

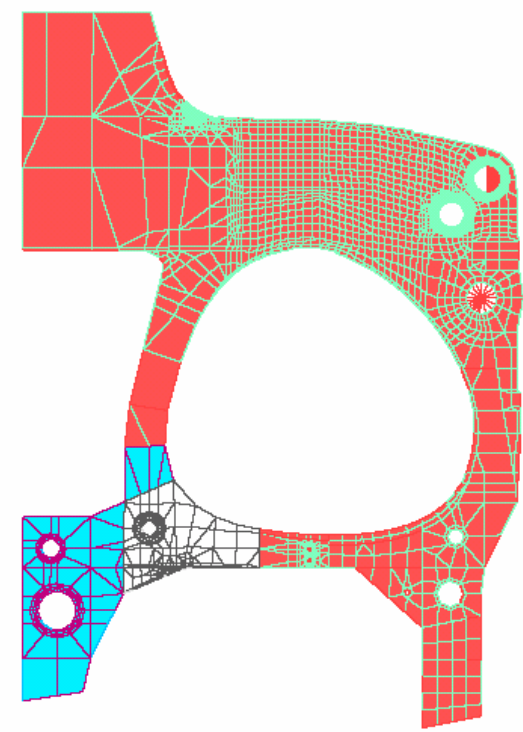

Figure 27. A plan view of the finite element model of the F/A-18 bulkhead, from [94]. 


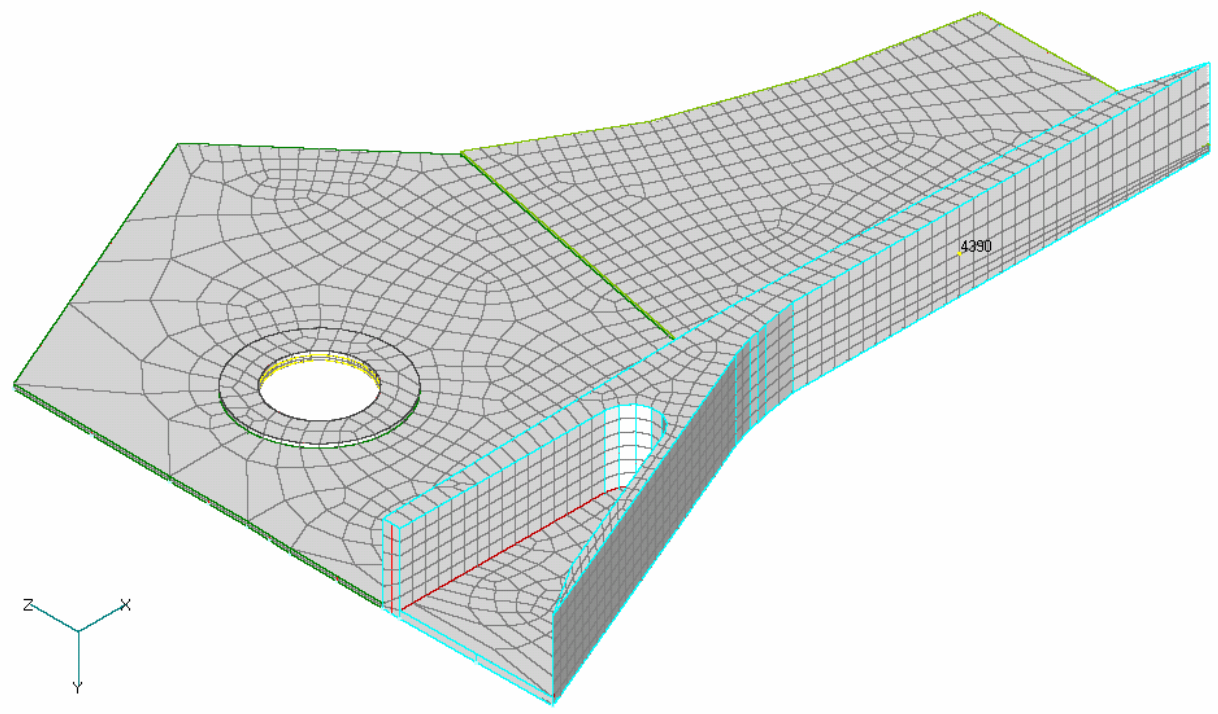

Figure 28. The local mesh, from [94].

The crack depth history, allowing for changes in the aspect ratio of the flaw as the crack grows, was computed using the NASGRO small crack growth equation given in $[14,58]$ for AA7050T7451, viz:

$$
\mathrm{da} / \mathrm{dN}=7.010^{-10}(\Delta \mathrm{K}-0.1)^{2} /\left(1-\mathrm{K}_{\max } / 47\right)
$$

The corresponding computed crack depth history is also shown in Figure 29. Here we see that, as was the case for crack growth in the F-111 wing test, using the NASGRO equation together with the associated small crack da/dN versus $\Delta \mathrm{K}$ equation yields a computed crack depth history that is in good agreement with the measured data. We also see that using FASTRAN, together with the long crack da/dN versus $\Delta \mathrm{K}$ data, predicted failure at approximately 1300 cycles whereas failure in the test occurred at approximately 2800 cycles.

The examples presented in this section substantiate the conclusions given in Appendix X3 of the ASTM test standard E64713a that, for aircraft sustainment related problems, the use of long crack da/dN versus $\Delta \mathrm{K}$ data to compute the life to failure is inappropriate. Whereas in Appendix $\mathrm{X} 3$ it is stated that this approach can give non-conservative lives the examples presented in this Chapter show that using long crack da/dN versus $\Delta \mathrm{K}$ data to compute the life from an initial crack size of $1.27 \mathrm{~mm}$, which corresponds to the mandatory size stated in the USAF Damage Tolerance Design Handbook, can also yield remaining lives, and hence inspection intervals, that are much too short. This would results in significantly reduced aircraft availability and a significant increase in both manpower requirements and maintenance costs. Hence fleet management decisions and assessment of the effect of repairs on the fleet need to be based on analyses that use realistic small crack $d a / d N$ versus $\Delta K$ data. 


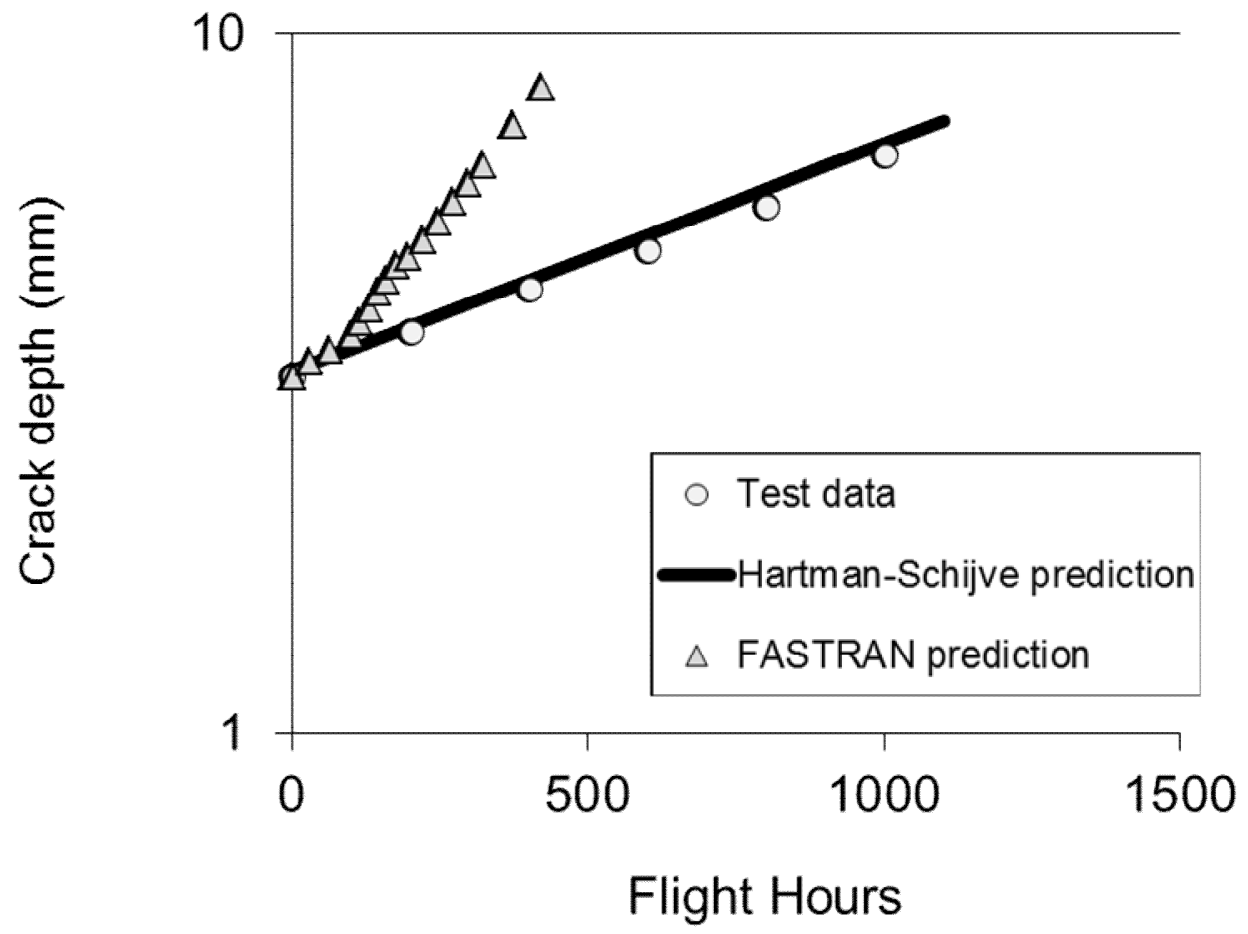

Figure 29. Measured and predicted crack growth histories.

\subsection{The RAAF AP3C repair assessment tests}

As part of the RAAF AP3C repair assessment program tests were performed on 7075-T6 centre notched panels under a measured RAAF AP3C (Orion) flight load spectrum corresponding to control point FCA301. This control point is in the outer wing lower front spar cap. In one test the peak stress was approximately $182 \mathrm{MPa}$, Test 1 . Test 2 had a peak stress of approximately 172 $\mathrm{MPa}$. The measured and predicted, using long crack da/dN versus $\Delta \mathrm{K}$ curves are shown in Figure 30. Here we again see that using the the predictions obtained using the long crack da/dN versus $\Delta \mathrm{K}$ curves significantly under predicted the actual crack length histories. 


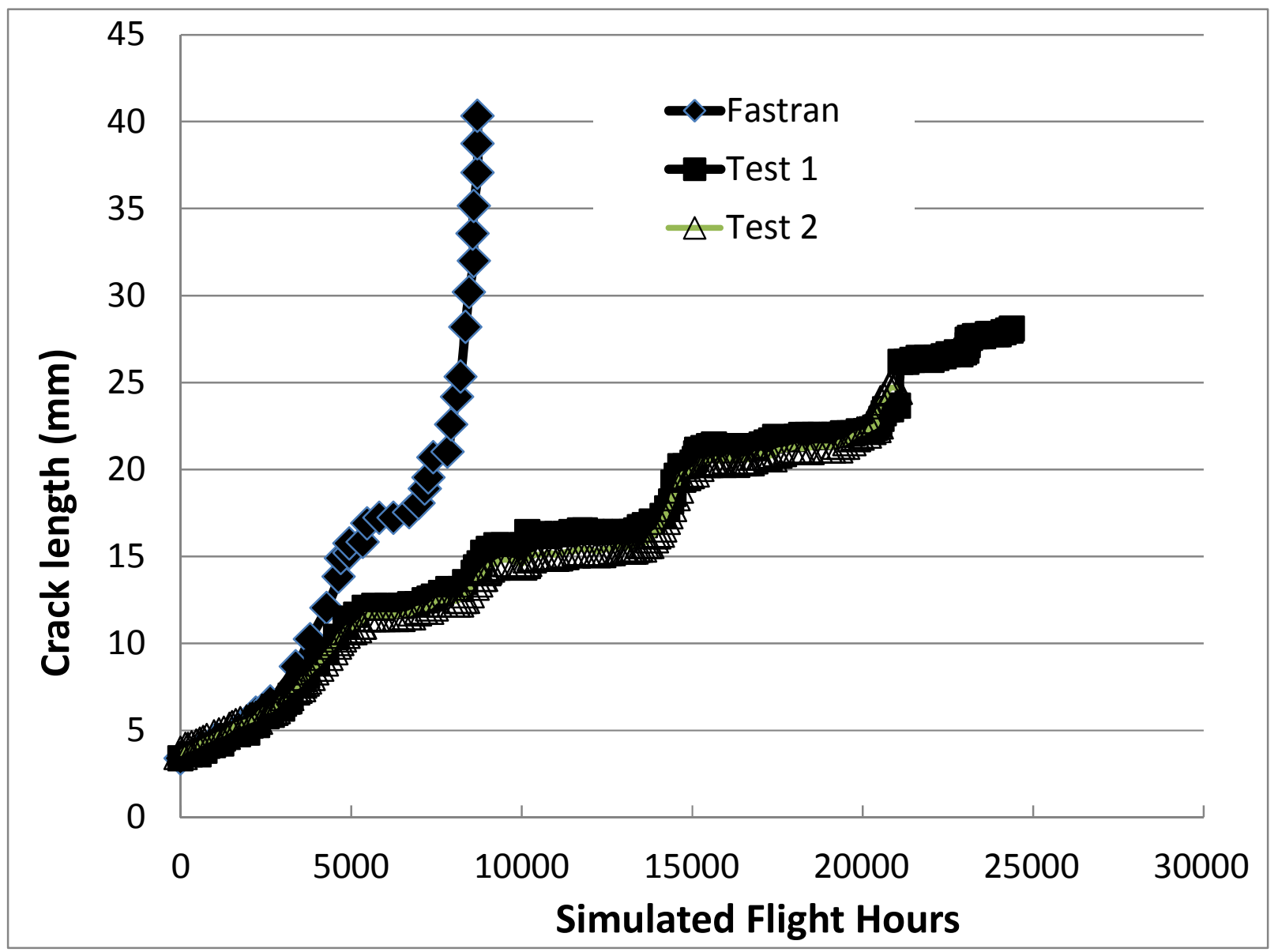

Figure 30 Comparison of the computed and measured crack growth histories, from [108].

\subsection{Implications for composite repairs}

This finding raises the question: What effect does this have on the tests needed to assess the effect of a composite repair on an operational aircraft? To answer this question let us consider the conclusion reached in [99]. This paper studied the effect that elevated temperatures and the environment, including the effect of combined temperature and moisture, has on composite repairs have on both static strength and fatigue. It highlighted the role that $1^{\text {st }}$ ply failure plays, which for composite repairs to operational aircraft was first reported in [128, 129], in composite repairs and concluded:

"The fracture paths in this bonded system indicated that the environment appeared to have affected the adhesive and/or composite matrix materials to a greater extent than the adhesiveadherend interfaces. Additionally, the crack growth rate sensitivity of this bonded metalcomposite system far exceeded that of metals. Though unaffected by long-term environmental exposure, this high sensitivity suggests that continued operation of bonded structures below the identified threshold is necessary to avoid unanticipated rapid Mode I crack growth." 
In the tests described in [99] hot/wet exposure for 5000 hours resulted in a reduction in the load carrying capacity of up to $50 \%$. In these tests the fracture surfaces of the hot/wet exposed specimens were similar to those of the as-received specimens. This led to the realisation that hot/wet environment adversely affected the adhesive and/or composite matrix rather than the metal-adhesive interface. Similar findings have been reported for CFRP to steel joints/repairs. The design methodology needed to account for these failure mechanisms is discussed in Chapter 7.

However, the with respect to this proposed design approach whereby a repair is designed such that the associated value of $\Delta \mathrm{K}$ after patching is below its (long crack) threshold $\Delta \mathrm{K}_{\text {th }}$ it is explained above, and in in Appendix X3 of the ASTM fatigue test standard E647-13a, that for cracks that occur in operational structures the fatigue threshold is very low. Indeed, E647-13a Appendix questions if a threshold exists.

The conclusion stated in [99], and repeated above follows from using tests on specimens with long cracks grown from an artificial notch and then repaired. As such the proposed design methodology follows from a common misunderstanding in the nature of the tests needed to assess the effect of composite repairs to operational structures, albeit either aerospace or civil infrastructure. Let us examine this statement in more detail.

Until recently tests used composite repairs applied to long cracks that were generated using ASTM like specimens, viz: centre notch panels or edge cracked specimens with initial cracks that were grown from artificial initial notches. As explained in ASTM E647-13a and [7] such specimens yield a da/dN versus $\Delta \mathrm{K}$ curve that has a sigmoidal shape with a well defined fatigue threshold $\Delta \mathrm{K}_{\mathrm{th}}$. As such this "no growth" design philosophy is based on the concept that when repaired with a composite patch if the value of $\Delta \mathrm{K}$ after patching is less than the long crack value of $\Delta \mathrm{K}_{\mathrm{th}}$ then cracked growth is stopped. However, as explained in Appendix X3 of ASTM E647-13a, and also in [7], for cracks that have arisen and grown naturally in operational structures the threshold is dramatically lower that the $\Delta K_{\text {th }}$ for such specimens. As such even though the stress intensity factor after patching is greatly reduced it can still be greater than the true threshold value that is seen in the real structure and hence even though the laboratory test would suggest that the patch would stop crack growth when applied to the real structure crack growth will occur. (Here it should be recalled that, as mentioned above, E647-13a questions whether a threshold exists for cracks that arise and grow naturally in operational structures.) As such, as first explained in [40], if laboratory tests are to be performed to evaluate the effect of composite patches to an operational structure then it is essential that in these tests the cracks are first allowed to developed naturally and then patched/repaired. One means of achieving this is to grow cracks from small etch pits $[14,72,73]$, another way is to use lasers, as per Section 4 and $[72,73]$, to create small near micron size initial notches.

At this point it should be stressed that, the inability of tests on long cracks that have been grown from a long artificially induced initial starter notch and then repaired with a composite patch to represent the growth of cracks that had been grown from smaller starter notches and then patched at 
the same crack length was one of the primary conclusions of experimental tests performed as part of the Mirage III patch repair program [100]. As such tests on cracks grown from relatively large, i.e. more than $1 \mathrm{~mm}$, initial starter notches and then patched should not be used to assess the effect of composite patches on operational structures.

Unfortunately this realisation means that whilst most of the studies conducted to date on composite repairs are very valuable in that they highlight the potential benefit that may be obtained using composite repairs such tests can't be used to assess the effect of the repair on operational aircraft.

It should be stressed that patches designed in this fashion can still dramatically retard crack growth. Indeed the results of the boron epoxy repairs to the Mirage III [101], where the patch reduced the stress intensity factor by more than $90 \%$ [102] and hence was indeed beneath the long crack threshold, and the C-141 repair program [103] show that such repair designs can be very effective. However, a valid analysis, which uses valid da/dN versus $\Delta \mathrm{K}$ small crack data as per the F-22, F-15 and $\mathrm{F}-18$ programs $[8,52,57]$, and a test program using specimens whereby the (patched) cracks are grown from small initial material discontinuities is fundamental to composite repairs to operational aircraft.

\section{LOG LINEAR (EXPONENTIAL) CRACK GROWTH}

This finding raises the question: If we know from quantitative fractography the crack growth history associated with lead cracks that have been cut from operational fleet aircraft is there a simple means for rapidly assessing the effect of a composite repair, or a repair using supersonic particle deposition (SPD), on the fleet?

To answer this question let us recall that Section 2 revealed that for cracks that grow from small naturally occurring material discontinuities in operational aircraft and in full scale fatigue tests there is generally a linear relationship between the log of the crack depth/length and the number of cycles ${ }^{16}$ (or flight hours). This is shown in Figure 31, from [20], which presents the crack depth/length histories associated with a range of aircraft, both full scale fatigue tests and operational aircraft. As mentioned in Section 2 this relationship can be written in the form, viz:

$$
a=a_{0} e^{(\omega S F H)}
$$

where SFH is the number of "simulated flight hours", $\omega$ is a parameter that is geometry and load dependent, $a$ is the crack depth/length and $a_{0}$ is the initial crack-like flaw size (depth of the crack at the start of loading) which is referred to as the equivalent pre-crack size (EPS). The relationship between EPS and the equivalent initial flaw size (EIFS) is explained in [3, 18, 29]. As a first approximation the parameter $\omega$ is proportional to the cube of the maximum stress in the spectra $\sigma_{\max }$. The dependency of the crack growth rate on the stress is a feature of both the

${ }^{16}$ Both the log-linear relationship and the cubic stress dependency follow from the fractal nature of the fracture surface, see [24, 104], which suggests that it is due to surface roughness effects. 
British standard BS7910 [105] and the American Association of State Highway and Transportation Officials Design Specifications [106]. The cubic approximation is now used by the Royal Australian Airforce (RAAF) for both the F/A-18 Classic Hornet and the AP3C (Orion) fleets $[23,107,108]$.

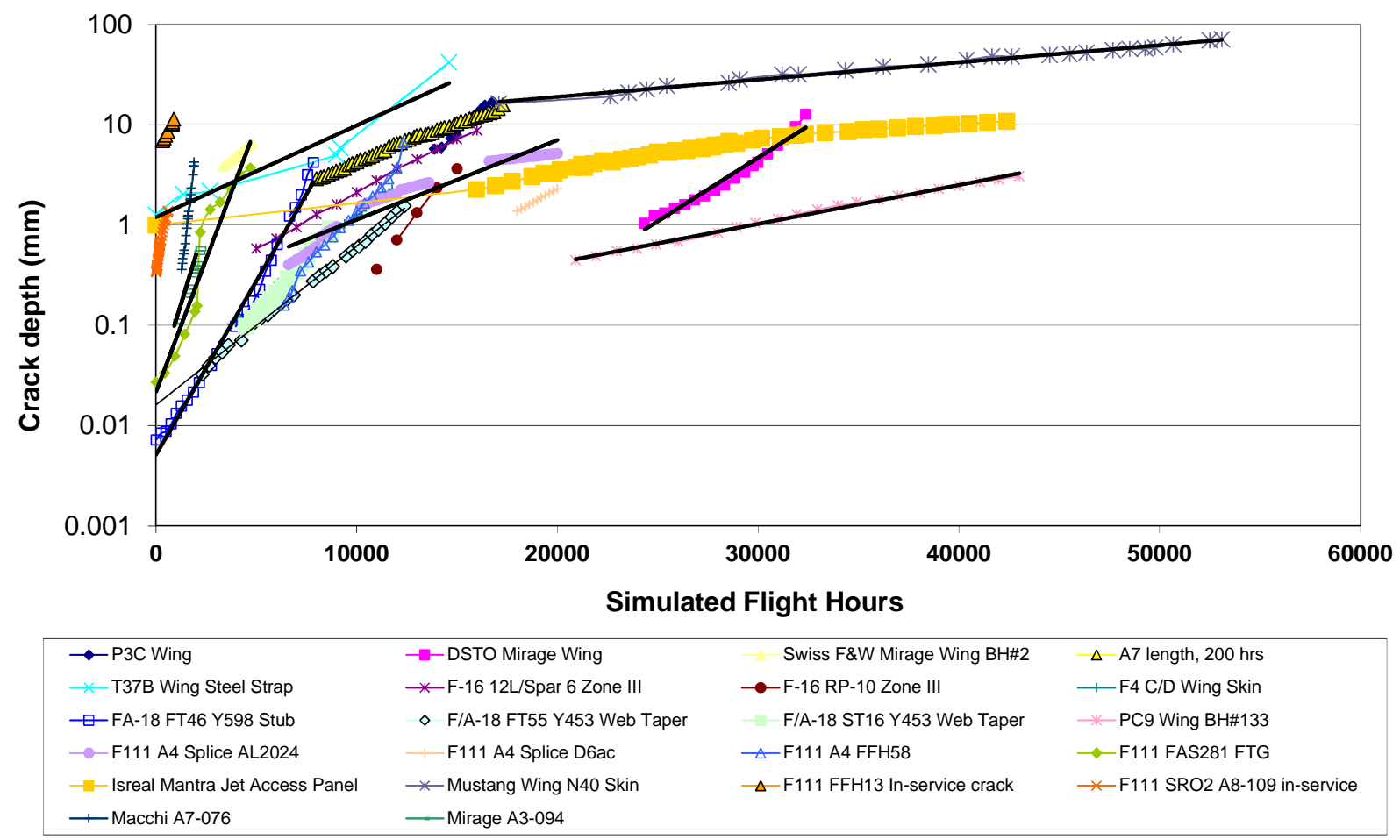

Figure 31. Crack growth histories in a range of aircraft, from [20].

The problem of crack growth in operational aircraft is further simplified by the fact that it is now known [3, 98, 109-110] that that for combat and civil transport aircraft true corrosionfatigue interaction may not occur and that the effect of the environment on the growth of fatigue cracks from small naturally occurring material defects in combat and civil transport aircraft essentially decouples with the environment:

- Creating material discontinuities of various sizes, which depend on the material and the level and nature of the corrosion damage, such that cracks subsequently grow from these discontinuities;

- Growing existing cracks/discontinuities during extended periods of inactivity (down time).

This means that for combat and civil transport aircraft the environment has little effect on growth that occurs in flight $[3,98,109-110]$. This, in turn, simplifies the determination of the appropriate inspection intervals/repair time scale(s). It also means that when establishing the Limit of Validity (LOV) of civil transport aircraft, which is defined as the period in which the aircraft is free from widespread fatigue damage (WFD), ground based full scale tests can be performed without an attempt to mimic the operational environment and that, as per [10], an 
additional scatter factor, to account for the variability due to environmental effects, is not required.

\subsection{A non-dimensional master curve representation of crack growth in full scale structures}

As explained in the USAF approach to assessing the Risk of Failure associated with crack growth in operational aircraft [48] crack growth in service aircraft is exponential. As explained in [3] when using the Hartman-Schijve variant of the NASGRO equation to compute the growth of cracks from small naturally occurring material discontinuities under operational load spectra provided that the crack length is small with respect to the dimensions of the panel, so that the beta function $(\beta)$ is (as a first approximation) relatively independent of the crack length, and there are a large number of load blocks (B) to failure. In such instances, ignoring the region where $\mathrm{K}$ approaches its toughness, the crack length histories associated with centre cracked and surface cracked specimens often conform (approximately) to the master curve:

$$
\left(B-B_{i}\right) /\left(B_{f}-B_{i}\right)=1-\ln \left(a / a_{f}\right) / \ln \left(a_{i} / a_{f}\right)
$$

regardless of the nature of the load spectra. Here $B_{i}$ and $B_{f}$ and $a_{i}$ and $a_{f}$ are the starting and end values of the number of load blocks (or simulated flight hours) and crack length respectively. At this point it should be noted that, as explained in [3], as the crack size approaches its critical length we need to account for $\mathrm{K}_{\max }$ approaching its fracture toughness. However, this effect often tends to be small and, as shown in [3], generally only affects the region $a / a_{f}>0.75$. It was also explained in [3] that a similar deviation from equation (13) occurs as the crack length approaches the initial discontinuity size. As a result the slope of the $\left(B-B_{i}\right) /\left(B_{f}-B_{i}\right)$ versus $\phi(a) \quad(=1-$ $\left.\ln \left(a / a_{f}\right) / \ln \left(a_{i} / a_{f}\right)\right)$ curves sometimes differs slightly from that suggested by equation (13). Figure 32, which presents the crack growth histories shown in Figure 31 plotted as per equation (13), reveals that, allowing for scatter and errors in the crack length measurements, this master curve representation also often holds (approximately) for crack growth in full scale aircraft structures subjected to a range of operational load spectra. The values of $B_{i}$ and $B_{f}$ and $a_{i}$ and $a_{f}$ used in this figure are given in Table 5. Given that it has been shown [3] that this master curve representation also holds for crack growth in centre cracked and surface cracked specimens tested under a wide range of load spectra this finding suggests that the use of crack growth equations that have significantly more than four disposable constants is questionable. 


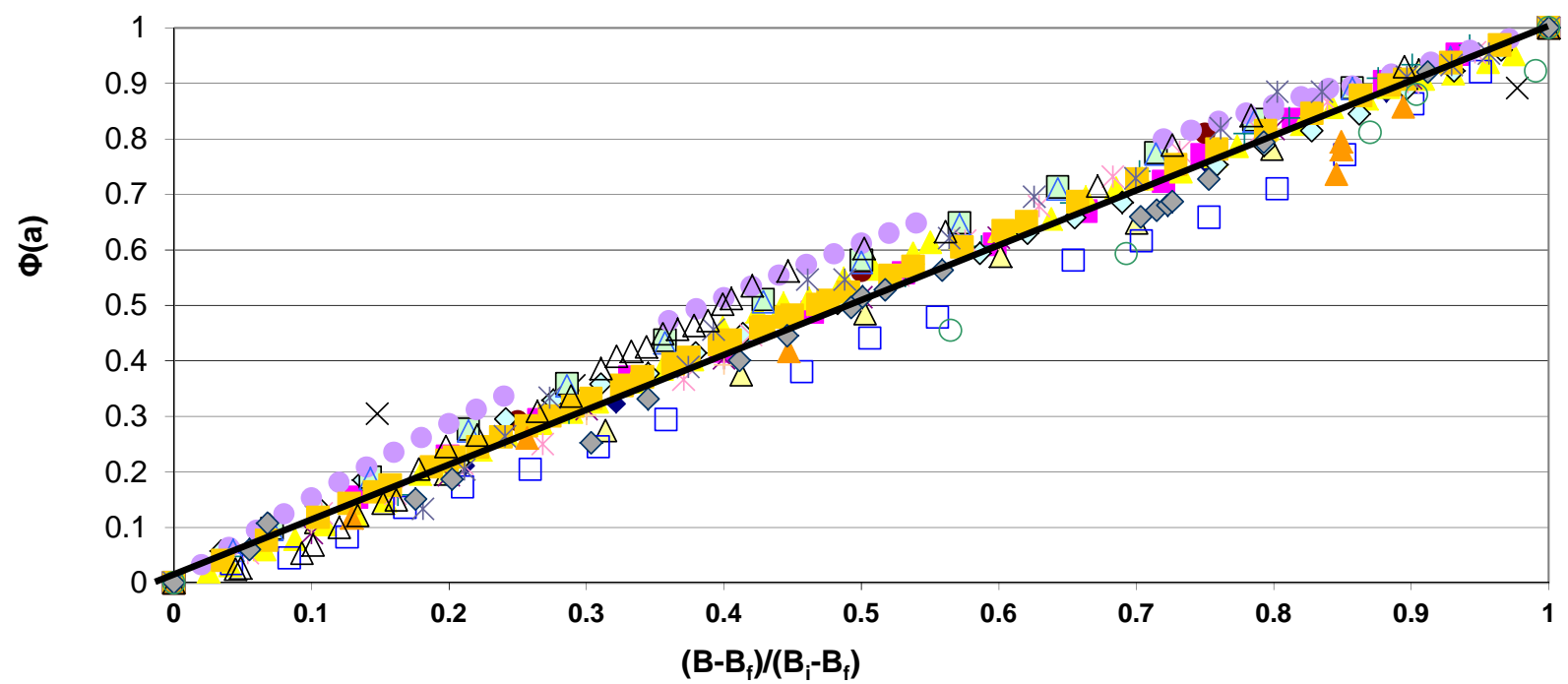

\begin{tabular}{|c|c|c|c|}
\hline$\diamond$ P3C Wing & DSTO Mirage Wing & $\Delta$ Swiss F\&W Mirage Wing BH\#2 & A7 length, $200 \mathrm{hrs}$ \\
\hline$\times$ T37B Wing Steel Strap & *F-16 12L/Spar 6 Zone III & -F-16 RP-10 Zone III & +F4 C/D Wing Skin \\
\hline$\square$ FA-18 FT46 Y598 Stub & $\diamond$ F/A-18 FT55 Y453 Web Taper & $\square$ F/A-18 ST16 Y453 Web Taper & $\nVdash$ PC9 Wing BH\#133 \\
\hline F111 A4 Splice AL2024 & F111 A4 Splice D6ac & $\triangle \mathrm{F} 111 \mathrm{~A} 4 \mathrm{FFH} 58$ & F111 FAS281 FTG \\
\hline Isreal Mantra Jet Access Panel & $*$ Mustang Wing N40 Skin & $\triangle$ F111 FFH13 In-service crack & $\triangle$ F111 SRO2 A8-109 in-service \\
\hline$\diamond$ Macchi A7-076 & Mirage A3-094 & & \\
\hline
\end{tabular}

Fig. 32. Non-dimensional crack growth histories in a range of aircraft, from [15].

Table 5: Full-Scale Fatigue Test and In-Service Crack Growth Data Summary, from [15]

\begin{tabular}{|l|l|l|}
\hline \multicolumn{1}{|c|}{ Aircraft Test - Location Description } & \multicolumn{1}{|c|}{ Material } & \multicolumn{1}{|c|}{$\begin{array}{c}\mathrm{B}_{\mathrm{i}}, \mathrm{B}_{\mathrm{f}}, \mathrm{a}_{\mathrm{i}}, \mathrm{a}_{\mathrm{f}} \\
\text { (Flight hours, } \\
\text { Flight hours, mm, } \\
\mathrm{mm})\end{array}$} \\
\hline $\begin{array}{l}\text { F/A-18 IFOSTP (FT46) Y598 frame vertical tail stub } \\
\text { radius. Manoeuvre + buffet spectrum. }\end{array}$ & $\begin{array}{l}\text { Al7050- } \\
\text { T7451 }\end{array}$ & $\begin{array}{l}258,7840, \\
0.00602,4.05\end{array}$ \\
\hline F/A-18 IFOSTP (FT55) Y453 bulkhead web taper & $\begin{array}{l}\text { Al7050- } \\
\text { T7451 }\end{array}$ & $\begin{array}{l}2314,11737, \\
0.0325,1.1933\end{array}$ \\
\hline F/A-18 OEM (ST16) Y453 Web Taper & Al7050- & 4500,8700, \\
& T7451 & $0.0983,0.917$ \\
\hline USN P3C lower wing weep hole & Al7075- & 14238,16390, \\
& T6511 & $5.976,15.65$ \\
\hline Swiss Mirage wing bolt hole (BH) No.2 & AU4SG & $3343,4675,3.83$, \\
& (Similar to & 6.32 \\
\hline Australian (DSTO) Mirage wing blind BH main spar & Al2014- & \\
\hline & AU4SG & 24335,31872, \\
\hline
\end{tabular}




\begin{tabular}{|c|c|c|}
\hline $\begin{array}{l}\text { Australian F111 lower wing FAS } 281 \text { location, fuel } \\
\text { flow groove (FFG). }\end{array}$ & $\begin{array}{l}\text { Al2024- } \\
\text { T851 }\end{array}$ & $\begin{array}{l}0.1,3704,0.027 \\
2.35\end{array}$ \\
\hline $\begin{array}{l}\text { OEM (A4) F-111 lower wing pivot fFitting (WPF) } \\
\text { fuel flow hole (FFH) No.58 }\end{array}$ & D6ac & $\begin{array}{l}6400,12000,0.159, \\
3.71\end{array}$ \\
\hline F-111 (A4) WPF splice BH & $\begin{array}{l}\text { A12024- } \\
\text { T851 }\end{array}$ & $\begin{array}{l}6600,16600,0.40 \\
4.32\end{array}$ \\
\hline F-111 (A4) WPF splice BH & D6ac & $\begin{array}{l}18000,20000 \\
1.38,2.27\end{array}$ \\
\hline $\begin{array}{l}\text { USAF T-37A Wing steel splice strap radius. } 1.27 \mathrm{~mm} \\
\text { initial flaw. }\end{array}$ & 4340 steel & $\begin{array}{l}0,14602,1.27 \\
5.88\end{array}$ \\
\hline USAF F-16 wing. BH 12L/Spar 6 Zone III & $\begin{array}{l}\text { Al7475- } \\
\text { T7351 }\end{array}$ & $\begin{array}{l}5000,16000,0.58 \\
8.78\end{array}$ \\
\hline USAF F-16 wing. BH RP-10 Zone III & $\begin{array}{l}\text { A17475- } \\
\text { T7351 }\end{array}$ & $\begin{array}{l}11000,16000 \\
0.36,3.63\end{array}$ \\
\hline Australian PC9 wing spar BH & $\begin{array}{l}\text { A12024- } \\
\text { T3511 }\end{array}$ & $\begin{array}{l}20906,434014 \\
0.044,3.07\end{array}$ \\
\hline $\begin{array}{l}\text { USAF A-7D lower wing BH. Here one block was } \\
\text { assumed to represent } 200 \text { flight hours. }\end{array}$ & $\begin{array}{l}\text { Al7075- } \\
\text { T6 }\end{array}$ & $\begin{array}{l}7992,17282,2.91 \\
15.7\end{array}$ \\
\hline USAF F-4 lower wing skin BH & $\begin{array}{l}\text { Al7075- } \\
\text { T651 }\end{array}$ & $\begin{array}{l}3800.8,11773 \\
0.103,2.27\end{array}$ \\
\hline $\begin{array}{l}\text { Israeli Mantra Jet lower wing assess panel hole. } 1 \\
\text { mm crack induced after 40,000 flights. }\end{array}$ & $\begin{array}{l}\text { Al7475- } \\
\text { T7351 }\end{array}$ & $\begin{array}{l}48869,63543 \\
2.27,10.9\end{array}$ \\
\hline $\begin{array}{l}\text { Australian Mustang P51D lower wing skin BH. Note } \\
\text { constant amplitude loading. Specimen No. } 40 .\end{array}$ & Al24 S-T & $\begin{array}{l}170856,47683 \\
1.27,4.34\end{array}$ \\
\hline $\begin{array}{l}\text { RAAF Aermacchi MB326H In-service wing spar BH } \\
\text { failure. One flight assumed }=1 \mathrm{hr} \text {. }\end{array}$ & Al7075 T6 & $\begin{array}{l}1292,1895 \\
0.3612,3.796\end{array}$ \\
\hline $\begin{array}{l}\text { RAAF F111 wing in-service - upper FFH No. } 13 \\
\text { (hours from last cold proof load test (CPLT)) }\end{array}$ & D6ac & $\begin{array}{l}336,893,6.95 \\
11.36\end{array}$ \\
\hline $\begin{array}{l}\text { RAAF F111 wing in-service }- \text { stiffener runout } \\
\text { (SRO) No. 2. (hours from last CPLT) }\end{array}$ & D6ac & $\begin{array}{l}1.5,448,0.338 \\
1.095\end{array}$ \\
\hline RAAF Mirage BH\#2 lower spar & AU4SG & $\begin{array}{l}904,2003,0.11 \\
0.58\end{array}$ \\
\hline
\end{tabular}

\subsection{Crack growth in composite repairs}

These findings raise the question: Do we see exponential growth in composite repaired specimens? The answer to this question is yes. References [25-27] revealed that not only do cracks in aluminium and steel structures repaired with a composite patch also exhibit a near linear relationship between the log of the crack length and the number of cycles but that the exponent is also proportional to the cube of the stress. Similarly [27] reveals that patched cracks also conform to the "Master Linear" curve given by equation (13). 


\subsection{Fractals and log-linear crack growth in operational aircraft}

The breakdown of physical similitude in fatigue crack growth was pioneeringly revealed in the early work of Barenblatt and Botvina [111]. Since then, several attempts have been made in order to understand the impact of this incomplete similarity on the Paris and Wöhler representations of fatigue. Experimental confirmation of size-scale effects has been reported by Ritchie [112] and generalized theories of fatigue based on dimensional analysis and incomplete similarity have been proposed $[113,114]$ to interpret this anomalous phenomenon. Using these concepts, a dependency of the Paris' law on the grain size has also been put into evidence).

Supported by these dimensional analysis considerations, a new fatigue crack growth theory based on fractality of crack profiles has been developed [113-122] to interpret the (experimentally evidenced) anomalous crack growth rate of short cracks and crack-size effects on the fatigue threshold, facts that are not fully explained in previous theories, viz:

$$
\mathrm{da} / \mathrm{dN}=\mathrm{C}_{1}(\mathrm{a})(\Delta \mathrm{K})^{\mathrm{m}}=\mathrm{C} \mathrm{a}^{\phi}(\Delta \mathrm{K})^{\mathrm{m}}
$$

where $\mathrm{m}$ and $\phi$ are constants. This law is formally identical to the classical Paris law except that the coefficient $\mathrm{C}_{1}$ depends on the crack depth $a$ whereas in the Paris law it is assumed to be a material constant.

In this context it should be noted that it is now known that fracture surfaces can be considered as an invasive fractal set, see Mandelbrot et al [123]. In this work Mandelbrot wrote:

"When a piece of metal is fractured either by tensile or impact loading the facture surface that is formed is rough and irregular. Its shape is affected by the metal's microstructure (such as grains, inclusions, and precipitates where characteristic length is large relative to the atomic scale), as well as by 'macrostructural' influences (such as the size, the shape of the specimen, and the notch from which the fracture begins). However, repeated observation at various magnifications also reveal a variety of additional structures that fall between 'micro' and 'macro' and have not yet been described satisfactorily in a systematic manner. The experiments reported here reveal the existence of broad and clearly distinct zone of intermediate scales in which the fracture is modelled very well by a fractal surface."

Analysis of the power-spectral density functions of profilometric traces associated with a large number of fatigue crack surfaces [24] has revealed that, as first suggested by Bouchard [124], a predominance of the fractal dimension $D=1.2$. This result leads to a particularization of the fatigue crack growth equation based on fractality which is very close to the generalized FrostDugdale equation [24, 43, 94, 104, 125], viz:

$$
\mathrm{da} / \mathrm{dN}=\mathrm{C}^{*} \mathrm{a}^{(1-\gamma / 2)}(\Delta \kappa)^{\gamma}-(\mathrm{da} / \mathrm{dN})_{0}
$$

where $\Delta \kappa$ is a crack driving force 


$$
\Delta \kappa=\Delta \mathrm{K}^{\mathrm{p}}\left(\mathrm{K}_{\max }\right)^{(1-\mathrm{p})}
$$

that has been successfully used to compute crack growth in operational aircraft. Here $p, \gamma$, which in most instances is approximately equal to 3 , and $C^{*}$ are constants, and the term $(\mathrm{da} / \mathrm{dN})_{0}$ reflects both the fatigue threshold and the nature of the notch (defect/discontinuity) from which cracking initiates. It has been shown [104] that this equation leads to exponential (log-linear) crack growth (log-linear) with a cubic stress dependency. At this point it should be noted that it follows from [3, 24, 43, 58, 94, 126] that the NASGRO equation and the Generalised FrosDugdale equation are operationally equivalent.

\section{THE USAF APPROACH TO ASSESSING RISK OF FAILURE AND THE CUBIC RULE}

Section 2 noted that the growth of lead cracks, which as shown in Section 7 and in the USAF Risk of Failure report [48], generally exhibit exponential crack growth, could be predicted using the cubic stress rule ${ }^{17}$ (equation). This is important because it allows us to estimate the effect of a structural modification/repair on the airframe by merely accounting for the change in stress due to the modification/repair. To illustrate the cubic rule consider the experimental data presented in [127] which included surface-etched and as-machined AA7050-T7451 coupons with a high $K_{t}$ configuration and were fatigue tested under the fighter aircraft WRBM spectrum. Here simple 'dog bone' coupons containing a $6.35 \mathrm{~mm}$ diameter hole in the centre were tested. The thickness and width of the specimen were $10 \mathrm{~mm}$ and $32 \mathrm{~mm}$ respectively. The net $K_{t}$ of 2.66 (the gross $K_{t}$ is 3.32) for the hole was calculated by FEA. The net-section stress range tested was 155 to 250 $\mathrm{MPa}$. The stress ranges were chosen such to avoid gross section yield, but given that the yield stress of the material was approximately $470 \mathrm{MPa}$, local yielding of the hole in the high $\mathrm{K}_{\mathrm{t}}$ specimens would have occurred. The effect of yielding was not specifically addressed.

As can be seen in Figure 33 the fastest growing crack in the $155 \mathrm{MPa}$ tests has a value of $\omega^{18}=$ 0.1302 . The values of $\omega$ for the 200,225 and $250 \mathrm{MPa}$ tests were then calculated using the cubic rule, for example:

$\omega($ for fastest crack in the $200 \mathrm{MPa}$ test $)=0.1302 \times(250 / 200)^{3}=0.28$

$\omega$ (for fastest crack in the $225 \mathrm{MPa}$ test $)=0.1302 \times(250 / 225)^{3}=0.40$

$\omega($ for fastest crack in the $250 \mathrm{MPa}$ test $)=0.1302 \times(250 / 155)^{3}=0.55$

and the resultant predicted crack growth histories are shown in Figures 34-36 where we see that this approach yields good estimates for the (fastest) crack growth histories. However, as previously mentioned it is important to note that in this approach it is best to base predictions on

\footnotetext{
${ }^{17}$ As previously mentioned the dependency of the crack growth rate upon the cube of the stress is discussed in both the British Standard BS7910 [105] and the AASHTO Design Standard [106].

${ }^{18}$ Here it should be noted that $\omega$ is as defined in equation (1).
} 
the fastest crack (i.e. the lead crack which has small fatigue threshold). The application of this methodology to predict the crack growth in composite repairs will be discussed in Chapter 7 .

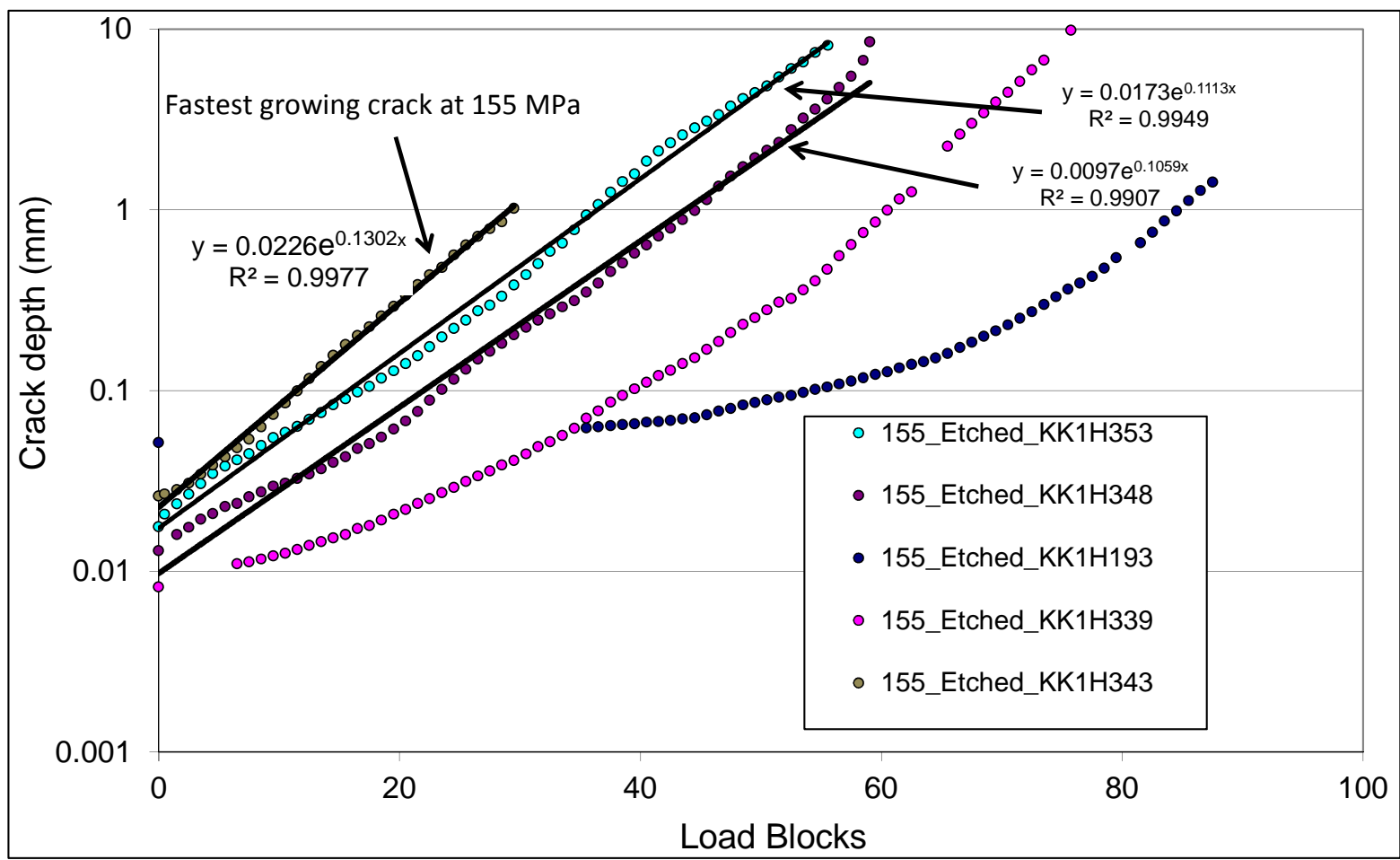

Figure 33: Measured and computed crack depth histories for etched specimens tested at 155 $\mathrm{MPa}$. 


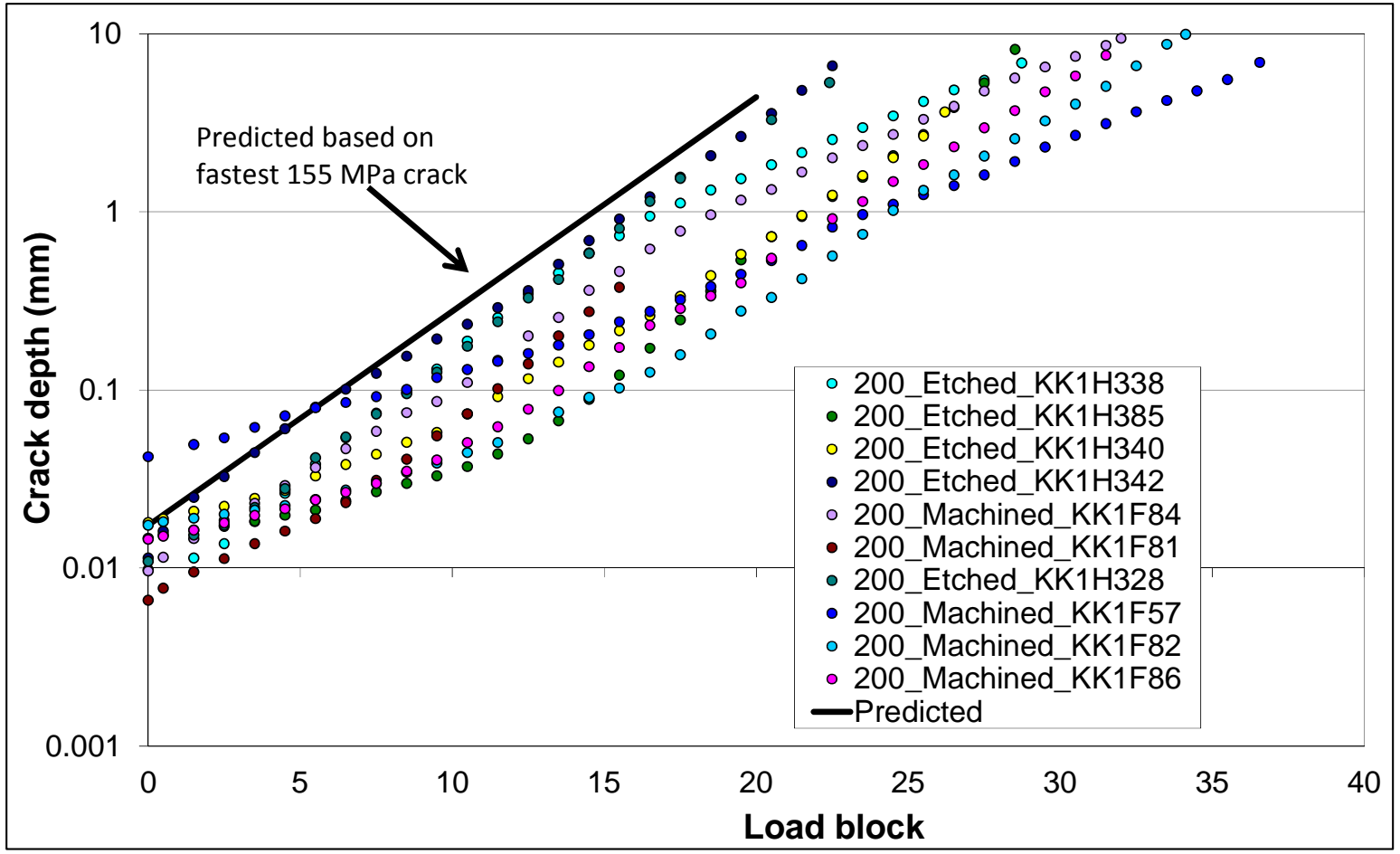

Figure 34: Measured and computed crack depth histories for etched and as-machined specimens tested at $200 \mathrm{MPa}$. 


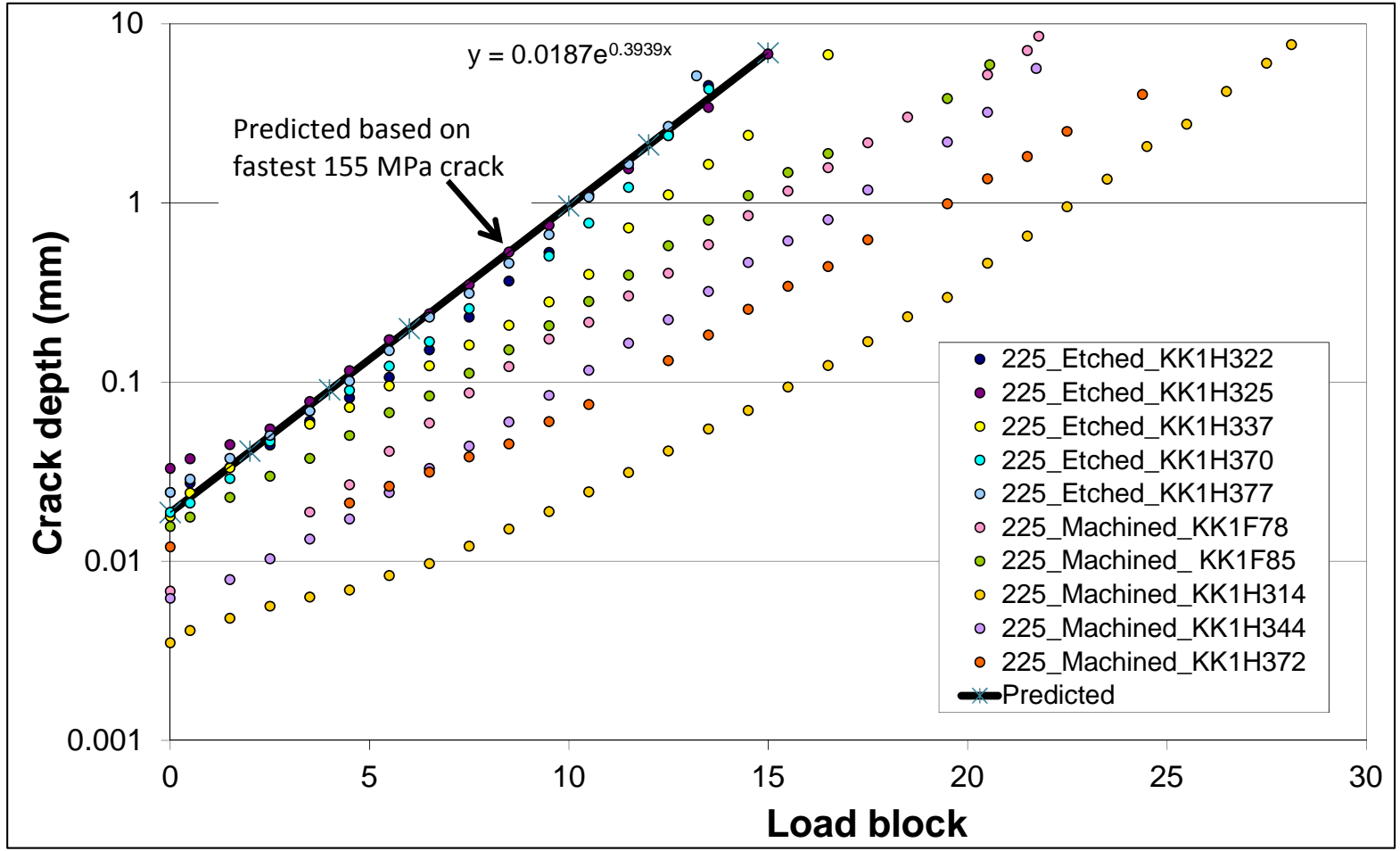

Figure 35: Measured and computed crack depth histories for etched and as-machined specimens tested at $225 \mathrm{MPa}$. 


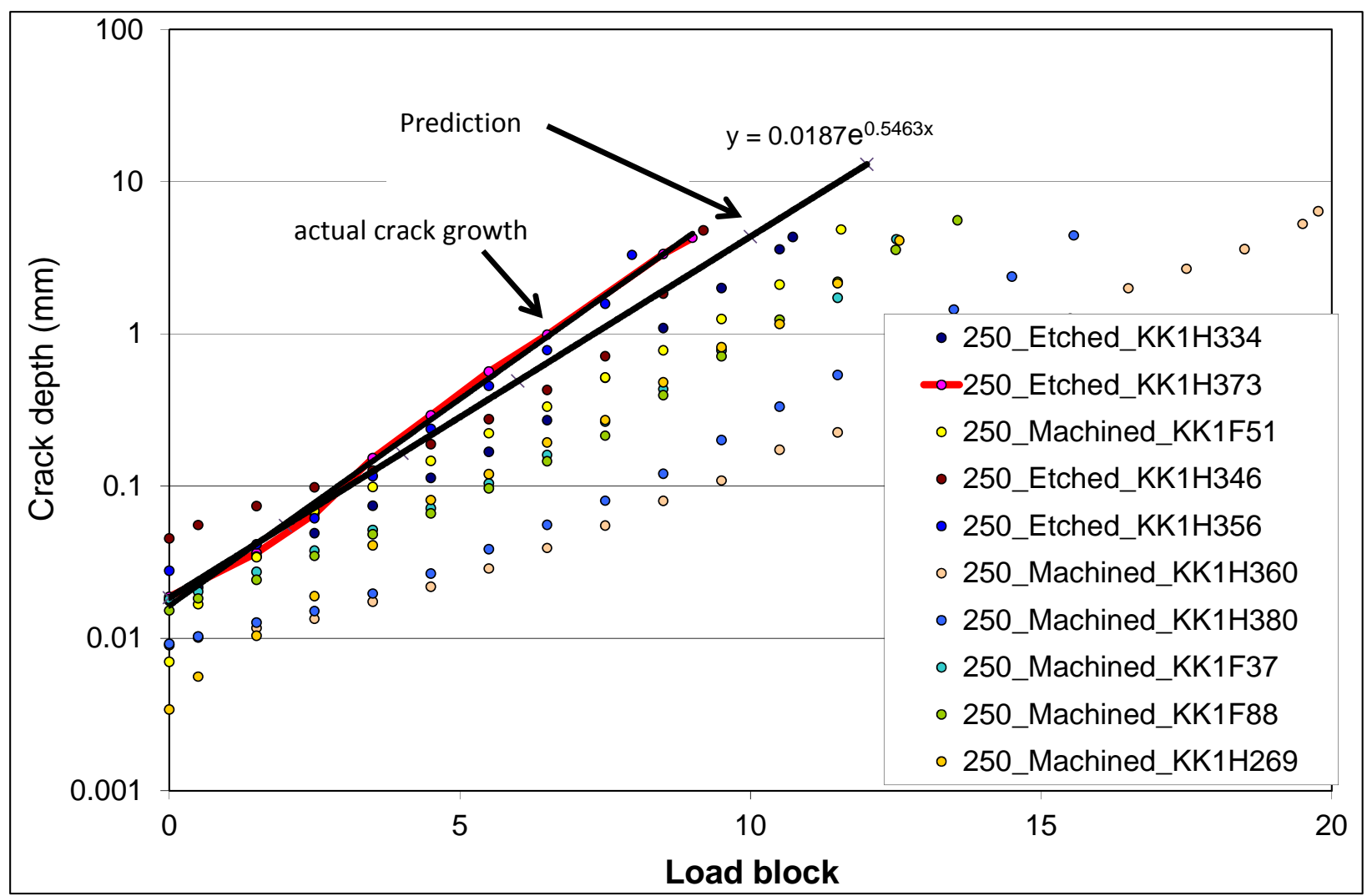

Figure 36 Measured and computed crack depth histories for etched and as-machined specimens tested at $250 \mathrm{MPa}$.

Having established the validity of the cubic rule and the fact that composite repairs do indeed exhibit exponential crack growth, a requirement that is needed if the cubic rule is to be used to estimate crack growth, the ability of the cubic rule to predict crack growth in composite repairs will be discussed in the next Chapter. At this point it should be noted that this use of the cubic rule is routinely used to assess (and certify) repairs to RAAF aircraft [21, 23].

\section{CONCLUSION}

This Chapter first discussed difference between the analysis tools needed for ab initio design and aircraft sustainment. Attention is then focused on the problem of aircraft sustainment. In this context it is shown that there is little crack tip shielding (closure, etc.) associated with this problem set and that the ASTM ACR method and CPC can sometimes be used to determine an approximate $\mathrm{da} / \mathrm{dN}$ versus $\Delta \mathrm{K}$ short crack relationship. It is next shown how the HartmanSchijve variant of the NASGRO equation, with closure switched off, and using a small value for the threshold term can be used to accurately compute the growth of small cracks under a range of representative flight load spectra.

In this context the conclusions given in Appendix X3 of the ASTM test standard E647- 13a viz: 
that for aircraft sustainment related problems the use of long crack da/dN versus $\Delta \mathrm{K}$ data to compute the life to failure is inappropriate, are further discussed. However, whereas in Appendix $\mathrm{X} 3$ it is stated that this approach can give non-conservative lives the examples presented in this Chapter show that using long crack da/dN versus $\Delta \mathrm{K}$ data to compute the life from an initial crack size of $1.27 \mathrm{~mm}$, which corresponds to the mandatory size stated in the USAF Damage Tolerance Design Handbook, can also yield remaining lives, and hence inspection intervals, that are much too short. This would result in significantly reduced aircraft availability and a significant increase in both manpower requirements and maintenance costs. Hence fleet management decisions need to be based on analyses that use the realistic small or physically short crack da/dN versus $\Delta K$ data. It is also shown that tests to establish the effect of repairs, either composite and SPD repairs, should involve specimens where by prior to repair cracks are first grown from small material discontinuities.

It is shown that the growth of lead cracks in operational aircraft is exponential, i.e. there is a near linear relationship between the $\log (a)$ and the number of cycles and the physical basis for this law is explained. It is then shown that crack growth in structures repaired with a composite repair also exhibit a near linear relationship between the log of the crack length and the number of cycles. We also show that crack growth in composite repairs can be represented by the same simple master curve relationship that has been found to hold for cracks growing in operational aircraft and in full scale fatigue tests.

These findings are important since they suggest that the methodology used by the Royal Australian Airforce to certify structural modifications to operational aircraft, which are based on the observation that crack growth in operational aircraft is near log-linear and that that crack growth is proportional to the cube of the stress, may also be applicable to composite repairs/modifications to civil infra-structure and also to SPD repairs.

The use of the Hartman-Schijve variant of the NASGRO equation to accurately compute the effect of SPD repairs to intergranular cracking is shown in Chapter 16.

\section{ACKNOWLEDGEMENT}

The authors would like to thank Dr. Simon Barter (DSTO), for making his experimental data available, Pu Huang (Monash), for the analysis of the high $\mathrm{K}_{\mathrm{T}}$ problem, Khawla Alia (Monash), for her analysis of cracks repaired using CFRP, and Dr. Daren Peng (Monash) for his analysis of many of the problems discussed in this Chapter.

\section{REFERENCES}

1. Miedlar P.C., Berens A.P., Gunderson A., and Gallagher J.P. Analysis and support initiative for structural technology (ASIST), AFRL-VA-WP-TR-2003-3002. 
2. Tiffany CF., Gallagher J.P., Babish IV C.A., Threats to aircraft structural safety, including a compendium of selected structural accidents/incidents, Aeronautical Systems Center, Engineering Directorate, Wright-Patterson Air Force Base, ASC- TR-2010-5002.

3. Jones R., (2014) Fatigue crack growth and damage tolerance. Fatigue and Fracture of Engineering Materials and Structures 37, pp. 463-483.

4. Ritchie RO., Yu W., Blom AF., Holm DK. (1987) An analysis of crack tip shielding in aluminium alloy 2124: A comparison of large, small through-crack and surface fatigue cracks, Fatigue and Fracture of Engng Materials and Structures, 10, 5, pp. 343-363.

5. McEvily AJ. and Eifler D., Macherauch E. (1991) An analysis of the growth of short fatigue cracks, Eng. Fract. Mech., 40, pp. 571-584.

6. Molent L., Jones R (2016) The influence of cyclic stress intensity threshold on fatigue life scatter, International Journal of Fatigue, 82, pp. 748-756.

7. Jones R., D. Tamboli, (2013) Implications of the lead crack philosophy and the role of short cracks in combat aircraft, Engineering Failure Analysis, 29.149-166.

8. Park J. and Garcia W., Impacts on Crack Growth Analysis of Ti-6Al-4V Small Crack Test Data, 2015 Aircraft Structural Integrity Program (ASIP), The Hyatt Regency, San Antonio, Texas, USA; 1st-3rd December 2015.

9. FAA-2010-1280-001, Federal Register, Vol 76, 6, Monday January 2011, Rules and Regulations.

10. FAA AC No: 120-104, Establishing and implementing limit of validity to prevent widespread fatigue damage, $01 / 01 / 2011$.

11. Eastin R. (2009) 'WFD' - What is it and what's 'LOV' got to do with it? International Journal of Fatigue, 31, pp. 1012-1016.

12. Eastin RG., Sippel W. (2011) The "WFD rule" - have we come full circle?, Proceedings, 2011 USAF Aircraft Structural Integrity Conference, 29th November- 1st December 2011, San Antonio, Texas, USA.

13. NTSB. (1989) Aircraft Accident Report, Aloha Airlines, Flight 243, Boeing 737-200, N73711, near Maui, Hawaii, April 28, 1988 (Aircraft Accident Report No. NTSB/AAR89/03), Washington DC, National Transportation Safety Board.

14. Jones R., Molent L., Barter S., (2013) Calculating crack growth from small discontinuities in 7050-T7451 under combat aircraft spectra, International Journal of Fatigue, 55, pp. 178182.

15. Jones R., Peng D., Singh RRK., Pu Huang, Tamboli D., Matthews N., (2015) On the growth of fatigue cracks from corrosion pits and manufacturing defects under variable amplitude loading, JOM, 67, 6, pp. 1385-1391.

16. Lo M., Jones R., Peng D., Bowler A. and Edwards D., Fatigue Crack Growth from Environmentally Induced Damage in 7075 Alloy, Proceedings 28th ICAF Symposium Helsinki, $3^{\text {rd }}-5$ th June, 2015.

17. Arrieta A., C-130 Full Scale Wing Durability Test with an ESL Wing: Coupon Test Program, Proceedings 2015 USAF Aircraft Structural Integrity, San Antonio, Texas, 2nd3rd December 2015.

18. Molent L. and Gallagher JP., The Equivalence of EPS and EIFS Based on the Same Crack Growth Life Data, International Journal of Fatigue, doi:10.1016/j.ijfatigue.2015.05.009 
19. Barter SA., Molent L, N. Goldsmith and Jones R., An experimental evaluation of fatigue crack growth, Journal Engineering Failure Analysis, Vol 12, 1, pp 99-128, 2005.

20. Molent L., Barter SA., A comparison of crack growth behaviour in several full-scale airframe fatigue tests, International Journal of Fatigue, 9 (2007). 1090-1099.

21. Molent L., Jones R., (2016) A Stress versus Crack Growth Rate Investigation (aka Stress Cubed Rule), International Journal of Fatigue, 87, pp, 435-443.

22. Molent L., Barter S.A., Wanhill R.J.H. (2011) The lead crack fatigue lifing framework, International Journal of Fatigue, 33, pp. 323-331.

23. Ayling J., Bowler A., Brick G., and lgnjatovic M., Practical application of structural repair fatigue life determination on the AP-3C Orion platform, Advanced Materials Research Vols. 891-892 (2014) pp 1065-1070.

24. Jones R., Chen F., Pitt S., Paggi M. and Carpinteri A., From NASGRO to fractals: Representing crack growth in metals, Int. Journal of Fatigue, 82, (2016) pp. 540-549.

25. Jones R., A scientific evaluation of the approximate $2 \mathrm{D}$ theories for composite repairs to cracked metallic components, Composite Structures, 87, 2, 2009, pp. 151-160.

26. Jones R., Barter SA., Molent L and Pitt S., Crack patching: an experimental evaluation of fatigue crack growth, Composite Structures, 67, 2, 2005, pp. 229-238.

27. Ali K., Singh RRK., Zhao XL., Jones R. and McMillan AJ., Composite repairs to bridge steels demystified, Journal of Composite Structures, 2016, http://dx.doi.org/10.1016/j.compstruct.2016.07.049.

28. Barter SA., Molent L. and Wanhill RH. (2012) Typical fatigue-initiating discontinuities in metallic aircraft structures, International Journal of Fatigue, 41, pp. 1-198.

29. Molent L, A review of equivalent pre-crack sizes in aluminium alloy 7050-T7451, Fat Fact Eng Mat Struct, 37 (2014)1055-74.

30. Forth SC., The purpose of generating fatigue crack growth threshold data, NASA Johnson Space Center, available on line at http://ntrs.nasa.gov/

31. Yamada Y., Newman JC. Jr. (2009) Crack-closure behavior of 2324-T39 aluminum alloy near-threshold conditions for high load ratio and constant $\mathrm{K}_{\max }$ tests, International Journal of Fatigue, 31, pp. 1780-1787.

32. Yamada Y., Newman JC. Jr. (2010) Crack closure under high load ratio and $\mathrm{K}_{\max }$ test conditions, Procedia Engineering 2, pp. 79-82.

33. Pippan R, Plöchl L, Klanner F, Stüwe HP. (1994) The use of fatigue specimens precracked in compression for measuring threshold values and crack growth. ASTM J Testing and Evaluation, 22:98.

34. Newman, JC. Jr, Ruschau JJ. and Hill MR. (2011) Improved test method for very low fatigue-crack-growth-rate data, Fatigue and Fracture of Engineering Materials and Structures, 34, pp. 270-279.

35. Donald JK. and Phillips EP. (1997) Analysis of Second ASTM Round Robin Program on Opening Load Measurement Using the Adjusted Compliance Ratio Technique, Advances in Fatigue Crack Closure Measurement and Analysis: Second Volume, ASTM STP 1343, R. C. McClung and J. C. Newman, Jr., Eds., ASTM International, West Conshohocken, PA, 1997. 
36. Donald, J. K. and Paris PC. (1999) An evaluation of $\Delta K_{\text {eff }}$ estimation procedures on 6061T6 and 2024-T3 aluminum alloys, International Journal of Fatigue, 21, pp. S47-S57.

37. Donald K., Paris PC. (1999) An evaluation of $\Delta \mathrm{K}$ estimation procedure on 6061-T6 and 2024-T3 aluminum alloys. Int J Fatigue, 21, S47-57.

38. Paris PC., Tada H., Donald JK. (1999) Service load fatigue damage - a historical perspective, Int. J. Fatigue, 21, pp. S35-46.

39. Kujawski D., (2001) Enhanced model of partial crack closure for correlation of R-ratio effects in aluminum alloys, International Journal of Fatigue, 23, pp. 95-102.

40. Hertzberg RW., Herman WA., Clark T., Jaccard R. (1992) Simulation of short crack and other low closure loading conditions utilizing constant $\mathrm{K}_{\max } \Delta \mathrm{K}$-decreasing fatigue crack growth procedures, Edited by Larsen JM, Allison JE., ASTM STP 1149, Small crack test methods. Philadelphia, PA. American Society for Testing and Materials, pp. 197-200.

41. Lados DA., Apelian D., Paris PC., Donald JK. (2005) Closure mechanisms in Al-Si-Mg cast alloys and long-crack to small-crack corrections, International Journal of Fatigue 27 , pp.1463-1472.

42. Zonker HR., Bray GH., George K., Garratt MD., Use of ACR Method to Estimate Closure and Residual Stress Free Small Crack Growth Data, (2005) Journal of ASTM International, July/August 2005, Vol. 2, No. 7, Paper ID JAI12023, available online at www.astm.org

43. Jones, R., Barter, S., and Chen, F. (2011) Experimental studies into short crack growth. Engineering Failure Analysis, 18, 7, pp. 1711-1722.

44. Ritchie RO., Lankford J. (1986) Small fatigue cracks: A statement of the problem and potential solutions, Materials Science and Engineering, 84, pp. 11-16.

45. Ritchie RO. And Wu Y., Short crack effects in fatigue: a consequence of crack tip shielding, Proceedings of the Second Engineering Foundation International Conference/ Workshop, Edited by Ritchie RO. And Langford J., Santa Barbara, California, January 510, pp. 167-189, 1986. Available at: https://www.researchgate.net/publication/284064244

46. Lugo M., Daniewicz SR., Newman J.C Jr. (2011) A mechanics based study of crack closure measurement techniques under constant amplitude loading, International Journal of Fatigue, 33, pp. 186-193.

47. Wanhill RJH. (2009) Characteristic stress intensity factor correlations of fatigue crack growth in high strength alloys: reviews and completion of NLR investigations 1985-1990. NLR-TP-2009-256.

48. Berens AP., Hovey PW., Skinn DA., Risk analysis for aging aircraft fleets - Volume 1: Analysis, WL-TR-91-3066, Flight Dynamics Directorate, Wright Laboratory, Air Force Systems Command, Wright-Patterson Air Force Base, October 1991.

49. Rudd JL. (1977) Applications of the equivalent initial quality method, AFFDL-TM-77-58FBE.

50. Manning SD., Garver WR., Henslee SP., Norris JW., Pendley BJ., Speaker SM., Smith VD., Yee BGW., Shinozuka M., and Yang YN. (1979) Durability Methods Development, Volume I - Phase I, AFFDL-TR-79.-3118., available at http://www.dtic.mil/dtic/tr/fulltext/u2/a087301.pdf

51. Rudd JL., Yang JN., Manning SD. and Yee BW. (1982) Probabilistic fracture mechanics analysis methods for structural durability, Proceedings of the Meeting of the AGARD 
Structures and .Materials Panel (55th), Toronto, Canada, 19-24 available at http://handle.dtic.mil/100.2/ADP001608.

52. Molent L, Sun Q. and Green AJ., The F/A-18 fatigue crack growth data compendium, DSTO-TR-1677, Melbourne, Australia, 2005.

53. Frost NE., Dugdale DS. (1958) The propagation of fatigue cracks in test specimens, Journal Mechanics and Physics of Solids, 6, pp. 92-110.

54. Merati A. (2005) A study of nucleation and fatigue behavior of an aerospace aluminum alloy 2024-T3, International Journal of Fatigue, 27, pp. 33-44.

55. Schijve J. (1994) Fatigue life until small cracks in aircraft structures: Durability and damage tolerance. Advanced Structural Integrity Methods for Airframe Durability and Damage Tolerance. Proceedings FAA/NASA International Symposium, Hampton, 1994, C.E. Harris, Editor, NASA Conference Publication 3274, 1994, pp. 665-681.

56. Sushant K., Jha SK., John R., James M. Larsen JM. (2013) Incorporating small fatigue crack growth in probabilistic life prediction: Effect of stress ratio in Ti-6Al-2Sn-4Zr6Mo, International Journal of Fatigue, 51, pp. 83-95.

57. Lincoln JW. Melliere RA. (1999) Economic Life Determination for a Military Aircraft, AIAA Journal of Aircraft, 36, 5, pp. 737-742.

58. Jones R., Molent L., Walker K., (2012) Fatigue crack growth in a diverse range of materials, Int. J. Fatigue, 40, pp. 43-50.

59. Jones R., Lo M., Peng D., Bowler A., Dorman M., Janardhana M. and Iyyer NS, (2014) A study into the interaction of intergranular cracking and cracking form corrosion pits at fastener holes, Meccanica, 2015, 50, 2, pp. 517-532.

60. Walker KF., Wang CH., Newman JC., (2015) Closure measurement and analysis for small cracks from natural discontinuities in an aluminium alloy, International Journal of Fatigue http://dx.doi.org/10.1016/j.ijfatigue.2015.03.016

61. Virkler DA., Hillberry BM., Goel PK. (1979) The statistical nature of fatigue crack propagation, Trans ASME,101, pp.148-53.

62. Schijve J. (1979) Fatigue crack growth under variable-amplitude loading, Engineering Fracture Mechanics, Engineering Fracture Mechanics, 207-221.

63. Jones R., Hu W. and Kinloch AJ., (2014) A convenient way to represent fatigue crack growth in structural adhesives, Fatigue and Fracture of Engineering Materials and Structures, 38, pp. 379-391.

64. Jones R, Pitt S., Brunner AJ., Hui D, (2013) Fatigue crack growth in nano-composites, Composite Structures, 99, pp. 375-379.

65. Jones R, Steltzer S., Brunner A.J., (2014) Mode I, II and mixed mode I/II delamination growth in composites, Composite Structures, 110, pp. 317-324.

66. Jones R, Pitt S., Brunner AJ., Hui D., (2012) Application of the Hartman-Schijve equation to represent Mode I and Mode II fatigue delamination growth in composites, Composite Structures, 94, 4, pp. 1343-1351.

67. Burchill M., Walker K., Barter SA., Wang C., Khadka A., Improvements to predicting fatigue crack growth rates in aluminium alloy (AA7050-T7451) loaded with a standard transport aircraft spectrum, in Recent Advances in Structural Integrity Analysis Proceedings of the International Congress (APCF/SIF-2014), Sydney, 2015, pp. 132-136.

68. Barter S., Tamboli D., Jones R., On The Growth Of Cracks From Small Naturally 
Occurring Material Discontinuities (Etch Pits) Under A Mini-Twist Spectrum, 2015 Aircraft Structural Integrity Program (ASIP), The Hyatt Regency, San Antonio, Texas, USA; $1^{\text {st }}-3^{\text {rd }}$ December 2015.

69. Jackson P., Wallbrink C., Walker K., Mongru D. and Hu W., Exploration of Questions Regarding Modelling of Crack Growth Behaviour under Practical Combinations of Aircraft Spectra, Stress Levels and Materials, DSTO-RR-0368, Melbourne, Australia, July 2011.

70. Iyyer N.S., Sarkar S., Merrill R., Phan N.,(2007) Aircraft life management using crack initiation and crack growth models - P-3C Aircraft experience, International Journal of Fatigue, 29, pp. 1584-1607.

71. Loader C., Goudie D., Salagaras M., Underwood J. and Walliker A., RAAF AP-3C Interaction between Intergranular Corrosion and Fatigue, DSTO Technical Report, DSTOTR-3408, December 2014.

72. Barter SA., (2003) Fatigue Crack Growth in Several 7050-T7451 Aluminium Alloy Thick Section Plates with Aircraft Manufacturers and Laboratory Surface Finishes Representing Some Regions of the F/A-18 Structure, DSTO-TR-1539, December 2003.

73. Barter SA., Fatigue Cracking in Aluminium Alloy 7050-T7451 - Quantitative Fractographic Methods and Life Prediction, Phd Thesis, Department of Mechanical Engineering, Faculty of Engineering, Monash University, March 2007.

74. Yamada Y., Newman JC. Jr. (2010) Crack closure under high load ratio and $\mathrm{K}_{\max }$ test conditions, Procedia Engineering 2. 79-82.

75. Lados DA., Apelian D., Paris PC., Donald JK. (2005) Closure mechanisms in Al-Si-Mg cast alloys and long-crack to small-crack corrections, International Journal of Fatigue 27.1463-1472

76. Pippan R, Plöchl L, Klanner F, Stüwe HP. (1994) The use of fatigue specimens precracked in compression for measuring threshold values and crack growth. ASTM J Testing and Evaluation. 22:98.

77. Newman, JC. Jr, Ruschau JJ. and Hill MR. (2011) Improved test method for very low fatigue-crack-growth-rate data, Fatigue and Fracture of Engineering Materials and Structures, 34. 270-279.

78. Donald JK. A procedure for standardizing crack closure levels. In:Newman Jr JC, Elber W, editors. Mechanics of fatigue crack closure, ASTM STP 982. Philadelphia, PA: American Society for Testing and Materials; 1988. p. 222-9.

79. Donald JK, Bray GH, Bush RW. An evaluation of the adjusted compliance ratio technique for determining the effective stress intensity factor. In: Panontin TL, Sheppard SD, editors. Fatigue and fracture mechanics 29, ASTM STP 1332. Philadelphia, PA: American Society for Testing and Materials; 1999. p. 674-95.

80. Donald, J. K. and Paris PC. (1999) An evaluation of $\Delta \mathrm{K}_{\text {eff }}$ estimation procedures on 6061T6 and 2024-T3 aluminum alloys, International Journal of Fatigue, 21. S47-S57.

81. Donald K., Paris PC. (1999) An evaluation of $\Delta \mathrm{K}$ estimation procedure on 6061-T6 and 2024-T3 aluminum alloys. Int J Fatigue, 21, S47-57.

82. Paris PC., Tada H., Donald JK. (1999) Service load fatigue damage - a historical perspective, Int. J. Fatigue, 21. S35-46. 
83. Kujawski D., (2001) Enhanced model of partial crack closure for correlation of R-ratio effects in aluminum alloys, International Journal of Fatigue, 23. 95-102.

84. Hertzberg RW., Herman WA., Clark T., Jaccard R. (1992) Simulation of short crack and other low closure loading conditions utilizing constant $\mathrm{K}_{\max } \Delta \mathrm{K}$-decreasing fatigue crack growth procedures, Edited by Larsen JM, Allison JE., ASTM STP 1149, Small crack test methods. Philadelphia, PA. American Society for Testing and Materials. 197-200.

85. Zonker HR., Bray GH., George K., Garratt MD., (2005) Use of ACR Method to Estimate Closure and Residual Stress Free Small Crack Growth Data Journal of ASTM International, July/August 2005, Vol. 2, No. 7, Paper ID JAI12023, available online at www.astm.org

86. Lugo M., Daniewicz SR., Newman J.C Jr. (2011) A mechanics based study of crack closure measurement techniques under constant amplitude loading, International Journal of Fatigue, 33. 186-193.

87. Kim S., Burns JT., Gangloff RP. (2009) Fatigue crack formation and growth from localized corrosion in Al-Zn-Mg-Cu, Engineering Fracture Mechanics, 76, pp. 651-667.

88. Li D., Burns J., Bush R., Garratt M., Hinkle A., Mills T., Marks C., James Moran, Scully J., and Gangloff RP. (2005) Characterization of corrosion-fatigue interaction for aluminum alloy substitution, Proceedings of the 8th. Joint. NASA/FAA/DoD Conference on Aging Aircraft, R. D. Young, Editor, web site publication: www. JCAA.US/AA_Conference2005.

89. Burns JT., Larsen JM. and Gangloff RP., (2012) Effect of initiation feature on microstructure-scale fatigue crack propagation in $\mathrm{Al}-\mathrm{Zn}-\mathrm{Mg}-\mathrm{Cu}$, International Journal of Fatigue, 42, pp. 104-121.

90. Jones R., Tamboli S., Huang P. and Peng D., (2014) Thoughts on the scatter associated with the growth of both small naturally occurring cracks and long cracks, Proceedings 8th Australasian Congress on Applied Mechanics, ACAM 8, 23rd -26th December 2014, Melbourne, Australia.

91. Newman JC., Wu XR., Swain MH., Zhao W., Phillips EP., Ding CF., (2000) Small crack growth and fatigue life predictions for high strength aluminium alloys. Part II: crack closure and fatigue analyses, Fat Fract Eng Mat Struct, 23, pp. 59-72.

92. Forth S.C., James M.A., Johnston W.M., and Newman, J.C. Jr., Anomalous Fatigue Crack Growth Phenomena In High-strength Steel, Proceedings Int. Congress on Fracture, Italy, 2007.

93. Forth S.C., (2008) Development and validation of advanced test methods to generate fatigue crack growth and threshold data for use in damage tolerance analyses, U.S. Department of Transportation and Federal Aviation Administration Report DOT/FAA/AR04/22, February 2008.

94. Jones R., Molent L., and Pitt S. (2007) Crack growth from small flaws, International Journal of Fatigue, 29, pp 1658-1667.

95. Venkateswara Rao KT., Yu W. and Ritchie R0., (1988) On the behavior of small fatigue cracks in commercial aluminum-lithium alloys, Engineering Fracture Mechanics, 31, 4, pp. 623-635.

96. Murtagh BJ., Walker KF., Comparison of Analytical Crack Growth Modelling and the A-4 Wing Test Experimental Results for a Fatigue Crack in an F-111 Wing Pivot Fitting Fuel 
Flow Hole Number 58DSTO-TN-0108, 1997.

97. Dixon B., Molent L., Barter S.A. The FINAL program of enhanced teardown for agile aircraft structures, Proceedings of 8th NASA/FAA/DOD Conference on Aging Aircraft, Palm Springs, 31 Jan - 3 Feb 2005.

98. Molent L. Managing airframe fatigue from corrosion pits - A proposal, Engng Fract Mech, 137, 2015, pp. 12-25.

99. Butkus LM., Valentin RV., Johnson WS., Evaluating Environmental Effects on Bonded

Repair Systems Using Fracture Mechanics, Chapter 6, A. Baker, L. R. F. Rose and Jones R., Elsevier Applied Science Publishers, 2002. ISBN 0-08-042699-9.

100. van Blaricum TJ., Fatigue behaviour of fatigue cracked aluminium alloy panels repaired with boron fibre patches, Aeronautical Research Laboratories, Structures Technical Memorandum 404, 1985.

101. Baker AA., Callinan RJ., Davis MJ., Jones R. and Williams JG., Application of B.F.R.P. patching to Mirage III Aircraft, Theoretical and Applied Fracture Mechanics, 2, 1, pp. 1-16 1984.

102. Jones R, Numerical analysis and design, Chapter 9, Bonded Repair of Aircraft Structure, A. Baker and Jones R., Martinus Nijhoff Publishers, The Hague, 1988. (Book).

103. Butkus LM., Gaskin JA., Greer JM., Jr., Guijt CM., Jacobs NJ., Kelly DF., Mazza JJ., Bonded Boron Patch Repair Evaluation: Final Report, USAFA-TR-2007-06, October 2007.

104. Jones R., Pitt S., Constable T., Farahmand B., (2011) Observations On Fatigue Crack Growth In A Range Of Materials, Materials and Design, 32:4362-4368.

105. BS 7910, Guide to methods for assessing the acceptability of flaws in metallic structures, 2005.

106. American Association of State Highway and Transportation Officials, AASHTO LRFD Bridge Design Specifications, SI Units, First Edition, Washington, D.C., 1994.

107. B. Main, Structural Analysis Methodology - F/A-18, Issue 2 AI2, RAAF, Directorate General technical Airworthiness, Dec 2007.

108. Duthie J. and E. Matricciani, DSTO P-3 Repair Assessment Methodology (RAM) coupon testing to validate the cubic rule, DSTO-CR-2010-0367, July 2011.

109. Trathan P., Corrosion Monitoring Systems on Military Aircraft (2011) Proceedings 18th International Conference on Corrosion, Perth 20th -24th November, 2011.

110. Burns JT., Gangloff RP. and Bush RW., Effect of environment on corrosion induced fatigue crack formation and early propagation in aluminum alloy 7075-T651. Proc. DoD Corrosion Conference, La Quinta Ca, 31 Jul-5 Aug., 2011.

111. Barenblatt, GI, Botvina, LR (1980) Incomplete self-similarity of fatigue in the linear range of fatigue crack growth. Fatigue Fract Eng Mater Struct 3:193-202.

112. Ritchie, RO (2005) Incomplete self-similarity and fatigue-crack growth. Int J Fract 132:197-203.

113. Spagnoli, A (2005) Self-similarity and fractals in the Paris range of fatigue crack growth, Mechanics of Materials, 37:519-529.

114. Ciavarella, M, Paggi, M, Carpinteri, A (2008) One, no one, and one hundred thousand crack propagation laws: a generalized Barenblatt and Botvina dimensional analysis approach to fatigue crack growth, Journal of the Mechanics and Physics of Solids, 
56:3416-3432.

115. Carpinteri, A (1994a) Fractal nature of material microstructure and size effects on apparent mechanical properties, Mech Mater, 18:89-101 [Internal Report, Laboratory of Fracture Mechanics, Politecnico di Torino, N. 1/92; 1992].

116. Carpinteri, A (1994b) Scaling laws and renormalization groups for strength and toughness of disordered materials. Int J Solids Struct, 31:291-302.

117. Carpinteri, A., Paggi, M. (2007) Self-similarity and crack growth instability in the correlation between the Paris' constants, Engineering Fracture Mechanics 74:1041-1053.

118. Carpinteri, A, Paggi, M (2009) A unified interpretation of the power laws in fatigue and the analytical correlations between cyclic properties of engineering materials, International Journal of Fatigue, 31:1524-1531.

119. Paggi, M, Carpinteri, A (2009) Fractal and multifractal approaches for the analysis of crack-size dependent scaling laws in fatigue, Chaos, Solitons and Fractals 40:1136-1145.

120. Carpinteri, A, Paggi, M (2010) A unified fractal approach for the interpretation of the anomalous scaling laws in fatigue and comparison with existing models, International Journal of Fracture, 161:41-52.

121. Carpinteri, A, Paggi, M (2011) Dimensional analysis and fractal modeling of fatigue crack growth. Journal of ASTM International, 8:104105.

122. Carpinteri, A, Paggi, M (2014) The effect of crack size and specimen size on the relation between the Paris and Wöhler curves, Meccanica, 49, pp.765-773.

123. Mandelbrot B.B., Passoja D.E., Paullay A.J. Fractal character of fracture surfaces of metals, Nature, 1984, 308, 721- 722.

124. Bouchaud, E (1997) Scaling properties of cracks, J. Phys.: Condens. Matter 9:4319-4344. S0953-8984(97)72446-9

125. Jones R., Pitt S., and Peng D, The Generalised Frost-Dugdale approach to modelling fatigue crack growth, Engineering Failure Analysis, Volume 15, (2008), pp. 1130-1149.

126. Jones, R, Chen B, Pitt S (2007) Similitude: cracking in steels, Theoretical and Applied Fracture Mechanics, 48:161-168.

127. Huynh J., Molent L. and Barter S., (2008) Experimentally derived crack growth models for different stress concentration factors, International Journal of Fatigue, vol. 30, pp. 17661786.

128. Jones R., Chiu WK. and Hanna S., Potential failure mechanisms of bonded composite repairs for metal and concrete, Theoretical and Applied Fracture Mechanics, 21, 107-119, 1994.

129. Jones R. and Smith R., Continued airworthiness of composite repairs to primary structures for military aircraft, Journal of Composite Structures, 33,17-26, 1995. 